\title{
Supporting healthcare professionals to encourage patients to decrease cardiovascular risk attributable to physical inactivity
}

Citation for published version (APA):

Sassen, B. (2011). Supporting healthcare professionals to encourage patients to decrease cardiovascular risk attributable to physical inactivity. [Doctoral Thesis, Maastricht University]. Universiteit Maastricht. https://doi.org/10.26481/dis.20111123bs

Document status and date:

Published: 01/01/2011

DOI:

10.26481/dis.20111123bs

Document Version:

Publisher's PDF, also known as Version of record

Please check the document version of this publication:

- A submitted manuscript is the version of the article upon submission and before peer-review. There can be important differences between the submitted version and the official published version of record.

People interested in the research are advised to contact the author for the final version of the publication, or visit the DOI to the publisher's website.

- The final author version and the galley proof are versions of the publication after peer review.

- The final published version features the final layout of the paper including the volume, issue and page numbers.

Link to publication

\footnotetext{
General rights rights.

- You may freely distribute the URL identifying the publication in the public portal. please follow below link for the End User Agreement:

www.umlib.nl/taverne-license

Take down policy

If you believe that this document breaches copyright please contact us at:

repository@maastrichtuniversity.nl

providing details and we will investigate your claim.
}

Copyright and moral rights for the publications made accessible in the public portal are retained by the authors and/or other copyright owners and it is a condition of accessing publications that users recognise and abide by the legal requirements associated with these

- Users may download and print one copy of any publication from the public portal for the purpose of private study or research.

- You may not further distribute the material or use it for any profit-making activity or commercial gain

If the publication is distributed under the terms of Article $25 \mathrm{fa}$ of the Dutch Copyright Act, indicated by the "Taverne" license above, 


\section{Supporting healthcare professionals}

to encourage patients to

decrease cardiovascular risk

attributable to physical inactivity

BARBARA SASSEN 
Colophon

(C) 2011, Barbara Sassen, Maarsssen, the Netherlands ISBN 9789088913426

Graphic design cover: Lex Verheesen

Printed by: BOXPress BV, Oisterwijk

All rights reserved. No part of this publication may be reproduced, stored in a retrieval system, transmitted in any form, or by any means, electronic, mechanical, photocopying, recording, or otherwise, without prior written permission of the author. 


\section{Supporting healthcare professionals \\ to encourage patients to \\ decrease cardiovascular risk \\ attributable to physical inactivity}

\section{PROEFSCHRIFT}

Ter verkrijging van de graad van doctor aan de Universiteit Maastricht, op gezag van de Rector Magnificus prof. mr. G.P.M.F Mols,

volgens het besluit van het College van Decanen,

in het openbaar te verdedigen op woensdag 23 november 2011 om $14.00 \mathrm{u}$

Door

BARBARA SASSEN 
PROMOTORES

Prof. Dr. G.J. Kok

Prof. Dr. L. Vanhees, Katholieke Universiteit Leuven

BEOORDELINGSCOMMISSIE

Prof. Dr. F. Zijlstra (voorzitter)

Dr. F. Boen, Katholieke Universiteit Leuven

Prof. Dr. B. van de Borne

Dr. R. Ruiter

Prof. Dr. N. de Vries 


\section{TABLE OF CONTENTS}

$\begin{array}{lll}\text { CHAPTER } 1 & \text { Introduction } & 7\end{array}$

CHAPTER 2 Physical fitness matters more than physical activity in controlling cardiovascular disease risk factors

CHAPTER 3 Cardiovascular risk profile: cross-sectional analysis of motivational determinants, physical fitness and physical activity

CHAPTER 4 Predictors of healthcare professionals' intention and behavior to encourage physical activity in patients with cardiovascular risk factors

CHAPTER 5 Stability of social-cognitive determinants over time: longitudinal design

CHAPTER 6 A web-based intervention for healthcare professionals and patients to decrease CVD risk attributable to physical inactivity 
CHAPTER 1

INTRODUCTION 


\section{CARDIOVASCULAR RISK FACTORS}

In the prevention of cardiovascular morbidity and mortality, the control of cardiovascular risk factors is of upmost importance [1,2]. Cardiovascular disease is the major cause of premature mortality in Europe [1]. If we can reduce the prevalence of cardiovascular risk factors, we probably can reduce the prevalence of cardiovascular disease, type 2 diabetes and all-cause mortality. The Interheart study showed that abdominal obesity, high blood pressure, elevated lipids and glucose levels, smoking combined with psychosocial factors and a low amount of consumption of fruit, vegetables and alcohol, and of regular physical activity, account for $90-94 \%$ of cardiovascular risk [2]. The last decade, the importance of the clustering of some of these risk factors, namely the metabolic syndrome, in the prevalence of cardiovascular disease and type 2 diabetes has been demonstrated [3]. The metabolic syndrome is defined as the presence of at least three of the following cardiovascular risk factors, namely abdominal obesity, high blood pressure, low HDL-C cholesterol, elevated triglycerides and elevated blood glucose levels. The classification of these cardiovascular risk factors is based on the extended ATPIII criteria of the National Cholesterol Education Program-Adult Treatment Panel III definition [4,5]. According to these ATPIII criteria, abdominal obesity is defined as having a waist circumference of $>102 \mathrm{~cm}$ for men, and $>88 \mathrm{~cm}$ for women. High blood pressure is defined as having a systolic blood pressure of $\geq 130 \mathrm{mmHg}$ and/or a diastolic blood pressure of $\geq 85$ $\mathrm{mmHg}$, and/or being on antihypertensive drug treatment. Low HDL-cholesterol is defined as $<1.03 \mathrm{mmol} / \mathrm{L}$ for men, and $<1.30 \mathrm{mmol} / \mathrm{L}$ for women, or being on drug treatment for reduced $\mathrm{HDL}-\mathrm{C}$. A person has high triglycerides levels when the level exceeds $\geq 1.70 \mathrm{mmol} / \mathrm{L}$ and/or if a person is on drug treatment. And at last, a person has high blood glucose levels when the level exceeds $\geq 6.1 \mathrm{mmol} / \mathrm{L}$, of if a person is on drug treatment for elevated glucose.

The consequences of cardiovascular diseases are substantial. With a population getting more and more inactive and having a sedentary lifestyle, the risk for cardiovascular disease and type 2 diabetes rises [7]. A sedentary lifestyle is associated with an increased cardiovascular risk and a lack of regular physical activity may contribute to the onset and progression of cardiovascular morbidity; though almost any increase in physical activity will result in health benefits [1]. This dissertation reports on people with one or more cardiovascular risk factors and inactive lifestyle behavior, and describes how healthcare professionals, in accordance with guidelines [1], can encourage these people at risk to become and stay physically active and fit in a way that cardiovascular fitness is improved. The corresponding assumption is that if an intervention can reduce the prevalence of risk factors, it can also reduce the prevalence of cardiovascular disease. When cardiovascular fitness improves and a person is capable to maintain active lifestyle behavior, levels and number of cardiovascular risk factors can decrease in a population. 
The last two decades more and more evidence is accumulated regarding the preventive effect of regular physical activity and physical fitness on cardiovascular disease mortality and morbidity $[7,8]$. This may be partly attributed to the favourable effect of increased physical activity or exercise training on the separate risk factors for cardiovascular disease. Research showed a reduction in systolic and diastolic blood pressure, beneficial effect on lipids, on glucose metabolism and on weight [8-12]. More recently it has been found that also the grouping of cardiovascular risk factors (abdominal obesity, high blood pressure, triglycerides and blood glucose, and low HDL-cholesterol) may be positively influenced by increased physical activity or physical fitness [3,4,13-18].

The relationship between cardiovascular risk factors, physical fitness and physical activity is made visual in the 'Model of health-related fitness' according to Bouchard and Shephard [20]. Health, health related fitness and physical activity are related, and lifestyle behaviour (as mentioned in the box environmental conditions), and heredity significantly contribute. Health-related fitness has important components including cardiorespiratory aspects (maximum aerobic capacity and lung function) and metabolic aspects (e.g. glucose tolerance and insulin sensitivity). Health-related fitness can be affected by lifestyle behaviors and habitual physical activity. From the perspective of disease prevention and especially the prevention of cardiovascular and metabolic diseases this model shows that lifestyle behaviors and physical activity, by influencing fitness, may influence (cardiovascular and metabolic) health.

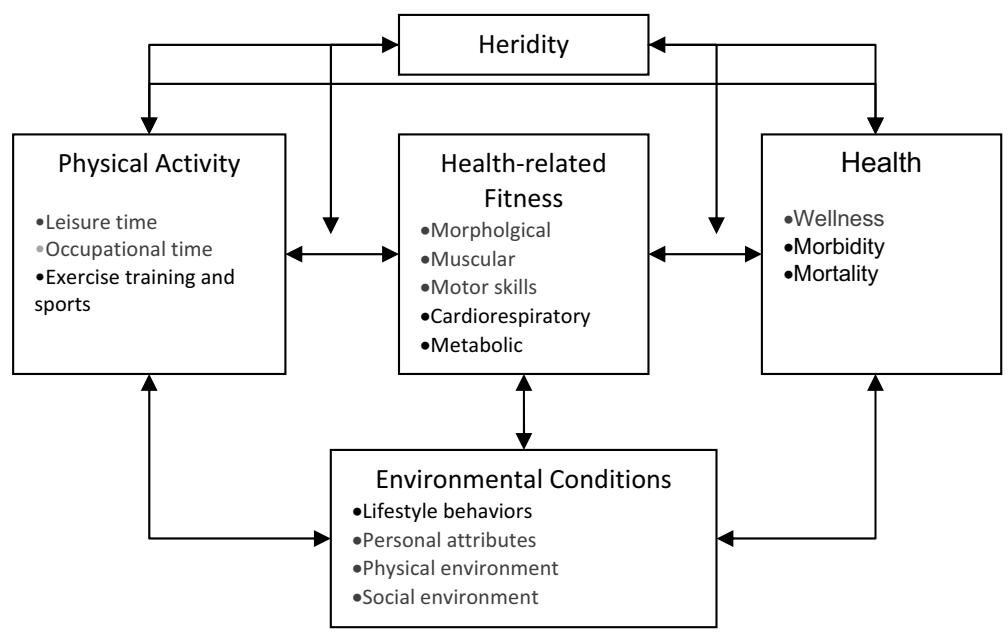

Figure 1. Model of health-related fitness (Bouchard \& Shephard 1994)

The prevalence of cardiovascular risk factors and the metabolic syndrome continues to increase and is becoming one of the costliest health problems [20]. The application of ATPIII criteria showed in our research that the prevalence of people having three or more cardiovascular risk factors is $19 \%$ in a Dutch working population, which is comparable to the rates observed in our neighbouring country of Germany (19.8\%), and slightly higher 
compared to the rates observed in a France and Italy [20,21]. Given the adverse outcome with the presence of even one or two cardiovascular risk factors components [21], this supports the need to develop efficacious and effective lifestyle interventions to reduce the prevalence and incidence of cardiovascular risk factors.

As shown in the Interheart study, several of the cardiovascular risk factors are related to the lifestyle behavior of people. Lifestyle behavior such as physical activity has a substantial impact on health. When lifestyle behavior has a negative impact on health, changing the lifestyle behavior of people conductive to health is a prerequisite [23-25]. But changing the lifestyle behavior of people is a difficult task. For changing lifestyle behavior, people need to know the relationship between lifestyle behavior and the health problem. But knowledge in itself is seldom a reason to change lifestyle behavior. Just a good explanation of cardiovascular risk will not make a person change his lifestyle. Even a good explanation of cardiovascular risk communicated by a healthcare professional will rarely change lifestyle behavior. Figuring out what personal advantages and disadvantages are in the long and short term, seeking support from the people around you and learn necessary skills are essential elements for changing lifestyle behavior. Planning to change lifestyle behavior is a prerequisite, in line with the identification of high-risk situations when putting behavior change into practice [24]. Changing an unhealthy lifestyle is important but only contributes to the prevalence of cardiovascular disease when people are capable to maintain the initiated lifestyle behavior change. Reduction of the prevalence of risk factors and the prevalence of diseases requires the incorporation of physical active lifestyle behavior in daily living.

Physical active lifestyle behavior needs recommendations for cardiovascular patients in inpatient and outpatient care, but also needs adherence to these recommendations. Patients with cardiovascular risk factors should adhere to the recommendations given by healthcare professionals and should be encouraged to become and also to stay physically active. When healthcare professionals are working together with patients, their relationship should be based on mutual exchanging information in an open and friendly though professional way. Interventions should supplement and not narrow the communication between healthcare professional and patient.

\section{CARDIOVASCULAR RISK FACTORS, CARDIOVASCULAR PHYSICAL FITNESS AND PHYSICAL ACTIVITY}

In chapter 2 we will describe the importance of physical fitness in controlling cardiovascular risk factors. Our research focused on the exploration of the importance of physical activity and cardiovascular physical fitness in relation to risk factors associated with cardiovascular disease and the metabolic syndrome. Research has demonstrated that physical activity and physical fitness have a preventive effect on cardiovascular disease morbidity and mortality. In the literature, only few studies $[13,17]$ attempted to differentiate the effect of different components of physical activity (intensity, duration, type and volume of physical activity) on cardiovascular risk factors or on the metabolic syndrome. Most of these studies focused on the effect of duration of physical activity. 
Recently the literature focuses more on the intensity of exercise and reported lower odds for the metabolic syndrome [13,17], or reduced risk for coronary heart disease [7] with increasing intensity. Further, poor physical fitness has been associated with an increased prevalence and incidence of the metabolic syndrome [17]. Nevertheless, whereas both higher levels of physical activity and physical fitness have favourable effects, a recent metaanalysis showed that physical activity and physical fitness may have significantly different relationships with cardiovascular and coronary heart disease risk, i.e. the reductions in relative risk are nearly twice as large for physical fitness as for physical activity [26].

\section{PEOPLE WITH CARDIOVASCULAR RISK FACTORS AND THEIR LIFESTYLE BEHAVIOR}

Building on the findings of chapter 2, we will describe in chapter 3 if the cardiovascular risk profile of people can be optimized by exploring social-cognitive predictors of lifestyle behavior, physical activity and cardiovascular physical fitness. The Theory of Planned Behavior, Social Cognitive Theory and other health behavior theories, are valuable to understand the determinants underlying intention and behavior and to select the social-cognitive determinants as input for intervention development [27-34]. This identification of social-cognitive determinants for a specific group is a prerequisite to initiate lifestyle behavior changes $[23,24]$. We studied social-cognitive determinants of the intention to engage in physical activity and physical active behavior, as well as extensive self-reported physical activity (in intensity and duration) and measured physical fitness (peak $\mathrm{VO}_{2}$ ). A better understanding of the social-cognitive correlates of intention to engage in physical activity on a daily basis and physical active behavior is imperative. Most studies refer to research on social-cognitive determinants without investigating physical activity and cardiovascular physical fitness in a broader scope.

\section{HEALTHCARE PROFESSIONALS ENCOURAGING PATIENTS WITH CARDIOVASCULAR RISK FACTORS}

In order to make cardiovascular prevention and the implementation of interventions directed at optimizing the health status of cardiovascular patients effective, it is imperative that we gain a better understanding of healthcare professionals' behavior and intentions, and the social-cognitive determinants of their intentions and behavior. Healthcare professionals can play an essential role in optimizing the health status of patients with cardiovascular risk factors. However, a substantial gap between clinical research findings and the daily practice of healthcare professionals remains [35-37]. Though nowadays it is common to work evidence-based for healthcare professionals, the daily practice for healthcare professionals is sometimes different. In order to increase congruence between theory and practice and better support patients, it is imperative that we investigate healthcare professionals' behavior and the determinants that underlie their behavior. We explored the relative importance of social-cognitive variables in relation to healthcare professionals' intention and behavior and investigated the congruence between healthcare professionals' intention to encourage physical activity in patients with cardiovascular risk factors and the self-reported behavior of encouraging patients. In chapter 4 insights is 
provided, by using the Theory of Planned Behavior, Social Cognitive Theory and other health behavior theories, in the prediction of healthcare professionals intention and behavior [27-34]. In this chapter it is also discussed whether efforts to change and strengthen the intention-behavior relationship of healthcare professionals can have beneficial effects for patients with cardiovascular risk factors.

\section{STABILITY OF SOCIAL-COGNITIVE DETERMINANTS}

People with cardiovascular risk factors and healthcare professionals intend to engage in (health) behaviors when the behavior is evaluated as positive, when the behavior is considered to be under personal control and when one thinks that significant others find the behavior to be important. The Theory of Planned Behavior, Social Cognitive Theory and other health behavior theories has extensively been studied to predict intention and behavior, for all kind of (health) problems and (healthcare) settings [27-34]. The assumption is that when we measure social-cognitive determinants and intention at time 1 and behavior at time 2, we will have a clear focus on the behavior under study [38]. The assumption is that intention is an important predictor of behavior and that intention and behavior can be changed in a positive direction by implementing carefully designed behavior change interventions. In chapter 5 we will unravel the stability of social-cognitive determinants over time according to the hypothesis that, if no intervention is implemented, social-cognitive determinants are stable over time; i.e. that if no intervention is implemented the social-cognitive variables will not differ much when measured at time 1 compared with time 2 . In this chapter insight is provided in the stability of social-cognitive determinants over time and also in the interdependence of social-cognitive determinants, when measured at two moments in time.

\section{DEVELOPMENT AND IMPLEMENTATION PIB2-INTERVENTION}

Building on the findings of chapter 2, 3 and 4, we developed a web-based intervention directed at both healthcare professionals and patients, to expand healthcare professionals' behavior as well as patients' risk-reduction behavior. According to the guidelines for cardiovascular risk management, healthcare professionals should encourage their patients to engage in physical activity. Patients with cardiovascular risk factors can reduce their risk of cardiovascular disease by increasing their physical activity levels and especially their physical fitness. Developing an intervention is not just figuring out a well thought idea, but it needs a plan how to design, implement and evaluate an intervention. Intervention Mapping provides a framework for building high quality interventions that are systematically planned and theory and evidence-based, and take perspectives of end users and intermediates into consideration [23-25,39-41]. Intervention Mapping places specific emphasis on the transparency of the translation of evidence-based behavior change techniques in intervention components not only to develop the specific intervention but also to explain its rationale [25]. Intervention Mapping has been found to be effective for developing interventions [24,42-46]. In chapter 6 insights is provided regarding the systematic development of the web-based PIB2-intervention. The different steps of the 
Intervention Mapping process are described to open up the black box of web-based intervention development and to provide support for future web-based intervention development. Research has demonstrated the favourable effects of Internet-delivered interventions [47-50]. Computer-delivered interventions can not only improve socialcognitive determinants, but also enhance health behaviour and general health maintenance [47]. An Internet-delivered behavioural change intervention facilitates the delivery of the intervention to a large group of professionals and patients. Using a website is appealing to the group of interest and has the benefits of making processes visible [51]. Internetdelivered physical activity interventions have been shown to be effective [52].

Using the Intervention Mapping protocol increases the likelihood that an intervention will be effective, shaped to the characteristics of the target group of healthcare professionals and patients with cardiovascular risk factors, and the setting in which the intervention can take place; and, in order to facilitate program logic transparency, reproducibility and diffusion of the PIB2-intervention [24]. The intervention sought to optimize behavioral coaching by healthcare professionals and encouraging previously physically inactive patients with cardiovascular risk factors to become physically active, following cardiovascular risk management guidelines with a potential for implementation in cardiovascular inpatient and outpatient care [53]. We implemented the PIB2-intervention and the intervention will be reported spring 2012.

\section{AIMS}

In this dissertation we had the following aims: (1) Physical activity and cardiovascular physical fitness are inversely associated with the clustering of cardiovascular disease risk factors, however, the role of individual components of physical activity (i.e. intensity, duration and volume) and physical fitness in the prevention of cardiovascular disease remains elusive. Therefore, the aim was to explore the importance of the components of physical activity in relation to cardiovascular risk factors, to explore the importance of cardiorespiratory fitness in comparison with components of physical activity in controlling cardiovascular risk factors, and finally to elucidate the pathway of the relation between physical activity and cardiovascular risk score. (2) To enable the development of effective lifestyle interventions for people with cardiovascular risk factors, we investigated socialcognitive determinants, next to physical activity and physical fitness. Therefore the aim was to explore the relative importance of social-cognitive variables and the intention to engage in physical activity; physical active behavior; the intensity of physical activity; and physical fitness (peak $\mathrm{VO}_{2}$ ); and also to investigate the congruence between a high and low intention to engage in physical activity vs. having physical active or inactive behavior. (3) To enable the development of effective interventions for healthcare professionals who encourage patients with cardiovascular risk factors to become and stay physically active, it is imperative that we understand the social-cognitive determinants that underlie healthcare professionals' intention and the corresponding behavior of actually encouraging patients. Therefore the aim was to explore the relative importance of social-cognitive variables in 
relation to healthcare professionals' intention and behavior, and also to explore the congruence between healthcare professionals' intention to encourage physical activity in cardiovascular risk patients and the self-reported behavior of encouraging patients. (4) In exploring the encouraging behavior of healthcare professionals, we hypothesized that, if no intervention is implemented, social-cognitive determinants are stable over time. Therefore the aim of the fourth study was to explore differences between the social-cognitive determinants measured at time 1 compared with the social-cognitive determinants at time 2 , and to explore the interdependence of social-cognitive determinants to predict intention and behavior when measured at time 1 and time 2. (5) In the systematic development process of the web-based PIB2-intervention, to optimize behavioral coaching by healthcare professionals and encouraging previously physically inactive patients with cardiovascular risk factors to become physically active, we applied Intervention Mapping. Therefore the aim of the fifth study was to open up the black box of web-based intervention development and to provide support for future web-based intervention development.

\section{OUTLINE OF THE DISSERTATION}

This dissertation can be divided in 3 parts. In part one, the background is described exploring the importance of (components of) physical activity and cardiovascular physical fitness in controlling cardiovascular risk factors (chapter 2), the research on social-cognitive determinants for intention, behavior, the intensity of physical activity and physical fitness; and the congruence between intention and physical active behavior for people with cardiovascular risk factors (chapter 3), and, the research on social-cognitive determinants for healthcare professionals' intention and behavior, and the congruence between their intention to encourage physical activity in cardiovascular risk patients and the self-reported behavior of encouraging patients (chapter 4). In part 2 we studied the stability and the interdependence of social-cognitive determinants when measured at two moments in time (chapter 5). In part three we will describe the systematic development process of the webbased PIB2-intervention to extent healthcare professionals' behaviour and to optimize patients' risk-reduction behavior (chapter 6). 
ссинтre 2

PART

ONE

PhYSICAL FITNESS MATTERS MORE THAN PHYSICAL ACTIVITY IN CONTROLLING CARDIOVASCULAR DISEASE RISK FACTORS

Chapter has been published as:

Barbara Sassen, Véronique Cornelissen, Henri Kiers, Harriet Wittink, Gerjo Kok, Luc Vanhees. Physical fitness matters more than physical activity in controlling cardiovascular disease risk factors. European Journal of Cardiovascular Prevention and Rehabilitation 2009, 16:677-683. 


\section{ABstract: Physical fitness MATters MORE Than PhySiCAL ACTIVITY IN CONTROLLING CARDIOVASCULAR DISEASE RISK FACTORS}

Background: Physical activity (PA) and physical fitness (PF) are inversely associated with the clustering of cardiovascular disease (CVD) risk factors (RF), associated with the metabolic syndrome (MS). However, the role of individual components of PA, i.e. intensity, duration and volume, and the interrelationship with PF in the prevention of the MS and its individual components remains elusive.

Design: Cross-sectional analysis.

Method: The study was based on 1298 (874 male and 424 female) police employees (aged 18-62 years) who participated in the Utrecht Police Lifestyle Intervention Fitness and Training (UP-LIFT) study. PA was assessed with an extensive questionnaire. $\mathrm{VO}_{2}$ peak and metabolic markers, including blood pressure, fasting glucose, triglycerides, HDL-cholesterol and waist circumference, were determined.

Results: The prevalence of the MS was $18.6 \%$ (22.5\% in men, $10.6 \%$ in women). After adjustment for age and gender, average PA intensity, PA duration, PA volume and PF were each associated with reduced odds of MS. Regression analyses further showed an inverse relation between total CVD risk score and average PA intensity, the hours of PA performed at high intensity (>6 METS) and PF, but no relation with total hours or the hours of PA performed at low or moderate intensity. When we adjusted our analyses for PF, the relations with the components of PA became non-significant. Using pathway analysis, we found that $\mathrm{VO}_{2}$ peak mediated $78 \%$ of the effect of average PA intensity and $93 \%$ of the effect of the hours performed at high intensity on total CVD risk score.

Conclusion: PA and PF are inversely associated with the clustering of metabolic abnormalities. With regard to $\mathrm{PA}$, it seems that intensity and more specifically higher intensity is the main characteristic of PA determining its effect on CVD RF. However, compared to PA, PF exerts greater effects on each of this individual CVD RF and its combination. 


\section{INTRODUCTION}

During the last two decades more and more evidence is accumulated regarding the preventive effect of regular physical activity (PA) [1,2] and measured physical fitness (PF) $[2,3]$ on cardiovascular disease (CVD) mortality and morbidity. This may be partly attributed to the favourable effect of increased PA or exercise training on separate risk factors (RF) for CVD: reduction in systolic (SBP) and diastolic blood pressure (DBP) [4]; beneficial effect on lipid [5] and glucose metabolism [6] and on weight [7]. More recently it has been found that also the grouping of interrelated RF for CVD (abdominal obesity, high BP, triglycerides and blood glucose, and low HDL-cholesterol), defined as the metabolic syndrome (MS) [8] may be positively influenced by increased PA [9-13] or PF [14,15].

In the literature, only few studies $[10,14]$ attempted to differentiate the effect of different components of PA (intensity, duration, type and volume of PA) on CVD RF or on the MS. Most of these studies focused on the effect of intensity and reported lower odds for the MS $[10,14]$ or reduced risk for coronary heart disease [1] with increasing intensity. Further, poor PF has been associated with an increased prevalence and incidence of MS [14]. Nevertheless, whereas both higher levels of PA and PF have favourable effects, a recent meta-analysis showed that PA and PF may have significantly different relationships to combined CVD and coronary heart disease risk, i.e. the reductions in relative risk are nearly twice as large for PF than PA [16].

Aim. Therefore, the primary aim of this study was to explore the relative importance of duration, average intensity and volume of PA in relation to CVD RF associated with the MS, secondly to explore the relative importance of PF in comparison with components of PA in controlling CVD RF, and finally to elucidate the pathway of the relation between PA and CVD risk score.

\section{METHODS}

\section{Population}

This study is part of the Utrecht Police Lifestyle Intervention Fitness and Training (UPLIFT) study, a voluntary fitness and lifestyle test for police employees in Utrecht, The Netherlands. The population comprised 874 men and 424 women, aged 18-62 years, who visited our research department between December 2004 and November 2008. All 1,298 participants provided written informed consent and approval for the study was obtained from the Ethical Committee of the Utrecht University Medical Centre.

\section{Assessment of cardiovascular risk factors}

The classification of CVD RF was based on the extended ATPIII criteria of the National Cholesterol Education Program-Adult Treatment Panel III definition [8]. MS is defined as the presence of any three of the following five RF: (1) central obesity (men: waist circumference $>102 \mathrm{~cm}$; women: $>88 \mathrm{~cm}$ ); (2) high BP (systolic $\geq 130 \mathrm{mmHg}$ and/or diastolic $\geq 85 \mathrm{mmHg}$ ) or on antihypertensive drug treatment; (3) low HDL-cholesterol (HDL-C, men <1.03 mmol/L; 
women $<1.30 \mathrm{mmol} / \mathrm{L}$ ) or on drugs treatment for reduced HDL-C; (4) high triglycerides $\geq 1.70$ $\mathrm{mmol} / \mathrm{L}$; and (5) high blood glucose ( $\geq 6.1 \mathrm{mmol} / \mathrm{L}$ ) or on drug treatment for elevated glucose. Waist circumference was measured at the level of the umbilicus with a plastic anthropometric tape. BP was measured twice at rest, in seated position, with a sphygmomanometer; the mean value of both measures was used. Following a four hour fast, a blood sample was taken at the fingertip. Concentrations of HDL-C, triglycerides and glucose were assayed with automatic Cholestec LDX cassettes $^{\circledR}$.

\section{Assessment of PF and PA}

For the assessment of PF, peak oxygen uptake ( $\mathrm{VO}_{2}$ peak) as golden standard for exercise capacity was measured [17]. Subjects were tested on a bicycle ergometer (SiemensElema 380B; Ergometrics $800{ }^{\circledR}{ }^{\circledR}$, Ergometrics, Bitz, Germany), in a laboratory with stabilized room temperature. The initial workload of 20 Watt was increased every minute by 20 Watt until volitional exhaustion. During the test, a 12-lead electrocardiogram and respiratory data through breath-by-breath analysis (Oxyxon $\mathrm{Pro}^{\circledR}$, Jaeger, Mijnhardt) were continuously measured. Heart rate (HR) was calculated from the electrocardiogram. The gas analysers and the flow meter were calibrated before each test according to the manufacturer's instructions. Oxygen uptake $\left(\mathrm{VO}_{2}\right)$ and carbon dioxide output $\left(\mathrm{VCO}_{2}\right)$ were determined from the continuous measurement of oxygen and carbon dioxide concentration in the inspired and expired air. The respiratory gas exchange ratio (RER) was calculated as $\mathrm{VCO}_{2} / \mathrm{VO}_{2}$.

PA was assessed with the Short QUestionnaire to ASsess Health enhancing PA (SQUASH) of which the reproducibility and validity has been tested and proved to be fairly reproducible and reasonably valid; the overall reproducibility was $r=0.58$ (95\% Cl 0.36-0.74) and the validity when compared to the Computer Science and Applications activity monitor was $r=0.45$ (95\% Cl 0.17-0.66) [18]. Participants were asked to report their average time (days per week, hours per day, minutes per day) and type of PA. For the purpose of our study we selected walking, cycling and sports activities. Activities were given a metabolic equivalent value (METS), range 1-12 METS [19]. The average intensity of PA was expressed as PA METS, the time spend on PA was expressed as PA hours/wk and the volume of PA was expressed as PA MET-hours (the total of the MET values of all activities multiplied by the time spent on this activities). PA MET-hours was divided in 3 categories by level of intensity; PA MET-hours low (hours *activities $\leq 4$ METS), PA MET-hours moderate (hours *activities 46 METS), and PA MET-hours high (hours *activities $>6$ METS).

\section{Statistical analysis}

Comparisons between individuals with $0-1,2$, or 3 or more CVD RF were performed by one-way analysis of variance, and chi-square contingency analysis. Logistic regression was used to explore the relation between PA and the MS. Odds ratios and their $95 \%$ confidence intervals are reported for single and multiple regression analyses. Variables included in the analyses were intensity, time and volume of PA, PF ( $\mathrm{VO}_{2}$ peak), age and gender. For PA parameters and $\mathrm{VO}_{2}$ peak, participants were divided in quartiles with the least active group 
as reference group. Trends were analysed for significance [20]. We computed a continuous CVD risk score by averaging the Z-scores of the five CVD RF measurements. The Z-score of HDL-C was multiplied by -1 because, in contrast with the other CVD RF, high HDL-C is considered to have a positive influence on the total CVD risk. The Z-scores of SBP and DBP were averaged and entered into the calculation as one Z-score.

TABLE 1 - Characteristics of 1298 police employees according to the number of CVD RF present

\begin{tabular}{lcccc}
\hline & $0-1$ risk factor & $2 \mathrm{RF}$ & $\geq 3 \mathrm{RF}$ & $\mathrm{P}$ \\
\hline Prevalence & $751(57.9)$ & $305(23.5)$ & $24(18.6)$ & \\
Gender (\% male) & 60.7 & 72.4 & 81.4 & $<0.001$ \\
Age (years) & $35.5 \pm 10.7$ & $39.7 \pm 10.8^{\mathrm{a}}$ & $44.8 \pm 9.4^{\mathrm{ab}}$ & $<0.001$ \\
Smoking abits present & $150(20.0)$ & $82(26.9)$ & $65(26.9)$ & $<0.01$ \\
Smoking habits past & $229(30.5)$ & $83(27.2)$ & $85(35.1)$ & $<0.01$ \\
Weight (kg) & $75.4 \pm 12.1$ & $83.5 \pm 11.7^{\mathrm{a}}$ & $91.5 \pm 13.4^{\mathrm{ab}}$ & $<0.001$ \\
\left. VO2peak (ml.kg ${\left.\text { - } \mathrm{min}^{-1}\right)}^{-1}\right)$ & $37.5 \pm 7.6$ & $34.4 \pm 8.1^{\mathrm{a}}$ & $31.0 \pm 7.5^{\mathrm{ab}}$ & $<0.001$ \\
Sedentary \% of value & $110.3 \pm 19.1$ & $107.4 \pm 18.6$ & $102.9 \pm 19.3^{\mathrm{ab}}$ & $<0.001$ \\
RER (VCO $/ \mathrm{VO}_{2}$ ) & $1.07 \pm 0.07$ & $1.06 \pm 0.08$ & $1.05 \pm 0.07^{\mathrm{a}}$ & $<0.01$ \\
Peak heart rate (bpm) & $171.8 \pm 13.2$ & $167.0 \pm 15.4^{\mathrm{a}}$ & $164.4 \pm 16.3^{\mathrm{a}}$ & $<0.001$ \\
Borg score & $15.6 \pm 1.4$ & $15.6 \pm 1.4$ & $15.5 \pm 1.6$ & $\mathrm{NS}$ \\
PA METS & $4.9 \pm 1.4$ & $4.6 \pm 1.5^{\mathrm{a}}$ & $4.3 \pm 1.5^{\mathrm{ab}}$ & $<0.01$ \\
PA hours & $9.6 \pm 8.7$ & $9.3 \pm 9.0$ & $8.1 \pm 8.4$ & $\mathrm{NS}$ \\
PA MET-hours & $47.4 \pm 43.8$ & $44.9 \pm 45.9$ & $37.6 \pm 38.6^{\mathrm{a}}$ & $<0.01$ \\
PA MET-hours high & $15.4 \pm 21.6$ & $14.1 \pm 28.3$ & $7.8 \pm 15.3^{\mathrm{ab}}$ & $<0.001$ \\
PA MET-hours moderate & $20.5 \pm 25.6$ & $18.5 \pm 24.3$ & $18.9 \pm 25.1$ & $\mathrm{NS}$ \\
PA MET-hours low & $11.4 \pm 18.6$ & $12.3 \pm 16.7$ & $10.8 \pm 16.1$ & $\mathrm{NS}$ \\
\hline
\end{tabular}

Values are numbers (\%) or mean \pm SD. Abbreviations: VO2peak, peak volume of oxygen consumption $\left(\mathrm{ml}^{\mathrm{kg}} \mathrm{g}^{-1} \cdot \mathrm{min}^{-1}\right)$; RER, respiratory exchange ratio; PA METS, average intensity of PA in METS; PA hours, duration of PA in hours/wk; PA MET-hours, total volume of PA in METS $x$ hours/wk; PA MET-hours high, PA MET-hours divided by level of intensity $>6$ METS $x$ hours p/wk; PA MET-hours moderate, PA MET-hours divided by level of intensity 4-6 METS $x$ hours/wk; PA MET-hours low; PA MET-hours divided by level of intensity low, $<4$ METS $\times$ hours/wk. $P, p$-value for difference; $a=$ different from 0-1 risk factor group, $b=$ different from 2 RF group. NS, not significant.

Linear regression analyses with the Z-score as dependent variable were undertaken to further explore the association between CVD RF and the independent variables for PA and $\mathrm{VO}_{2}$ peak. These variables were adjusted for age and gender. To investigate the percentage of the association between PA METS and MET-hours high on the CVD risk score, which could be explained by $\mathrm{VO}_{2}$ peak, we compared the strength of the association between the PA variable of interest and CVD Z-score in a single and in a multiple regression model. We calculated this percentage by subtracting the adjusted standardized beta coefficients from the univariate standardized beta and divided the outcome through the unadjusted beta. The outcome of this "path analysis" was subtracted from $100 \%$ and can be judged as the percentage variance in the association between the PA variable and CVD Z-score that is accounted for by $\mathrm{VO}_{2}$ peak. Significance of all tests was set at $\mathrm{p} \leq 0.05$. Statistical analyses were performed with 
SPSS package version 15.0 (SPSS inc 2006).

TABLE 2. Odds ratios (95\% confidence intervals) for having the metabolic syndrome in different categories of PA and in the categories of PF (VO2peak). In italic, the range of the quartiles for PA components or PF is presented

\begin{tabular}{|c|c|c|c|c|c|}
\hline & Quartile 1 & Quartile 2 & Quartile 3 & Quartile 4 & $\begin{array}{l}P \text { for } \\
\text { trend }\end{array}$ \\
\hline PA METS & $0-3.96$ & $3.97-4.49$ & $4.50-5.50$ & $5.50-10.67$ & \\
\hline Unadjusted & 1 & $0.66(0.46-0.95)$ & $0.49(0.33-0.72)$ & $0.38(0.25-0.57)$ & $<0.001$ \\
\hline $\begin{array}{l}\text { Adjusted for age } \\
\text { and gender }\end{array}$ & 1 & $0.79(0.53-1.16)$ & $0.62(0.41-0.94)$ & $0.59(0.37-0.93)$ & $<0.01$ \\
\hline $\begin{array}{l}\text { Adjusted for age, } \\
\text { gender and } \\
\text { VO2peak }\end{array}$ & 1 & $1.04(0.69-1.57)$ & $0.92(0.59-1.41)$ & $0.88(0.55-1.40)$ & NS \\
\hline PA hours & $0-4.00$ & $4.01-7.00$ & $7.17-11.50$ & $11.60-89.50$ & \\
\hline Unadjusted & 1 & $0.65(0.45-0.95)$ & $0.62(0.42-0.92)$ & $0.60(0.41-0.89)$ & $<0.001$ \\
\hline $\begin{array}{l}\text { Adjusted for age } \\
\text { and gender }\end{array}$ & 1 & $0.68(0.46-1.02)$ & $0.66(0.44-0.99)$ & $0.60(0.40-0.90)$ & $<0.05$ \\
\hline $\begin{array}{l}\text { Adjusted for age, } \\
\text { gender and } \\
\text { VO2peak }\end{array}$ & 1 & $0.96(0.63-1.46)$ & $1.02(0.66-1.56)$ & $1.01(0.65-1.57)$ & NS \\
\hline PA MET-hours & $0-19.75$ & $19.82-34.22$ & $34.25-56.50$ & $56.64-560.50$ & \\
\hline Unadjusted & 1 & $0.91(0.63-1.31)$ & $0.55(0.37-0.83)$ & $0.51(0.34-0.77)$ & $<0.001$ \\
\hline $\begin{array}{l}\text { Adjusted for age } \\
\text { and gender }\end{array}$ & 1 & $1.02(0.69-1.50)$ & $0.64(0.42-0.98)$ & $0.56(0.37-0.86)$ & $<0.01$ \\
\hline $\begin{array}{l}\text { Adjusted for age, } \\
\text { gender and } \\
\text { VO2peak }\end{array}$ & 1 & $1.47(0.97-2.22)$ & $1.01(0.65-1.58)$ & $1.02(0.64-1.62)$ & NS \\
\hline $\begin{array}{l}\text { VO2peak } \\
\left(\mathrm{ml}^{\prime} \mathrm{kg}^{-1} \mathrm{~min}^{-1}\right)\end{array}$ & $12.07-29.68$ & $29.71-35.46$ & $35.46-41.11$ & $41.12-61.86$ & \\
\hline Unadjusted & 1 & $0.56(0.39-0.79)$ & $0.28(0.19-0.42)$ & $0.15(0.09-0.25)$ & $<.001$ \\
\hline $\begin{array}{l}\text { Adjusted for age } \\
\text { and gender }\end{array}$ & 1 & $0.46(0.31-0.68)$ & $0.24(0.15-0.38)$ & $0.13(0.07-0.22)$ & $<.001$ \\
\hline $\begin{array}{l}\text { Adjusted for age, } \\
\text { gender and PA } \\
\text { MET-hours }\end{array}$ & 1 & $0.46(0.31-0.69)$ & $0.24(0.15-0.39)$ & $0.13(0.08-0.23)$ & $<.001$ \\
\hline
\end{tabular}

Abbreviations: PA METS, average intensity of PA in METS; PA hours, duration of PA in hours/week; PA MET-hours, total volume of PA in METS $x$ hours/week; VO2peak, peak oxygen uptake; NS, not significant.

\section{RESULTS}

Participants were aged 18-62 years (mean 44.8). The point prevalence of the MS was $18.6 \%$ (22.5\% in men, $10.6 \%$ in women). Based on the extended ATPIII criteria, $58 \%$ of our population was hypertensive and the proportion of subjects who were overweight was $19.4 \%$. Dislipidemia was highly prevalent $(25 \%$ with fasting triglycerides $>1.70 \mathrm{mmol} / \mathrm{L}$ and $36.6 \%$ with low HDL-C or on drugs treatment), whereas only 71 police employees (5.5\%) had abnormal glucose levels or were on drug treatment for high glucose. 
Table 1 shows the characteristics of the study sample, divided according to the number of CVD RF present. Participants with two or more CVD RF associated with the MS were significantly older and heavier compared to those having none or one CVD RF. $\mathrm{VO}_{2}$ peak, both expressed in $\mathrm{ml} / \mathrm{kg} / \mathrm{min}$ or in $\%$ of sedentary value, decreased with an increase in the number of CVD RF. Average PA intensity as well as the hours performed at higher intensity were significantly lower in subjects with at least three CVD RF compared to those with a maximum of one CVD RF. No differences could be detected between the three subgroups for PA hours and PA MET-hours performed at low or moderate intensity.

Further, increasing average PA intensity, PA hours, PA volume (MET-hours) or PF were each associated with reduced odds of MS in analyses adjusted for age and gender (Table 2). The odds ratios of MS in the top compared with the bottom categories were 0.59 (0.37-0.93), 0.60 (0.40-0.90), $0.56(0.37-0.86)$ and 0.13 (0.07-0.22), respectively. When we adjusted PA parameters by $\mathrm{VO}_{2}$ peak, these trends were no longer significant $(\mathrm{P}>0.05)$; whereas when we adjusted PF for PA volume (PA MET-hours), the trend remained highly significant.

TABLE 3 - Relation between measures of PA or PF, and z-scores of separate and combined CVD RF

\begin{tabular}{|c|c|c|c|c|c|c|c|}
\hline & PA METS & PA hours & $\begin{array}{l}\text { PA MET- } \\
\text { hours }\end{array}$ & $\begin{array}{c}\text { PA MET- } \\
\text { hours } \\
\text { high }\end{array}$ & $\begin{array}{l}\text { PA MET- } \\
\text { hours } \\
\text { moderate }\end{array}$ & $\begin{array}{l}\text { PA } \\
\text { MET- } \\
\text { hours } \\
\text { low }\end{array}$ & VO2peak \\
\hline \multicolumn{8}{|l|}{ Total CV risk score } \\
\hline -Unadjusted & $-0.145^{* * *}$ & $-0.06 *$ & $-0.081^{* *}$ & $-0.125 * * *$ & ns & ns & $-0.380 * * *$ \\
\hline $\begin{array}{l}\text {-Adjusted for age } \\
\text { and gender }\end{array}$ & $-0.055^{*}$ & ns & Ns & $-0.056 *$ & ns & ns & $-0.433^{* * *}$ \\
\hline \multicolumn{8}{|l|}{ Waist } \\
\hline \multicolumn{8}{|l|}{ circumference, } \\
\hline -Unadjusted & $-0.144 * * *$ & $-0.097 * * *$ & $-0.119 * * *$ & $-0.130 * * *$ & $-0.090 * *$ & ns & $-0.548 * * *$ \\
\hline $\begin{array}{l}\text {-Adjusted for age } \\
\text { and gender }\end{array}$ & ns & $-0.052^{*}$ & $-0.050^{*}$ & ns & $-0.057^{*}$ & ns & $-0.520 * * *$ \\
\hline \multicolumn{8}{|l|}{ Blood pressure } \\
\hline -Unadjusted & $-0.088 * *$ & ns & Ns & ns & ns & ns & $-0.174 * * *$ \\
\hline $\begin{array}{l}\text {-Adjusted for age } \\
\text { and gender }\end{array}$ & ns & ns & ns & ns & ns & ns & $-0.202 * * *$ \\
\hline \multicolumn{8}{|l|}{ Triglycerides } \\
\hline -Unadjusted & $-0.118 * * *$ & ns & $-0.060^{*}$ & $-0.13 * * *$ & s & ns & $-0.209 * * *$ \\
\hline $\begin{array}{l}\text {-Adjusted for age } \\
\text { and gender }\end{array}$ & $-0.072^{* * *}$ & ns & ns & $-0.079 * *$ & ns & ns & $-0.251^{* * *}$ \\
\hline \multicolumn{8}{|l|}{ HDL-cholesterol } \\
\hline -Unadjusted & ns & ns & ns & $0.056^{*}$ & ns & $-0.058^{*}$ & $0.155^{* * *}$ \\
\hline $\begin{array}{l}\text {-Adjusted for age } \\
\text { and gender }\end{array}$ & ns & ns & ns & $0.075^{* *}$ & ns & $-0.059 *$ & $0.276^{* * *}$ \\
\hline \multicolumn{8}{|l|}{ Glucose } \\
\hline -Undusted & ns & ns & ns & ns & ns & ns & ns \\
\hline $\begin{array}{l}\text {-Adjusted for age } \\
\text { and gender }\end{array}$ & ns & ns & ns & ns & ns & ns & ns \\
\hline
\end{tabular}


To assess the relation between components of PA and the severity of CVD RF, we related each of the individual PA components with z-scores of CVD RF. As demonstrated in Table 3, average PA intensity (PA METS) and the hours performed at high intensity (PA METhours high) showed an inverse association with the total CVD risk score, after adjustment for age and gender. Analyses further showed significant inverse associations between PA METS and PA MET-hours high and triglycerides. PA MET-hours high was also positively associated with HDL-C, whereas waist circumferences was inversely related to PA hours, total volume of PA (PA-MET hours) and PA MET-hours performed at moderate intensity. Finally, $\mathrm{VO}_{2}$ peak was inversely associated (positive for HDL-cholesterol) with the total CVD risk score and each of the individual RF, except fasting glucose $(P>0.05)$. The significant relations between PA and CVD RF disappeared when we further adjusted for $\mathrm{VO}_{2}$ peak. Adjustment for PA volume (PA MET-hours), however, did not attenuate the relation between $\mathrm{VO}_{2}$ peak and CVD RF.

Finally, we investigated the "pathway" of the relation between PA and CVD risk score through PF. The adjusted $\beta$-coefficient for $\mathrm{VO}_{2}$ peak with PA METS was -0.0032 and -0.009 with PA MET-hours high. $\mathrm{VO}_{2}$ peak, therefore, explains $[(-0.145+0.032) /-0.145] * 100 \%=$ $77.9 \%$ of total variance in PA METS and $[(-0.125+0.009) /-0.125]^{*} 100 \%=92.8 \%$ of total variance in PA MET-hours high (Figure 1).

Figure 1. Pathway of the relation between PA and CVD risk score (summarised z-scores) through PF

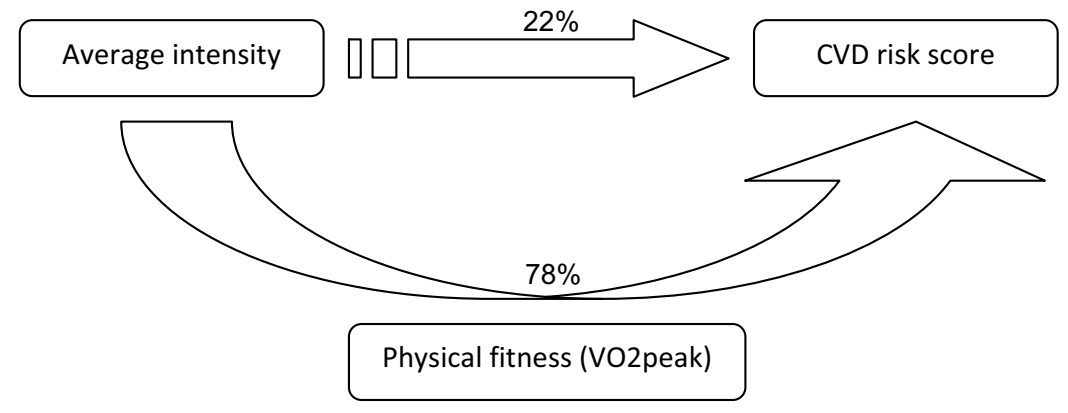

a. Pathway for average intensity of PA in METS

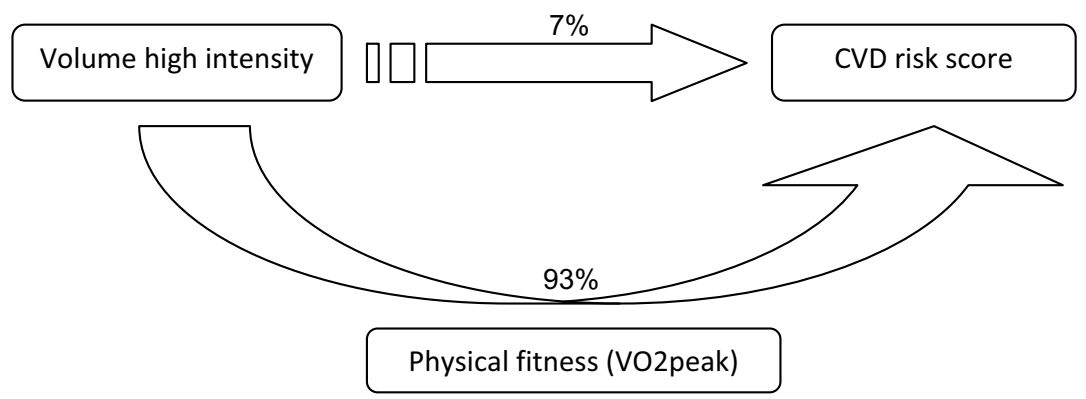

b. Pathway for volume of only high intensity PA (> 6 METS) in METS*Hour 


\section{DISCUSSION}

The cross-sectional study, involving 1,298 healthy police employees, shows significant inverse associations between PA, PF and clustering of CVD RF associated with the MS. With regard to $P A$, it seems that intensity and more specifically, high intensity is the most important characteristic of PA determining its effect on CVD risk profile. However, compared to PA, PF exerts greater effects on the total CVD risk score and each of its individual components.

The prevalence of the MS and its components continues to increase and is becoming one of the costliest health problems [21]. The application of ATPIII criteria showed MS prevalence to be $19 \%$, which is comparable to the rates observed in our neighbouring country of Germany (19,8\%) [25], and slightly higher compared to the rates observed in a France and Italy [21]. Given the adverse outcome with the presence of even one or two MS components [23], this supports the need to develop efficacious and effective lifestyle strategies to reduce the prevalence and incidence of the MS.

Our findings primarily demonstrate that higher levels of different characteristics of PA, i.e. intensity (PA METS), duration (PA hours), or the combination, i.e. volume (PA METhours) were all associated with lower odds ratios for having the MS. This is in agreement with previous research showing inverse associations between higher levels of PA and the clustering of three or more metabolic abnormalities [10,13,14,24]. Moreover, also moderate intensity (4.5-5.5 METS) is associated with lower odds for having the MS, adding further support to the increasing evidence that PA at moderate intensity may already reduce the incidence of coronary heart disease $[1,25]$.

The present results further confirm findings of cross-sectional [14,24-26] and prospective $[11,15]$ studies reporting a strong inverse dose-response relationship between $\mathrm{PF}$ and the likelihood of the clustering of metabolic abnormalities. I.e. the fittest police employees had an $78 \%$ lower risk of having the MS compared to the least fit men.

When one aims at recommending and implementing a healthy lifestyle, recommendations on $\mathrm{PA}$ are, in contrast to $\mathrm{PF}$, more feasible to apply in the general population. Thus far, questions remain on the role of components of PA in the prevention and control of CVD risk, i.e. the health effects of varying exercise intensity, duration and/or total volume remains unsolved [27]. Linear regression analyses were performed with $\mathrm{PF}$, and more importantly, with each of the different characteristics of PA. After adjusting for age and gender, only average PA intensity (PA METS) and more specifically, the hours of PA performed at high intensity ( $>6$ METS) showed a small but significant inverse association with the total CVD risk score. The total time of PA, as well as the hours of PA performed at low and moderate intensity and the total volume of PA, appeared to be of no great importance in optimizing the CVD risk profile. This suggests that intensity is the major characteristic of PA determining its effect on overall CVD risk. In a healthy population of 
middle-aged men, low intensity leisure-time PA was not associated with the MS, whereas the combination of moderate and vigorous leisure-time PA showed a highly significant inverse association with MS [14]. Similarly, Tanasescu et al [28] showed that PA intensity (walking speed) is associated with lower risk for coronary heart disease independent of PA volume (MET-hours), whereas PA volume was no longer significantly associated with a reduced risk for coronary heart disease after adjustment for walking speed. As a consequence increasing exercise intensity or increasing the time spent at vigorous intensity may result in greater risk reductions as reported by others $[25,29,30]$.

Given the fact that not every risk factor may respond in the same way to PA, linear regression analyses were also performed with each of the five individual CVD RF. Concordant to the results of a recent meta-analysis [4] we did not find any association between different components of PA and BP. Further, exercise studies suggest that PA can favourably alter blood lipids from a threshold of 1200 to $2200 \mathrm{kcal} /$ week whereas greater changes in HDL-C can be expected with additional increases in exercise training volume. Currently there is no evidence from the exercise training literature to support an intensity threshold for producing HDL-C levels [31]. This agrees with the lack of an association with PA METS in our study and the fact that higher levels of HDL-C were observed with more time spent at high intensity. Further, we did not observe an intensity effect for waist circumference [31], but lower values were reported with increasing time spent at PA, and more specifically time spent at moderate intensity. This may be related to the fact that in order to decrease body weight, total kcal expenditure is important. Therefore moderate intensity has to be performed for a long duration.

Contrary to PA, PF had an important significant inverse association with the overall CVD risk score and with each of its individual components, except glucose. This supports previous research showing that having CVD RF is associated with poor PF $[12,14,32)$. The lack of an association between fasting glucose and PA or PF is most likely due to the distribution curve in our population, showing a narrow range with $94 \%$ of the individuals having a normal glucose value.

It is important to notice that the effects of PA disappeared when we adjusted our analyses for $\mathrm{VO}_{2}$ peak. Previously, some authors suggested additional benefits of especially vigorous activities mediated through increased PF [16]. To the best of our knowledge, we showed for the first time by path analyses how PA interacts with the overall CVD risk score, through influencing PF. That is, $\mathrm{VO}_{2}$ peak explained $78-93 \%$ of the total variance in PA (high) intensity, and was an important contributor to the relation between PA and the CVD risk score. Nevertheless, still 7-22\% of the total variance in PA has a direct effect on the CVD risk score. Similarly, Rennie et al [10] showed that PF is an important mediator of the benefits of both moderate and vigorous PA; and Dvorak et al [32] reported that older men and women with high PF, regardless of their PA levels, showed lower concentrations of total cholesterol, LDL and total/HDL ratio, fasting insulin and triglycerides compared to individuals with low PF. 
The latter authors reported however that $13 \%$ of shared variance was found between PA and PF. Further, higher PF but not leisure-time PA predicted a reduced risk of coronary heart disease in healthy younger men [33]. Therefore, although PA and PF both have a CVD RF lowering effect, PF seems more important in the relationship compared to PA. This may suggest that PA should preferably increase $\mathrm{VO}_{2}$ peak in order to maximally influence CVD RF.

Within the present investigation there are obvious limitations. Most importantly the cross-sectional design of the analyses limits causal inferences and it is possible that those participants who reported low levels of moderate and vigorous activity may have reduced their activity as a result of having more CVD RF. Therefore, longitudinal data are undoubtedly required. Further, the self-administered questionnaires to assess PA, may under- or overestimate levels of PA intensity and PA hours, influenced by the perception of the subject. However, the reproducibility and validity have proved to be fairly reproducible and reasonably valid [18]. Finally, the present study findings involved healthy middle-aged men and women of a cohort of police employees and they may therefore not be generalized to other groups.

\section{CONCLUSION}

This study shows that PA and PF are inversely associated with the clustering of metabolic and cardiovascular risk factors. With regard to PA, it seems that intensity and more specifically higher intensity is the main characteristic of PA determining its effect on CVD risk factors. However, since PF exerts greater effects on each of these individual components, this suggest that in daily practice PA should preferably increase PF in order to "maximize" its effect on the prevention of the MS which is most likely achieved by exercise at higher intensity. 
CHAPTER

PART

ONE

Cardiovascular RISK PROFILE:

CROSS-SECTIONAL ANALYSIS OF MOTIVATIONAL DETERMINANTS, PHYSICAL FITNESS ANS PHYSICAL ACTIVITY

Chapter has been published as:

Barbara Sassen, Gerjo Kok, Herman Schaalma†, Henri Kiers, Luc Vanhees. Cardiovascular risk profile: cross-sectional analysis of motivational determinants, physical fitness and physical activity. BMC Public Health 2010, 10:592. 
ABStRAct: CARdiOVASCUlar RISK PROFILE: CROSS-SECTIONAL ANALYSIS OF MOTIVATIONAL DETERMINANTS, PHYSICAL FITNESS AND PHYSICAL ACTIVITY

Background: Cardiovascular risk factors are associated with physical fitness and, to a lesser extent, physical activity. Lifestyle interventions directed at enhancing physical fitness in order to decrease the risk of cardiovascular diseases should be extended. To enable the development of effective lifestyle interventions for people with cardiovascular risk factors, we investigated motivational, social-cognitive determinants derived from the Theory of Planned Behavior (TPB) and other relevant social psychological theories, next to physical activity and physical fitness.

Method: In the cross-sectional Utrecht Police Lifestyle Intervention Fitness and Training (UP-LIFT) study, 1298 employees (aged 18 to 62) were asked to complete online questionnaires regarding social-cognitive variables and physical activity. Cardiovascular risk factors and physical fitness (peak $\mathrm{VO}_{2}$ ) were measured.

Results: For people with one or more cardiovascular risk factors $(78.7 \%$ of the total population), social-cognitive variables accounted for $39 \%(p<.001)$ of the variance in the intention to engage in physical activity for 60 minutes every day. Important correlates of intention to engage in physical activity were attitude (beta=.225, $p<.001$ ), self-efficacy (beta=.271, $p<.001$ ), descriptive norm (beta=.172, $p<.001$ ) and barriers (beta=-.169, $p<.01$ ). Social-cognitive variables accounted for $52 \%(p<.001)$ of the variance in physical active behavior (being physical active for 60 minutes every day). The intention to engage in physical activity (beta=.469, $p<.001$ ) and self-efficacy (beta $=.243, p<.001$ ) were, in turn, important correlates of physical active behavior.

In addition to the prediction of intention to engage in physical activity and physical active behavior, we explored the impact of the intensity of physical activity. The intensity of physical activity was only significantly related to physical active behavior (beta=.253, $p<.01$, $\mathrm{R}^{2}=.06, \mathrm{p}<.001$ ). An important goal of our study was to investigate the relationship between physical fitness, the intensity of physical activity and social-cognitive variables. Physical fitness $\left(R^{2}=.23, p<.001\right)$ was positively associated with physical active behavior (beta=.180, $p<.01$ ), self-efficacy (beta=.180, $p<.01$ ) and the intensity of physical activity (beta $=.238$, $\mathrm{p}<.01$ ). For people with 1 or more cardiovascular risk factors, $39.9 \%$ had positive intentions to engage in physical activity and were also physically active, and $10.5 \%$ had low intentions but were physically active. $37.7 \%$ had low intentions and were physically inactive, and about $11.9 \%$ had high intentions but were physically inactive.

Conclusion: This study contributes to our ability to optimize cardiovascular risk profiles by demonstrating an important association between physical fitness and social-cognitive variables. Physical fitness can be predicted by physical active behavior as well as by selfefficacy and the intensity of physical activity, and the latter by physical active behavior. 
Physical active behavior can be predicted by intention, self-efficacy, descriptive norms and barriers. Intention to engage in physical activity by attitude, self-efficacy, descriptive norms and barriers. An important input for lifestyle changes for people with one or more cardiovascular risk factors was that for ca. $40 \%$ of the population the intention to engage in physical activity was in line with their actual physical active behavior.

\section{INTRODUCTION}

In the prevention of cardiovascular disease, the control of cardiovascular risk factors is of upmost importance. Several risk factors are related to lifestyle behavior, such as physical activity patterns [1-3]. Cardiovascular risk factors, namely abdominal obesity, high blood pressure, low HDL-C cholesterol, elevated triglycerides and elevated blood glucose levels, are also interrelated. These risk factors increase the risk for cardiovascular diseases, type 2 diabetes and all-cause mortality [1, 3-5]. Research has demonstrated that physical activity and physical fitness have a preventive effect on cardiovascular disease morbidity and mortality [6-10].

Regular physical activity results in increased cardio-respiratory physical fitness. A graded dose-response change in physical fitness was demonstrated with increasing intensities of exercise training or higher levels of physical activity [11-14]. Physical fitness and physical activity are associated with important health benefits for every individual cardiovascular risk factor, having beneficial effect on lipids, blood pressure and glucose metabolism and on weight [15-18]. Research has also shown that physical fitness and physical activity positively influence the group of interrelated risk factors [1, 5, 19-24].

In a recent study, we found inverse associations between both physical fitness and physical activity with the clustering of cardiovascular risk factors. With regard to physical activity, it appears that particularly (high) intensity physical activity impacts cardiovascular risk factors. Cardiovascular risk factors are strongly associated with physical fitness and, to a lesser extent, with physical activity. Efforts to improve the cardiovascular risk profile and subsequently prevent cardiovascular morbidity and mortality should focus on physical activity which leads to improved physical fitness [25].

In order to enable the development of effective lifestyle interventions that prevent cardiovascular morbidity related to an inactive lifestyle, the social-cognitive determinants of an active lifestyle should be identified $[26,27]$. In this study, we investigated physical fitness, the intensity of physical activity and the social-cognitive determinants of intentions to engage in an active lifestyle as posited by the Theory of Planned Behavior (TPB), Social Cognitive Theory and other health behavior theories [28-33,35,36]. According to the TPB, the intention to engage in physical activity predicts future physical active behavior. Intention is the key motivational determinant of behavior. Behavioral intentions, in turn, are determined by three social-cognitive factors, namely attitude, subjective norm and perceived behavioral control or self-efficacy [36]. Attitude refers to the general evaluation of the behavior, and is determined by behavioral beliefs (perceptions regarding the 
advantages and disadvantages of the behavior) and perceptions regarding the consequences of the behavior. The subjective norm refers to perceived social approval for the behavior. The subjective norm is determined by normative beliefs and by expectations regarding whether important reference individuals or groups will approve of the behavior. In addition to the subjective norm, the descriptive norm, which can be viewed as the behavior of others in the social environment, is important [37]. Perceived behavioral control is one's confidence in one's ability to perform a specific behavior. Perceived behavioral control is determined by control beliefs that are based upon perceptions of opportunities, as well as perceived barriers and required resources. An additional and related concept is self-efficacy [36]. People intend to engage in behaviors when the evaluation of the behavior is positive, when social influence is perceived as influential and when the behavior is considered to be under personal control. According to the Theory of Planned Behavior, the influence of general dispositions and socio-demographic factors are mediated by attitude, subjective norms and perceived behavioral control.

In the prevention of cardiovascular risk factors, lifestyle interventions directed at increasing physical activity and hereby enhancing physical fitness may improve the cardiovascular risk profile. A better understanding of the social-cognitive correlates of intention to engage in physical activity on a daily basis and physical active behavior is imperative. Most studies refer to research on social-cognitive determinants without investigating physical activity and physical fitness in a broader scope. We studied socialcognitive determinants of the intention to engage in physical activity and physical active behavior, as well as extensive self-reported physical activity (in intensity and duration) and measured physical fitness (peak $\mathrm{VO}_{2}$ ).

Aims The aims of this study were first to explore the relative importance of social-cognitive variables and a) the intention to engage in physical activity; b) physical active behavior; c) the intensity of physical activity; and d) physical fitness (peak $\mathrm{VO}_{2}$ ). Secondly we investigated the congruence between a high and low intention to engage in physical activity vs. having physical active or inactive behavior.

\section{METHODS}

This cross-sectional study was part of the Utrecht Police Intervention Lifestyle Fitness and Training (UP-LIFT) study, which is a voluntary fitness and lifestyle evaluation for police in Utrecht, the Netherlands. The subjects in the present study comprised 1298 people ( 874 men and 424 women) aged 18 to 62 who visited our research department of Health and Lifestyle between December 2004 and November 2008. All respondents provided written informed consent and approval for the study was obtained from the Ethics Committee at Utrecht University's Medical Centre. We assessed: 1) motivational, socialcognitive determinants, 2) cardiovascular risk factors, 3) physical fitness (peak $\mathrm{VO}_{2}$ ), and 4) physical activity (intensity and duration). Motivational, social-cognitive determinants, cardiovascular risk factors and physical fitness were measured when the respondent came to the laboratory; the questionnaire measuring physical activity (intensity and duration) was 
filled in before coming to the laboratory.

\section{Assessment of motivational social-cognitive determinants}

For the assessment of motivational, social-cognitive determinants, participants were asked to complete an online secure website questionnaire. The questionnaire content was derived from a literature study and in-depth interviews on physical activity conducted with people who had cardiovascular risk factors. The construction of the questionnaire is, according to the TPB, specific to the definition of the behavior and the specification of the research population $[30,44]$. The following motivational, social-cognitive determinants were included in the questionnaire.

Attitude was assessed with two items: 'In my view being physically active for 60 minutes every day is very good-very bad' and ' In my view being physically active for 60 minutes every day is very pleasant to do/very unpleasant to do' (Cronbach's $\alpha=.73$ ). Beliefs were measured by eight items. An example item is: 'Being physically active for 60 minutes every day is very healthy/very unhealthy' (Cronbach's $\alpha=.31$ ). Subjective norm was measured by two items: 'Most people/most colleagues who are important to me think I should be physically active.' Answer options ranged from 'no, certainly not' to 'yes, certainly' (Cronbach's $\alpha=.74)$. Descriptive norm was indexed by one item: 'Are those people who are important to you physically active?' Perceived behavioral control was measured by five items on being physically active even when busy, in pain, etc. (Cronbach's $\alpha=.82$ ). Selfefficacy was indexed with three questions referring to one's capability, trust in one's capability and experienced difficulty to be physically active every day (Cronbach's $\alpha=.81$ ). Intention was measured with two items: 'Do you intend to be physically active tomorrow and the day after tomorrow?' and 'Do you surely intend to be physically active tomorrow and the day after tomorrow?' (Cronbach's $\alpha=.93)$. Intention was also dichotomized in a high and low intention group by categorizing 'definitely yes' as high intention and all other answers as low intention. Behavior was measured by averaging two questions: 'Are you physically active for at least 60 minute a day?' and 'Do you think you engage in adequate physical activity?' Behavior was also dichotomized in active and inactive lifestyle behavior by splitting the averaged item. Those scores above 4.5 were considered active. Barriers were measured with five questions about being 'no, certainly not/yes, certainly' physically active for 60 minutes every day even when one is tired, busy, in pain, etc. Responses were provided on a seven-point scale (1=definitely not, $7=$ definitely yes). An inverse scale was used for barriers. A determinant score was calculated by averaging the total score and dividing that average by the number of items.

\section{Assessment of cardiovascular risk factors}

Next to the assessment of social-cognitive determinants we measured cardiovascular risk factors. Respondents were classified without or as having one, two or three or more cardiovascular risk factors. In this study, the group at risk for cardiovascular morbidity was having at least one cardiovascular risk factor. The cardiovascular risk factors are, based on the extended ATP-III criteria put forth by the National Cholesterol Education 
Program Adult Treatment Panel III definition: 1) abdominal obesity (men: waist circumference $>102 \mathrm{~cm}$; women: $>88 \mathrm{~cm}$ ); 2) high blood pressure (systolic $\geq 130 \mathrm{~mm} \mathrm{Hg}$ or diastolic $\geq 90 \mathrm{mmHg}$ ) or being on antihypertensive medication; 3) low HDL-C cholesterol (high-density lipoprotein, men $<1.03 \mathrm{mmol} / \mathrm{L}$, women $<1.30 \mathrm{mmol} / \mathrm{L}$ ) or being on medication for HDL-C; 4) elevated triglycerides ( $\geq 1.70 \mathrm{mmol} / \mathrm{L}$ ) or being on medication for elevated triglycerides; and 5 ) high blood glucose ( $\geq 6.1 \mathrm{mmol} / \mathrm{L}$ ) or being on medication for elevated glucose definition $[1,4]$.

\section{Assessment of physical fitness and physical activity}

For the assessment of physical fitness, peak oxygen uptake (peak $\mathrm{VO}_{2}$ ) as the gold standard for exercise capacity, was measured [14]. The individual's maximum cardiorespiratory fitness level was tested using a bicycle ergometer (Siemens-Elema 380B; Ergonomics $800 \mathrm{~S}^{\circledR}$, Ergonomics, Bitz, Germany) in a laboratory with a stabilized room temperature. The initial workload of 20 Watts was increased every minute by 20 Watts until volitional exhaustion was reached. During the test, a 12-lead electrocardiogram and respiratory data through breath-by-breath analysis (Oxyxon Pro ${ }^{\circledR}$, Jaeger, Mijnhardt) were continuously measured. Heart rate (HR) was calculated from the electrocardiogram. The gas analyzers and the flow meters were calibrated before each test according to the manufacturer's instructions and oxygen uptake $\left(\mathrm{VO}_{2}\right)$ was determined from the continuous measurement of oxygen concentration in the inspired and expired air.

Next to social-cognitive determinants, cardiovascular risk factors and physical fitness, we assessed physical activity. Physical activity was assessed with the Short Questionnaire to Assess Health Enhancing Physical Activity (SQUASH), of which the reproducibility and validity has been tested and proved to be fairly reproducible and reasonably valid. The overall reproducibility was $r=0.58(95 \% \mathrm{Cl} 0.36-0.74)$ and the validity when compared to the Computer Science and Applications activity monitor was $r=0.45(95 \%$ Cl 0.17-0.66) [38]. Data were collected online on a secure website. Participants were asked to report average time (days per week, hours per day, minutes per day) and type of physical activity. For the purposes of our study, we selected walking, cycling and sports activities. We calculated physical activity in intensity and duration. The average intensity of physical activity was expressed as the intensity of physical activity, for this physical activities were given a metabolic equivalent value (METS), ranging from 1 to 12 METS [39]. The time spent on physical activity was expressed as physical activity duration in hours per week. For details see 25 .

\section{Statistical analysis}

One-way analyses of variance (ANOVA) and Chi-square analyses were conducted for people without, with one, with two or with three or more cardiovascular risk factors. Subsequently, a correlation matrix of all the social-cognitive variables as well as physical fitness and physical activity was generated for people with one or more cardiovascular risk factors. To explore the congruence between having a high versus low intention to engage in physical activity and physical active versus physical inactive behavior, Chi-square analyses 
were conducted. Hierarchical regression analyses were applied to model intention to engage in physical activity, physical active behavior, the intensity of physical activity and physical fitness (peak $\mathrm{VO}_{2}$ ). We analyzed the association for people with one or more cardiovascular risk factors between: 1) the intention to engage in physical activity and social-cognitive variables; 2) physical active behavior, intention and social-cognitive variables; 3 ) the intensity of physical activity, physical active behavior, intention and socialcognitive variables; and 4) physical fitness, the intensity of physical activity, physical active behavior, intention and social-cognitive variables. Significance was set at $p<.05$ and at $p<.01$ for the (hierarchical) regression analysis. Statistical analyses were conducted with SPSS version 15.0 (SPSS inc. 2006).

\section{RESULTS}

Table 1 presents descriptive statistics for the cardiovascular risk factor groups, people having resp. zero, one, two or three or more cardiovascular risk factors. Four out of every five participants were classified as having one or more cardiovascular risk factors, with men being more likely to have risk factors than women. Age was positively associated with the number of cardiovascular risk factors. Of the total sample, $18.6 \%$ had three or more cardiovascular risk factors. Cardiovascular risk factor groups differed significantly on behavior and social-cognitive correlates, but not on the intention to engage in physical activity. ANOVAs revealed differences for attitude, beliefs, subjective norms and selfefficacy between the different risk factors groups. Cardiovascular risk factor groups differed significantly on physical fitness (peak $\mathrm{VO}_{2}$ ) and intensity of physical activity, but not on duration of physical activity. Both physical fitness and physical activity intensity being negatively associated with the number of cardiovascular risk factors.

The correlation matrix (Table 2) displays positive correlations for people with one or more cardiovascular risk factors between physical active behavior and the key motivational determinant of behavior, namely the intention to engage in physical activity for 60 minutes every day $(r=.66)$. Physical active behavior was found to be positively related to self-efficacy $(r=.57)$, and perceived behavioral control $(r=.41)$ and negatively related to barriers $(r=-.43)$. Associations were also found between physical active behavior and physical fitness $(r=.38)$. The correlation between physical active behavior and physical activity intensity was lower $(r=.25)$. Physical fitness was positively correlated with self-efficacy $(r=.37)$.

According to the Theory of Planned Behavior, intention is determined by attitude, subjective norm and perceived behavioral control. Positive correlations were found between the intention to engage in physical activity for 60 minutes every day and attitude $(r=.47)$, subjective norm ( $r=.32)$, and perceived behavioral control $(r=-.39)$. 
Table 1 - People having $0,1,2$ or $\geq 3$ cardiovascular risk factors and social-cognitive determinants, physical fitness, physical activity intensity and physical activity duration, total population

\begin{tabular}{llllll}
\hline $\mathrm{N}=1298$ & 0 risk & 1 risk & 2 risk & $\geq 3$ risk & \\
& factors & factor & factors & factors & $P$ \\
\hline & $276(21.3)$ & $475(36.6)$ & $305(23.5)$ & $242(18.6)$ & \\
Male & $138(15.8)$ & $318(36.4)$ & $221(25.3)$ & $197(22.5)$ & $<.001$ \\
Female & $138(32.6)$ & $157(37.0)$ & $84(19.8)$ & $45(10.6)$ & \\
Age (years) & $32.8 \pm 9.3^{\mathrm{bcd}}$ & $37.0 \pm 11.1^{\mathrm{acd}}$ & $39.7 \pm 10.8^{\mathrm{abd}}$ & $44.8 \pm 9.4^{\mathrm{abc}}$ & $<.001$ \\
Social-cognitive determinants: & & & & & \\
Behavior & $4.33 \pm 0.98^{\mathrm{d}}$ & $4.31 \pm 1.01^{\mathrm{d}}$ & $4.14 \pm 1.05^{\mathrm{d}}$ & $3.83 \pm 1.09^{\mathrm{abc}}$ & $<.001$ \\
Intention & $6.30 \pm 1.07$ & $6.18 \pm 1.14$ & $6.14 \pm 1.19$ & $6.05 \pm 1.18$ & $\mathrm{Ns}$ \\
Attitude & $6.35 \pm 0.61^{\mathrm{d}}$ & $6.25 \pm 0.63^{\mathrm{d}}$ & $6.25 \pm 0.67$ & $6.11 \pm 0.75^{\mathrm{ab}}$ & $<.01$ \\
Beliefs & $4.60 \pm 0.52$ & $4.56 \pm 0.49^{\mathrm{d}}$ & $4.62 \pm 0.53$ & $4.68 \pm 0.56^{\mathrm{b}}$ & $<.05$ \\
Subjective norms & $4.83 \pm 1.21^{\mathrm{cd}}$ & $4.90 \pm 1.25^{\mathrm{cd}}$ & $5.13 \pm 1.22^{\mathrm{ab}}$ & $5.21 \pm 1.11^{\mathrm{ab}}$ & $<.001$ \\
Perceived control & $4.96 \pm 0.98$ & $5.07 \pm 1.02$ & $4.98 \pm 1.02$ & $4.88 \pm 1.07$ & $\mathrm{Ns}$ \\
Self-efficacy & $5.99 \pm 0.94^{\mathrm{d}}$ & $5.96 \pm 0.95^{\mathrm{d}}$ & $5.80 \pm 1.10$ & $5.60 \pm 1.16^{\mathrm{ab}}$ & $<.001$ \\
Descriptive norms & $3.15 \pm 1.09$ & $3.05 \pm 1.08$ & $3.10 \pm 1.03$ & $3.06 \pm 1.13$ & $\mathrm{Ns}$ \\
Barriers & $3.09 \pm 0.98$ & $3.13 \pm 1.05$ & $3.12 \pm 1.01$ & $3.24 \pm 1.04$ & $\mathrm{Ns}$ \\
& & & & & \\
Physical fitness & $38.4 \pm 7.28^{\mathrm{cd}}$ & $37.0 \pm 7.78^{\mathrm{cd}}$ & $34.4 \pm 8.12^{\mathrm{abd}}$ & $31.0 \pm 7.49^{\mathrm{abc}}$ & $<.001$ \\
Physical activity intensity & $4.95 \pm 1.33^{\mathrm{cd}}$ & $4.86 \pm 1.42^{\mathrm{d}}$ & $4.64 \pm 1.53^{\mathrm{a}}$ & $4.33 \pm 1.47^{\mathrm{ab}}$ & $<.001$ \\
Physical activity duration & $9.66 \pm 8.90$ & $9.54 \pm 8.56$ & $9.34 \pm 9.02$ & $8.07 \pm 8.39$ & $\mathrm{Ns}$ \\
\hline
\end{tabular}

Values are numbers (and percentages) or mean \pm SD. Abbreviations: $P, p$-value; $a=$ different from 0 risk factor group, $b=$ different from 1 risk factor group, $c=$ different from the 2 risk factor group, $d=$ different from the $\geq 3$ risk factor group.

Congruence between intention to engage in physical activity and physical active behavior Analyses were undertaken to explore sensitivity and specificity for physical active behavior (Table 3). Do people with positive intentions to engage in physical activity for 60 minutes every day actually show physical active behavior? Among people with one or more cardiovascular risk factors, $50.4 \%$ reported having positive intentions to engage in physical activity and $51.8 \%$ reported physical active behavior. Also, $39.9 \%$ of the participants had positive intentions to engage in physical activity and had physical active behavior, while $11.9 \%$ had a positive intention but had physical inactive behavior. A large group (37.7\%) scored low on intention to engage in physical activity and had inactive behavior, while $10.5 \%$ scored low on intention but reported physical active behavior. We found that inactive behavior increased as the number of cardiovascular risk factors increased, and that the number of participants with low intentions increased as the number of cardiovascular risk factors increased. 
Table 2 - Correlations between social-cognitive determinants, physical fitness and physical activity for people with one or more cardiovascular risk factors

\begin{tabular}{|c|c|c|c|c|c|c|c|c|c|c|c|c|}
\hline $\mathrm{N}=989$ & Beh & Int & Att & SN & PC & DN & SE & Bel & Barr & $\mathrm{PF}$ & $\begin{array}{l}\text { PA } \\
\text { int }\end{array}$ & $\begin{array}{l}\text { PA } \\
\text { dur }\end{array}$ \\
\hline Behavior & Beh & & & & & & & & & & & \\
\hline Intention & $.66^{* \star *}$ & Int & & & & & & & & & & \\
\hline Attitude & $.40^{\star \star \star}$ & $.47^{\star \star \star}$ & Att & & & & & & & & & \\
\hline $\begin{array}{l}\text { Subjective } \\
\text { norms }\end{array}$ & $.20^{\star \star \star}$ & $.32^{* \star *}$ & $.31^{* \star *}$ & SN & & & & & & & & \\
\hline $\begin{array}{l}\text { Perceived } \\
\text { control }\end{array}$ & $.41^{\star \star \star}$ & $.39^{\star \star \star}$ & $.41^{\star \star *}$ & $.24^{* \star *}$ & PC & & & & & & & \\
\hline $\begin{array}{l}\text { Descriptive } \\
\text { norms }\end{array}$ & $.37^{\star \star \star}$ & $.37^{\star \star \star}$ & $.27^{\star \star \star}$ & $.53^{\star \star \star}$ & $.26^{\star \star \star}$ & DN & & & & & & \\
\hline $\begin{array}{l}\text { Self- } \\
\text { efficacy }\end{array}$ & $.57^{\star \star \star}$ & $.52^{\star \star *}$ & $.51^{\star \star \star}$ & $.32^{\star \star *}$ & $.53^{\star \star \star}$ & $.35^{* \star *}$ & DSE & & & & & \\
\hline Beliefs & $-.07^{*}$ & ns & $.09^{* *}$ & $.47^{\star \star *}$ & $-.09^{\star \star}$ & ns & $-.12^{\star \star \star}$ & Bel & & & & \\
\hline Barriers & $-.43^{\star \star *}$ & $-.43^{\star \star *}$ & $-.39^{\star \star *}$ & $-.27^{\star \star \star}$ & $-.78^{\star \star \star}$ & $-.26^{\star \star \star}$ & $-.48^{* \star *}$ & ns & Barr & & & \\
\hline $\begin{array}{l}\text { Physical } \\
\text { fitness }\end{array}$ & $.38^{\star \star \star}$ & $.18^{\star \star \star}$ & $.17^{\star \star \star}$ & ns & $.23^{\star \star \star}$ & ns & $.37^{\star \star \star}$ & $-.23^{\star \star \star}$ & $-.24^{\star \star \star}$ & PF & & \\
\hline $\begin{array}{l}\text { Physical } \\
\text { activity } \\
\text { intensity }\end{array}$ & $.25^{\star \star *}$ & $.10^{* *}$ & ns & -.09 & ns & ns & $.10^{\star \star}$ & ns & $-.073^{\star}$ & $.31^{* * *}$ & $\begin{array}{l}\text { PA- } \\
\text { int }\end{array}$ & \\
\hline $\begin{array}{l}\text { Physical } \\
\text { activity } \\
\text { duration }\end{array}$ & $.44^{\star \star \star}$ & $.31^{\star \star \star}$ & $.21^{\star \star *}$ & $.11^{\star *}$ & $.25^{\star \star \star}$ & $.15^{\star \star \star}$ & $.28^{\star \star \star}$ & ns & $-.28^{\star \star \star}$ & $.23^{* \star \star}$ & ns & $\begin{array}{l}\text { PA } \\
\text { dur }\end{array}$ \\
\hline Mean & 4.18 & 6.17 & 6.24 & 4.99 & 4.98 & 3.08 & 5.86 & 4.60 & 3.16 & 35.56 & 4.93 & 12.52 \\
\hline SD & 1.04 & 1.14 & 0.66 & 1.21 & 1.2 & 1.08 & 1.03 & 0.52 & 1.03 & 8.12 & 1.44 & 11.34 \\
\hline Range & $1-6$ & $1-7$ & $1-7$ & $1-7$ & $1-7$ & $1-7$ & $1-7$ & $1-7$ & $1-7$ & $12-61$ & $\begin{array}{l}0- \\
215\end{array}$ & $0-215$ \\
\hline
\end{tabular}

Values represent correlation coefficients;

P-value; $* * * 0.001, * *<0.01, *<0.05$. 
Table 3 - High and low intention and active and inactive behavior for people with one or more cardiovascular risk factors

\begin{tabular}{|c|c|c|c|c|c|}
\hline \multirow[t]{2}{*}{$N=989$} & \multicolumn{4}{|l|}{ Behavior } & \multirow[b]{2}{*}{ Total } \\
\hline & Active & & Inactive & & \\
\hline \multirow[t]{2}{*}{ Intention high } & $394(77.0)$ & & $104(21.8)$ & & $498(50.4)$ \\
\hline & & 39.9 & & 11.9 & \\
\hline \multirow[t]{2}{*}{ Intention low } & $118(23.0)$ & & 373 (78.2) & & 491 (49.6) \\
\hline & & 10.5 & & 37.7 & \\
\hline Total & $512(51.8)$ & & $477(48.2)$ & & \\
\hline
\end{tabular}

Chi-square analysis, $p<0.05$; values are numbers and (\%); Cursive, percentage of the total group.

Prediction of intention, physical active behavior, physical activity intensity and physical fitness

We employed (hierarchical) regression analyses to identify correlates of the intention to engage in physical activity, of physical active behavior, of physical activity intensity and of physical fitness for people with one or more cardiovascular risk factors (table 4). Socialcognitive variables accounted for $39 \%$ of the variance $(p<.001)$ in intention to engage in physical activity. Salient variables were attitude $(\beta=.225, p<.001)$, self-efficacy $(\beta=.271$, $p<.001)$, descriptive norm $(\beta=.172, p<.001)$ and barriers $(\beta=-.169, p<.01)$. With respect to physical active behavior, $52 \%$ of the variance $(p<.001)$ was explained by intention and socialcognitive variables, with intention $(\beta=.469, p<.001)$ and self-efficacy $(\beta=.243, p<.001)$ being the strongest predictors.

In addition to the prediction of intention to engage in physical activity and physical active behavior, we explored the intensity of physical activity. Only $6 \%$ of the variance $(p<.001)$ in physical activity intensity was explained by social cognitive variables with physical active behavior $(\beta=.253, p<.01)$ as significant predictor. An important goal of our research was to investigate the relationship between physical fitness, on the one hand, and the intensity of physical activity and the social-cognitive variables, on the other. In this regression analysis, $23 \%$ of the variance $(p<.001)$ in physical fitness was explained by physical active behavior ( $\beta=.180, p<.01)$, self-efficacy $(\beta=.180, p<.01)$ and physical activity intensity $(ß=.238, p<.01)$.

\section{DISCUSSION}

In order to optimize the cardiovascular risk profile of people with one or more cardiovascular risk factors, this study explored physical fitness and the intensity of physical activity in relation to social-cognitive variables derived from the Theory of Planned Behavior and other relevant social psychological theories. We determined that $23 \%$ of the variance in physical fitness could be predicted by physical active behavior, self-efficacy and the intensity of physical activity. These three variables are therefore likely to be important objectives for interventions directed at deceasing cardiovascular morbidity and mortality. The findings also suggest that, in order to optimize the preventive effect of physical fitness, efforts to 
encourage behavior change by strengthening behavioral intention, strengthen self-efficacy and then later adding intensity to physical activity are worthwhile.

With respect to the mean intensity of physical activity, research has demonstrated that the volume of (high) intensity and, most importantly, physical fitness have an important effect on reducing cardiovascular risk factors [25]. In this study, we showed that the intensity of physical activity is an important predictor of physical fitness and that the intensity of physical activity was, in turn, predicted by physical active behavior. Physical active behavior only accounted for $6 \%$ of the variance in the intensity of physical activity.

In addition to physical fitness and physical activity intensity, we explored socialcognitive variables, which are prerequisite inputs for the development of effective lifestyle interventions to prevent cardiovascular risk [27]. We showed that physical active behavior predicted physical fitness and physical activity intensity. We also found that social-cognitive variables are useful predictors of physical active behavior and of the intention to engage in physical activity for 60 minutes every day. Social-cognitive variables accounted for $52 \%$ of the variance in physical active behavior and $39 \%$ of the variance in intention to engage in physical activity. A meta-analytic review showed that social-cognitive variables accounted for $27 \%$ of the variance in behavior and $39 \%$ of the variance in intention [42]. Previous studies have shown regression values of $36 \%$ for behavior and $42 \%$ to $66 \%$ for intention $[30,40]$. In our study, the amount of variance explained by behavior was not smaller than the amount of variance explained by intention, stating a clear association between intention and behavior [43].

Table 4 - Prediction of intention, physical active behavior, physical activity intensity and physical fitness for people with one or more cardiovascular risk factors

\begin{tabular}{|c|c|c|c|c|c|c|c|c|}
\hline \multirow[t]{2}{*}{$\mathrm{N}=989$} & \multicolumn{2}{|c|}{ Intention } & \multicolumn{2}{|c|}{$\begin{array}{l}\text { Physical active } \\
\text { Behavior }\end{array}$} & \multicolumn{2}{|c|}{$\begin{array}{l}\text { Physical activity } \\
\text { intensity }\end{array}$} & \multicolumn{2}{|c|}{ Physical fitness } \\
\hline & $r$ & ß & $\mathrm{R}$ & B & $r$ & $\beta$ & $r$ & ß \\
\hline $\begin{array}{l}\text { Physical activity } \\
\text { intensity }\end{array}$ & & & & & & & $.31 * *$ & $.238 * *$ \\
\hline Behavior & & & & & $.25 * *$ & $.253^{* *}$ & $.38 * *$ & $.180 * *$ \\
\hline Intention & & & $.66 * *$ & $.469 * *$ & $.10^{*}$ & - & $.18^{* *}$ & - \\
\hline Attitude & $.47^{* *}$ & $.225^{* *}$ & $.40 * *$ & - & ns & - & $.17^{* *}$ & - \\
\hline Subjective norms & $.32 * *$ & - & $.20 * *$ & - & ns & - & ns & - \\
\hline Perceived control & $.39 * *$ & - & $.41 * *$ & - & ns & - & $.23 * *$ & - \\
\hline Self-efficacy & $.52 * *$ & $.271 * *$ & $.57 * *$ & $.243 * *$ & $.10 * *$ & - & $.37 * *$ & $.180 * *$ \\
\hline Descriptive norms & $.37^{* *}$ & $.172^{* *}$ & $.37 * *$ & $.084^{*}$ & ns & - & ns & - \\
\hline Barriers & $-.43 * *$ & $-.169 *$ & $-.43 * *$ & $-.095 * *$ & ns & - & $-.24 * *$ & - \\
\hline $\mathrm{R}^{2}$ & & $.39 * *$ & & $.52 * *$ & & $.06^{*}$ & & $.23 * *$ \\
\hline
\end{tabular}

P-value; $* * 0.001, *<0.01$.

Physical active behavior was largely associated with the intention to engage in physical activity for 60 minutes every day. Self-efficacy, descriptive norms and barriers were also relevant predictors. This corresponds with previous studies in which behavior was found 
to be largely predicted by intention [32,34]. In our study, self-efficacy was found to be an important predictor of behavior and this is congruent with other research [35]. The claim that perceived behavioral control does not strongly predict behavior once intention is included was supported by our study, although we know self-efficacy and perceived behavioral control have the same underlying concept $[32,44]$.

Four social-cognitive variables explained a significant proportion of the variance in physical active behavior. The results suggest that people with positive intentions and high levels of self-efficacy are more likely to engage in physical active behavior. They also suggest investing in efforts that develop the skills necessary to overcome barriers. According to the Theory of Planned Behavior, intention to engage in physical activity predicts future physical active behavior. Our study confirmed this.

Also, our results indicated that, among people with one or more cardiovascular risk factors, intention to engage in physical activity for 60 minutes every day was strongly associated with attitude and self-efficacy and, to a lesser extent, with descriptive norms and barriers. That attitude and self-efficacy are significant contributors to intention to engage in physical activity is congruent with other research $[30,40,42,46]$. Our findings also revealed that people who are physically active have more positive attitudes and higher self-efficacy are more likely to have positive intentions about physical activity. Similar to other studies, our study found subjective norms to be weak predictors of exercise intention $[30,31,40]$. In our study, the variables attitude and self-efficacy accounted for a large part of the variance in intention. People with one or more cardiovascular risk factors and who are physically active, perceived more advantages than disadvantages to engage in regular physical activity. Interventions should therefore endeavor to highlight and clarify the advantages of engaging in physical activity while providing solutions for the disadvantages. Also, self-efficacy was associated with intention thus suggesting that for people with one or more cardiovascular risk factors and who are physically active, physical activity is perceived as relatively easy to adopt and that interventions should gradually add intensity to physical activity as physical activity levels improve. Interventions should also support the development of control over physical activity. Subjective norm appeared to be less important. The influence of significant others was found to impact the intention to engage in physical activity for 60 minutes every day. Interventions should therefore be directed at both learning skills necessary to handle negative social influence and strengthening positive social support.

According to a meta-analytic review [42], social-cognitive variables predict selfreported behavior better than observed behavior. In our study, social-cognitive variables were found to be good predicators of intention, behavior and physical fitness. They were less adept at predicting physical activity intensity.

In addition to exploring the contribution of social-cognitive variables to intention and physical active behavior, we explored the congruence between high and low intention vs. having physical active or inactive behavior [45]. Do people with positive intentions actually engage in physical active behavior? And, more importantly, how many people have positive 
intentions but are inactive? Among those with one or more cardiovascular risk factors, about $40 \%$ had positive intentions and were physically active, about $40 \%$ had low intentions and were inactive, about $10 \%$ had high intentions but were inactive and about $10 \%$ had a low intentions but were active. This incongruence between high and low intentions and reporting physically active versus inactive behavior is an important input for lifestyle changes, because the probability of physical active behavior is higher when the intention to be physically active is high.

The present study had several strengths including its sample size, the inclusion of social-cognitive variables and the simultaneous assessment of physical fitness and physical activity. A limitation is the cross-sectional design of the study and that the study was carried out in a police department.

\section{CONCLUSION}

This study contributes to our ability to optimize cardiovascular risk profiles by demonstrating an important association between physical fitness and social-cognitive variables. Physical fitness can be predicted by physical active behavior as well as by selfefficacy and the intensity of physical activity, and the latter by physical active behavior.

Physical active behavior can be predicted by intention, self-efficacy, descriptive norms and barriers. Intention to engage in physical activity can be predicted by attitude, selfefficacy, descriptive norms and barriers. An important input for lifestyle changes for people with 1 or more cardiovascular risk factors was that for ca. $40 \%$ of the population the intention to engage in physical activity was in line with their actual physical active behavior. 
CHAPTER

Predictors OF HEALTHCARE PROFESSIONALS' INTENTION AND BEHAVIOR TO ENCOURAGE PHYSICAL ACTIVITY IN PATIENTS WITH CARDIOVASCULAR RISK FACTORS

Chapter has been published as:

Barbara Sassen, Gerjo Kok, Luc Vanhees. Predictors of healthcare professionals' intention and behavior to encourage physical activity in patients with cardiovascular risk factors. BMC Public Health 2011, 11:246. 


\section{Abstract: Predictors of healthcare Professionals' INTENTION AND BEHAVIOR TO ENCOURAGE PHYSICAL ACTIVITY IN PATIENTS WITH CARDIOVASCULAR RISK FACTORS}

Introduction: Healthcare professionals can play a crucial role in optimizing the health status of patients with cardiovascular risk factors (abdominal obesity, high blood pressure, low HDL cholesterol, elevated triglycerides and elevated blood glucose). In order to do this, it is imperative that we understand the social-cognitive determinants (including habits) that underlie healthcare professionals' intention and the corresponding behavior of actually encouraging patients with cardiovascular risk factors to engage in physical activity.

Method: In this longitudinal Professionals' Intention and Behavior (PIB) study, healthcare professionals ( $\mathrm{N}=278$, aged $20-61$ years with approximately $60 \%$ having attained an education level exceeding bachelor's degree, types of healthcare professionals $60 \%$ in physiotherapy and $40 \%$ in nursing), completed online surveys measuring the socialcognitive determinants of healthcare professionals' intention and the corresponding behavior of actually encouraging patients with cardiovascular risk factors to engage in physical activity.

Results: Social-cognitive determinants accounted for $41 \%(p<.001)$ of the variance in healthcare professionals' intention to encourage physical activity among cardiovascular patients. Important correlates of intention were attitude ( $\beta=.443, p<.001)$, subjective norms $(\beta=.201, p<.001)$ and perceived behavioral control $(\beta=.137, p<.01)$. With respect to the selfreported behavior of encouraging patients, social-cognitive determinants accounted for $29 \%(p<.001)$ of the variance. Intentions ( $\beta=.311 p<.001)$, habit $(\beta=.163 p<.01)$, and barriers $(\beta=-.239 p<.001)$ were significant correlates of professionals' behavior of encouraging patients to engage in physical activity.

We explored the congruence between healthcare professionals' intention to encourage patients and the self-reported behavior of encouraging patients. We found that intention and behavior were congruent in $39.7 \%$ of the healthcare professionals. Additionally, the intention to encourage and the corresponding behavior of encouraging was incongruent in $31.7 \%$ of the healthcare professionals.

Conclusion: In the prevention of cardiovascular disease, healthcare professionals' intention to encourage physical activity among patients and subsequent behavior of encouraging patients is important for the improvement of patients' cardiovascular risk profiles. We found that the intentions and self-reported behavior of healthcare professionals working with patients with cardiovascular risk factors can be predicted by social-cognitive determinants thus implying that efforts to change and strengthen the intention-behavior relationship of healthcare professionals may have beneficial effects for cardiovascular risk patients (Trial ID: ECP-92). 


\section{INTRODUCTION}

Healthcare professionals can play an essential role in optimizing the health status of patients with cardiovascular risk factors. However, a substantial gap between clinical research findings and the daily practice of healthcare professionals remain [1-7]. Though nowadays it is common to work evidence-based for healthcare professionals, the daily practice for healthcare professionals is sometimes different. In order to increase congruence between theory and practice and better support patients, it is imperative that we gain an improved understanding of healthcare professionals' behavior and the determinants that underlie their behavior.

Cardiovascular risk factors, namely abdominal obesity, high blood pressure, low HDL cholesterol (HDL-C), elevated triglycerides and elevated blood glucose levels, increase one's risk for cardiovascular disease, type 2 diabetes and all-cause mortality [8-11]. According to the classification based on the extended ATPIII criteria put forth by the National Cholesterol Education Program's Adult Treatment Panel III definition, people at cardiovascular risk are having one or more of the following risk factors: abdominal obesity (for men a waist circumference $>102 \mathrm{~cm}$ and for women $>88 \mathrm{~cm}$ ); high blood pressure (with a systolic blood pressure of $\geq 130 \mathrm{~mm} \mathrm{Hg}$, or diastolic $\geq 90 \mathrm{mmHg}$, or being on antihypertensive drug treatment); people with low HDL cholesterol (high-density lipoprotein, for men $<1.03$ $\mathrm{mmol} / \mathrm{L}$, for women $<1.30 \mathrm{mmol} / \mathrm{L})$ or being on medication; elevated triglycerides $(\geq 1.70$ $\mathrm{mmol} / \mathrm{L}$, or being on medication that reduces triglycerides, and; elevated blood glucose $(\geq 6.1$ $\mathrm{mmol} / \mathrm{L}$, or being on medication that reduces blood glucose $[8,9]$.

The number of patients with cardiovascular risk factors is increasing and the prevalence is being exacerbated by decreasing physical activity levels $[9,10,12]$. Research has demonstrated that physical activity and physical fitness have a preventive effect on cardiovascular morbidity and mortality [13-17]. Physical activity and physical fitness are associated with important health benefits for every cardiovascular risk factor and also for the group of interrelated risk factors. Physical activity and physical fitness can have a beneficial effect on lipids, blood pressure, glucose metabolism, and on body composition $[9,11,18-27]$. In a recent study on physical activity, we found that particularly (high) intensity physical activity impacts cardiovascular risk factors and concluded that interventions should focus on high intensity physical activity leading to physical fitness [28].

In order to enable the development of effective cardiovascular disease prevention interventions, we must understand how healthcare professionals can best be engaged to promote an active lifestyle in cardiovascular patients. Consequently, in this study, we investigated the social-cognitive determinants of healthcare professionals' intention to encourage physical activity among cardiovascular patients as posited by the Theory of Planned Behavior and other relevant social psychological theories [29-38]. The Theory of Planned Behavior is considered appropriate for explaining both healthcare professionals' intentions and behavior $[1,5,30]$. 
According to the Theory of Planned Behavior, healthcare professionals' behavior of encouraging physical activity among cardiovascular patients is predicted by their intention to encourage physical activity among these patients and behavior is also determined by habits and barriers. Behavioral intention can be explained by three social-cognitive determinants, namely attitude, subjective norm, and perceived behavioral control [38]. Attitude refers to the general evaluation of the behavior, and is determined by behavioral beliefs (perceptions regarding the advantages and disadvantages of the behavior) and perceptions regarding the consequences of the behavior. The subjective norm refers to the perceived social approval for the behavior, and is determined by expectations regarding whether important reference individuals or groups will approve of the behavior. In addition to the subjective norm, the descriptive norm from Bandura's Social Cognitive Theory is an extension of the Theory of Planned Behavior [39]. The descriptive norm can be considered as the behavior of others in the social environment. The moral norm, also an extension of the Theory of Planned Behavior, is essential as the individuals' responsibility and the individuals' moral obligation towards the behavior to act in a specific way [30]. Perceived behavioral control is one's confidence in one's ability to perform a specific behavior and is determined by control beliefs that are based on perceptions of opportunities as well as perceived barriers and required resources [38].

People intend to engage in behaviors when the behavior is evaluated as positive, when one thinks that significant others find the behavior to be important, and when the behavior is considered to be under personal control. Behavior can be predicted by intention, barriers and habit [33]. Habit, as an extension of the Theory of Planned Behavior, can influence the intention-behavior relationship. Habit is determined by past behavior and concerns the individuals' personal experience with a specific behavior in a stable context, such as a healthcare setting [40]. Barriers can obstruct the behavior, even though the intention to engage in the behavior is positive. According to the Theory of Planned Behavior, the influence of general dispositions and socio-demographic factors are mediated by attitude, subjective norms and perceived behavioral control.

In order to make cardiovascular prevention and the implementation of interventions directed at optimizing the health status of cardiovascular patients effective, it is imperative that we gain a better understanding of healthcare professionals' behavior and intentions, and the social-cognitive determinants of behavior and intentions.

Aims. The aims of this study were first to explore the relative importance of social-cognitive variables in relation to healthcare professionals' intention and behavior. Secondly we investigated the congruence between healthcare professionals' intention to encourage physical activity in cardiovascular risk patients and the self-reported behavior of encouraging patients.

\section{METHODS}

In the Professionals' Intention and Behavior (PIB) study, healthcare professionals completed online surveys measuring their intention to encourage physical activity among 
cardiovascular risk patients, their self-reported behavior of encouraging cardiovascular risk patients, the social-cognitive determinants of their intentions and behavior, and demographic variables. Participants were recruited from the Department of Physiotherapy and Department of Nursing at the University of Applied Sciences in the Netherlands. Participants were (former) students of the University of Applied Sciences in the Netherlands. Healthcare professionals with at least a Bachelor's degree in nursing (approximately $40 \%$ of the study group) or physiotherapy (60\% of the study group) and who conduct consultations with cardiovascular risk patients were included in the analyses. In total 739 were invited to complete the online survey, with three reminders send. 572 healthcare professionals completed the survey at time 1 (T1, April 2009) and of those, 278 professionals completed the survey at time 2 (T2, October 2009). Statistical analysis in separated groups revealed no differences between healthcare professionals' with a background in physiotherapy or nursing. The ethics committee of the Maastricht University, The Netherlands, granted approval to the study (Trial ID: ECP-92).

\section{Assessment of motivational social-cognitive determinants}

The survey content was derived from a literature review and in-depth interviews with professionals on how they encourage cardiovascular patients to engage in and maintain physical activity. There were eight elicitation interviews held, four with healthcare professionals with a background in physiotherapy and four in nursing. Four of those professionals were observed in their professional activities for a regular working day. For measuring social-cognitive determinants, no valid questionnaires are available, but only valid procedures. The construction of the questionnaire is, according to the Theory of Planned Behavior, specific to the definition of the behavior and the specification of the research population $[33,41]$. The questionnaire was piloted; as a result no revisions were made. We collected data at time 1 (T1) and time 2 (T2). At T1 the baseline measurement, we measured all social-cognitive determinants except self-reported behavior. At T1 all social-cognitive determinants underlying behavior were investigated. At T2 the follow-up measure, we measured self-reported behavior. By measuring social-cognitive determinants at T1 (socialcognitive determinants) followed by $\mathrm{T} 2$ (behavior) makes it possible to predict behavior from intention. A complete overview of the scale can be found in table 5 .

Behavior was assessed by averaging two items: 'Do you encourage cardiovascular patients to become physically active?' And 'In the past month, how many of your cardiovascular patients did you encourage to become physically active?' Answers ranged from 'none' (1) to 'all' (7) on a seven-point scale (Cronbach's $\alpha=.64)$. Behavior was also dichotomized as encouragement versus no encouragement. For dichotomizing the socialcognitive determinant behavior, we calculated quintiles of the determinant score. The highest two quintiles were positioned as encouraging behavior and the lowest two quintiles were positioned as less encouragement. We left the $20 \%$ in between the two groups (encouraging vs. less encouraging) out, to make a clear distinction between groups.

Intention was indexed with three questions: 'Do you intend to encourage 
cardiovascular patients to become physically active tomorrow and the day after tomorrow?', 'Do you expect to encourage cardiovascular to become physically active tomorrow and the day after tomorrow?', and 'Of the first 10 cardiovascular patients you see, how many do you intend to encourage to become physically active?' (Cronbach's $\alpha=.82$ ). Answers ranged on a seven-point scale $(1=$ 'definitely not' to $7=$ 'most definitely'), except for the question 'Of the first 10 cardiovascular patients ...' We recalculated this question on a 10-point scale multiplying it by 0.7 . Intention was also dichotomized as high versus low intention. For dichotomizing the social-cognitive determinant intention, we calculated quintiles of the determinant score. The highest two quintiles were positioned as having a high intention and the lowest two quintiles were positioned as having a low intention. We left the $20 \%$ in between the two groups (high vs. low intention) out, to make a clear distinction between groups.

Attitude was assessed by ten items on a seven-point scale. Answers ranged on a seven-point scale (1=bad/very useless to $7=$ good/very useful). First we asked 'In my view, encouraging cardiovascular patients to become physically active is very good - very bad' and 'Encouraging cardiovascular patients is very useful - very useless'. Then we asked, 'Is it useful to: assess patients' motivation, assess the pros and cons of physical activity, teach patients how to resist social pressure, teach patients specific skills pertaining to physical activity, teach patients how to handle barriers in regard physical activity, formulate physical activity goals together with patients, teach patients how to handle relapses, and help patients understand the relationship between the specific health problem and physical inactivity?'. These eight items ('Is it were useful to ...') were averaged and that score was averaged with the first two item scores to represent attitude (Cronbach's $\alpha=.63$ ).

Perceived behavioral control was assessed by 11 questions on a seven-point scale. First we asked, 'Do you think that you have the skills and knowledge to encourage cardiovascular patients to become physically active?' We then asked, 'Do you think you can rely on your skills and knowledge to encourage cardiovascular patients to become physically active?' Answers ranged from 'no, certainly not' (1) to 'yes, certainly' (7) on a seven-point scale. Thirdly we asked 'Encouraging every cardiovascular patients to become physically active is very difficult (1) -very easy (7)'. Perceived behavioral control was further assessed by an eight item scale that paralleled the eight item scale used for attitudes. 'It is very difficult (1) - very easy (7) to: assess patients' motivation, assess the pros and cons of physical activity, teach patients how to resist social pressure, teach patients specific skills pertaining to physical activity, teach patients how to handle barriers in regard physical activity, formulate physical activity goals together with patients, teach patients how to handle relapses, and help patients understand the relationship between the specific health problem and physical inactivity?'. Once again this scale score was calculated and combined with the previous three items as a measure of perceived behavioral control (Cronbach's $\alpha=.78)$.

Subjective norm was measured by four items: 'Most colleagues who are important to me think I should encourage cardiovascular patients to become physically active', 'Most 
colleagues value that I encourage cardiovascular patients to become physically active', 'Patients value that I encourage them to become physically active', and 'The organization I work for values that I encourage cardiovascular patients to become physically active'. Answers ranged from 'no, certainly not' (1) to 'yes, certainly' (7) on a seven-point scale (Cronbach's $\alpha=.73$ ).

Descriptive norm was indexed by four items: 'Do you encourage more cardiovascular patients to engage in physical activity than your colleagues do?', 'Do you encourage more cardiovascular patients to engage in physical activity than professionals that have the same academic background as you do?', 'Most colleagues encourage patients to engage in physical activity themselves', and 'Do you consult colleagues when you experience problems encouraging cardiovascular patients to become physically active?'. Answers ranged from 'no, certainly not' (1) to 'yes, certainly' (7) on a seven-point scale (Cronbach's $\alpha=.61$ ).

Moral norm was assessed by three questions: 'Encouraging patients to engage in physical activity is my professional duty', 'Encouraging patients to engage in physical activity is a moral obligation', and 'Encouraging patients to engage in physical activity is an obvious part of my job'. Responses were provided on a seven-point scale ranging from 'definitely

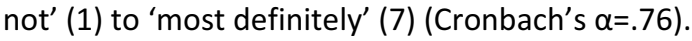

Habit was measured by two questions [40]: 'Encouraging patients to be physically active is something I do without thinking', and 'Encouraging patients to be physically active is something I do automatically'. Answers ranged on a seven-point scale ( $1=$ 'definitely not' to 7='most definitely') (Cronbach's $\alpha=.75$ ).

Barriers were indexed by two questions that focused on encouraging patients 'even when one is busy' and 'even when one's organization makes it difficult to encourage patients'. Answers ranged from 'no, certainly not' (7) to 'yes, certainly' (1) on a seven-point scale (Cronbach's $\alpha=.69$ ). In this way, we measure perceived barriers, which may be part of perceived behavioral control. Because barriers are relevant in an organizational context, we measured them separately.

A determinant score was calculated for every social-cognitive determinant. Per social-cognitive determinant we summed up the scores on the questions and divided this by the number of items.

\section{Statistical analysis}

Descriptive statistics were first calculated and Chi-square analysis was used to explore the population under study. Subsequently, a correlation matrix of all social-cognitive determinants was generated. To explore the congruence between professionals having a high or low intention and encouraging or no encouraging behavior, Chi-square analyses were conducted on dichotomized variables. Hierarchical regression analyses were then applied to model healthcare professionals' intention and behavior. To do this, we analyzed the association between: 1) intention at $\mathrm{T} 1$ and the social-cognitive determinants; entering attitude, perceived behavior control and subjective norm in the first block, and entering descriptive norms and moral norms in the second block of hierarchical regression. 2) 
Behavior at T2, and intention at T1 together with the social-cognitive determinants; entering intention in the first block and habit and barriers in the second block of hierarchical regression. Significance was set at $p<.05$. Statistical analyses were undertaken with SPSS version 17.0 (SPSS inc. 2009).

Table 1 - Characteristics of the study population

\begin{tabular}{ll}
\hline$N=278$ & \\
\hline Male & $26.3 \%(73)$ \\
Female & $73.7 \%(205)$ \\
Age, years & $36.2 \pm 10.1$ \\
Professional experience, years & $8.58 \pm 7.70$ \\
Completed Bachelor's degree in nursing or physiotherapy & $37.8 \%(105)$ \\
Completed or currently acquiring a degree above Bachelor's level & $31.3 \%(87)$ \\
Completed or currently acquiring a Master's degree in nursing or physiotherapy & $30.9 \%(86)$ \\
Consultation time devoted to health education & $60.4 \%$ \\
Average number of consultations with one patient & $10.1 \pm 12.2$ \\
Minimum number of consultations with one patient & $3.69 \pm 4.23$ \\
\hline
\end{tabular}

Values are percentages (and numbers) or mean \pm SD.

\section{RESULTS}

Table 1 presents descriptive statistics for the study population. We found that $73.7 \%$ of the healthcare professionals were female. The mean age was 36.2 years $( \pm 10.1)$. In the sample, about $40 \%$ completed a Bachelor's degree in nursing or physiotherapy and about $60 \%$ were studying at a level above Bachelor's degree or had completed an additional degree after their Bachelor's degree. Statistical analysis in separated groups revealed no differences between healthcare professionals' with a background in physiotherapy or nursing $(p<0.05)$. Healthcare professionals had $8.58( \pm 7.70)$ years experience working as a professional. They reported to have at least $3.69( \pm 4.23)$ consultations with one patient. The average number of consultations was $10.1( \pm 12.2)$ with one patient. Also, participants indicated that $60.4 \%( \pm 25.2)$ of their consultation time is spent on health education.

The correlation matrix (table 2) shows positive correlations between healthcare professionals' intention to encourage physical activity among cardiovascular patients and behavior (a moderate to strong association, $r=.44$ ). According to the Theory of Planned Behavior, healthcare professionals' intention is determined by their attitude, the subjective norm and their perceived behavioral control in addition to moral and descriptive norms. Positive correlations were found between intention and attitude (a strong association $r=.59$ ), subjective norm (a moderate-to-strong association, $r=.45$ ), perceived behavioral control (a moderate-to- strong association, $r=.41$ ), descriptive norm (a weak-to-moderate association, $r=.25$ ), and moral norm (a weak association, $r=.14$ ). Healthcare professionals' behavior was found to be positively related to perceived behavioral control (a weak-to-moderate association, $r=.28$ ) and the habit of encouraging patients to engage in physical activity (a moderate association $r=.30$ ). As expected, a moderate-to-strong negative association 
between barriers and self-reported behavior was found $(r=-.40)$.

Table 2 - Correlations between behavior, intention and social-cognitive determinants

\begin{tabular}{|c|c|c|c|c|c|c|c|c|c|}
\hline$N=278$ & BehT2 & IntT1 & Att & PBC & SN & $\mathrm{DN}$ & $\mathrm{MN}$ & $\mathrm{Hab}$ & Barr \\
\hline Behavior Time 2 & BehT2 & & & & & & & & \\
\hline Intention Time 1 & $.44 * * *$ & IntT1 & & & & & & & \\
\hline Attitude & $.27^{* * *}$ & $.59 * * *$ & Att & & & & & & \\
\hline $\begin{array}{l}\text { Perceived } \\
\text { behavioral } \\
\text { control }\end{array}$ & $.28 * * *$ & $.41 * * *$ & $.43^{* * *}$ & PBC & & & & & \\
\hline Subjective norms & $.25 * * *$ & $.45^{* * *}$ & $.43 * * *$ & $.43 * * *$ & SN & & & & \\
\hline Descriptive norms & $.29 * * *$ & $.25 * * *$ & $.25^{* * *}$ & $.34 * * *$ & $.50 * * *$ & $\mathrm{DN}$ & & & \\
\hline Moral norms & ns & $.14 *$ & ns & ns & ns & ns & MN & & \\
\hline Habit & $.30 * * *$ & $.27 * * *$ & $.16^{* *}$ & $.40 * * *$ & $.19 * *$ & $.21 * *$ & ns & $\mathrm{Hab}$ & \\
\hline Barriers & $-.40 * * *$ & $-.38 * * *$ & $-.39 * * *$ & $-.42 * * *$ & $-.40 * * *$ & $-.33 * * *$ & ns & $-.37 * * *$ & Barr \\
\hline Mean & 5.77 & 6.20 & 6.18 & 5.04 & 5.63 & 4.86 & 5.57 & 5.29 & 2.64 \\
\hline SD & 0.91 & 0.94 & 0.60 & 0.60 & 0.77 & 0.72 & 1.13 & 1.26 & 1.00 \\
\hline Range & $1-7$ & $1-7$ & $1-7$ & $1-7$ & $1-7$ & $1-7$ & $1-7$ & $1-7$ & $1-7$ \\
\hline
\end{tabular}

Values represent correlation coefficients; ${ }^{* * *} p<0.001,{ }^{* *} p<0.01,{ }^{*} p<0.05$.

Congruence between healthcare professionals' intention and behavior

Analyses were undertaken to explore the congruence between the healthcare professionals' intention to encourage physical activity among cardiovascular patients and the self-reported behavior of encouraging patients (table 3 ). For behavior, we found that $56.8 \%$ of the healthcare professionals encourage physical activity among cardiovascular patients. For intention, we found that $51.3 \%$ of the healthcare professionals reported positive intentions to encourage physical activity among cardiovascular patients. In terms of congruence between intention and behavior, $39.7 \%$ of the healthcare professionals reported both positive intentions and the corresponding behavior of encouraging physical activity among cardiovascular patients. $31.7 \%$ of the professionals scored low on intention and had the corresponding behavior of not encouraging patients to engage in physical activity. In addition, $17.1 \%$ of the healthcare professionals demonstrated behavior that encourages physical activity among cardiovascular patients despite low intention. Also, $11.5 \%$ of the professionals had high scores on intention but failed to perform the self-reported behavior of encouraging physical activity among cardiovascular patients.

Healthcare professionals with high versus low intention differed on all socialcognitive determinants $(p<.05)$. Also, healthcare professionals that engaged in the behavior of encouraging physical activity among cardiovascular patients differed significantly from those who did not on all social-cognitive determinants except on moral norm ( $p<.05)$ (see table 4). 
Table 3 - High and low intention at T1 versus the presence or absence of behavior that encourages physical activity in cardiovascular patients at $\mathrm{T} 2$

\begin{tabular}{|c|c|c|c|c|c|}
\hline \multirow[t]{2}{*}{$N=199$} & \multicolumn{5}{|l|}{ Behavior T2 } \\
\hline & Encouragement & & No encouragement & & Total \\
\hline \multirow[t]{2}{*}{ Intention high T1 } & $69.9(79)$ & & $26.7(23)$ & & $51.3(102)$ \\
\hline & & 39.7 & & 11.5 & \\
\hline \multirow[t]{2}{*}{ Intention low T1 } & $30.1(34)$ & & $73.3(63)$ & & 48.7 (97) \\
\hline & & 17.1 & & 31.7 & \\
\hline Total & $56.8(113)$ & & $43.2(86)$ & & \\
\hline
\end{tabular}

Regression analyses identified correlates of healthcare professionals' intention to encourage physical activity among cardiovascular patients and the behavior of encouraging these patients (table 4). Social-cognitive variables accounted for $41 \%(p<.001)$ of the variance in intention. Intention was, in turn, predicted by attitude ( $\beta=.443, p<.001)$, subjective norms ( $\beta=.201, p<.001)$, and perceived behavioral control ( $\beta=.137, p<.05)$. With respect to the self-reported behavior of encouraging physical activity among cardiovascular patients, $29 \%$ of the variance $(p<.001)$ was explained by intention $(\beta=.311, p<.001)$, next to habit $(\beta=.163, p<.01)$ and barriers $(\beta=-239, p<.001)$. With respect to the self-reported behavior, intention showed the strongest predictor, and additional predictors were the habit of encouraging patients to engage in physical activity and barriers that obstruct the encouragement of patients to engage in physical activity.

Table 5 - Predictors intention T1 and behavior T2 to encourage physical activity in cardiovascular patients

\begin{tabular}{lllll}
\hline$N=278$ & Intention T1 & & \multicolumn{2}{l}{ Behavior T2 } \\
& $r$ & $B$ & $r$ & $\beta$ \\
\hline Intention & & & $.44^{* * *}$ & $.311^{* * *}$ \\
Attitude & $.59^{* * *}$ & $.443^{* * *}$ & $.27^{* * *}$ & \\
Perceived behavioral & $.41^{* * *}$ & $.137^{*}$ & $.28^{* * *}$ & \\
control & & & & \\
Subjective norms & $.45^{* * *}$ & $.201^{* * *}$ & $.25^{* * *}$ & \\
Descriptive norm & $.25^{* * *}$ & & $.29^{* * *}$ & \\
Moral norm & $.14^{*}$ & & $\mathrm{~ns}$ & \\
Habit & $.27^{* * *}$ & & $.30^{* * *}$ & $.163^{* *}$ \\
Barriers & $-.38^{* * *}$ & & $-.40^{* * *}$ & $-239^{* * *}$ \\
\hline $\mathrm{R}^{2}$ & & & \\
\hline
\end{tabular}

Regression, ${ }^{* * *} p<.001,{ }^{* *} p<.01,{ }^{*} p<.05 ; r$ correlations; $ß$ beta's.

\section{DISCUSSION}

The study reported here explored healthcare professionals' intention to encourage physical activity among cardiovascular patients and the subsequent behavior of encouraging 
patients. We investigated the relative importance of social-cognitive variables derived from the Theory of Planned Behavior and other relevant social psychological theories in relation to healthcare professionals' intention and behavior, and the congruence between healthcare professionals' intention and behavior.

In this study, we demonstrated that social-cognitive variables are useful predictors of both healthcare professionals' intention to encourage physical activity in cardiovascular patients and their self-reported behavior of encouraging patients. Social-cognitive variables accounted for $29 \%$ of the variance in behavior, and $41 \%$ of the variance in intention. We found that behavior was predicted by high levels of intention, established habits of encouraging patients and low levels of barriers. Our finding that behavior is largely predicted by intention corresponds with previous studies including studies that focus specifically on the behavior of healthcare professionals $[1,30,35,42,43]$.

Our results indicate that, among healthcare professionals, the intention to encourage physical activity among cardiovascular patients is strongly associated with attitude, subjective norms, and perceived behavioral control, and, to a lesser extent, descriptive and moral norms. That attitude, subjective norms and perceived behavioral control are significant predictors of intention is congruent with other research, including research focusing particularly on healthcare professionals' intention [1,5,29,30,34,44-46].

In a systematic review on the predictors of healthcare professionals' behavior, socialcognitive determinants predicted $35 \%$ of the variance in behavior and $59 \%$ of the variance in intention [30]. As in our study, a meta-analytic review showed that social-cognitive variables accounted for $27 \%$ of the variance in behavior and $39 \%$ of the variance in intention [34]. Previous studies have shown regression values of $36 \%$ for behavior and $42 \%$ to $66 \%$ for intention $[29,44,46]$. According to a meta-analysis and the above mentioned studies, the amount of variance in behavior explained in our study was smaller than the amount of variance in intention [42].

The social-cognitive determinants of healthcare professionals are consequently expected to be key objectives for cardiovascular morbidity-reducing interventions directed at increasing healthcare professionals' intention to encourage physical activity in cardiovascular patients and the behavior of encouraging patients. Our findings suggest that, in order to optimize healthcare professionals' behavior, strengthen both behavioral intention and habit are worthwhile, and reduce barriers.

In addition, our findings revealed that professionals with more positive attitudes, more positive subjective norms, and higher perceived behavioral control were more likely to have positive intentions to encourage physical activity in cardiovascular patients. Professionals perceived more advantages than disadvantages to encouraging cardiovascular patients to become physically active. Interventions should therefore endeavor to highlight and clarify the advantages of encouraging patients while providing explanations for the disadvantages. Healthcare professionals should get convinced that being physically active is important for patients with cardiovascular risk factors.

Also, subjective norms was in our study, found to be associated with intention, thus 
suggesting that professionals who felt that encouraging patients is expected and also done by other healthcare professionals had more positive intentions. Interventions should therefore be directed at seeking positive social support from other healthcare professionals, and learn to communicate the importance of encouraging patients to engage in physical activity with other healthcare professionals.

In our study, perceived behavioral control was found to be associated with the intention to encourage physical activity in cardiovascular patients, thus suggesting that professionals felt competent to perform the behavior and that encouraging patients was perceived as relatively easy to do. Interventions should support the feeling of competence and teach skills necessary to handle difficult situations encouraging patients to become or stay physically active.

The habit of encouraging patients can also contribute to behavior of encouraging patients and should therefore be consolidated via environmental interventions that strengthen such habits $[40,47]$. Our results suggest that investing in the development of the skills necessary to overcome barriers is worthwhile.

In addition to exploring the role of social-cognitive variables in the prediction of intention and behavior, we explored the relationships between intention and behavior. Do professionals with positive intentions actually encourage cardiovascular patients to become physically active? How many professionals have low intentions and do not engage in the behavior of encouraging patients to engage in physical activity? In our study, only $40 \%$ of the healthcare professionals had positive intentions and engaged in the self-reported behavior of encouraging patients and about 32\% had low intentions and did not encourage cardiovascular patients to engage in physical activity. About $10 \%$ of the professionals had positive intentions but did not display the behavior of encouraging patients and about $17 \%$ had low intentions but nonetheless engaged in the behavior of encouraging patients to become physically active. This lack of congruence between high versus low intention and the behavior of encouraging patients versus not encouraging patients is an important input for interventions.

Interventions should be directed at strengthening the intention to encourage physical activity and the corresponding encouraging behavior for healthcare professionals. The socialcognitive determinants of intentions and behaviors may be changed in a more positive direction by planned interventions, deciding which determinants need to be changed, which need to be reinforced, and which need to be introduced $[41,48]$. To translate our results into an intervention for healthcare professionals aiming at increasing a positive intention towards encouragement of patients with cardiovascular risk factors and increasing their encouragement behavior, we will use Intervention Mapping. Intervention mapping provide a framework to built a systematically planned theory- and evidence-based intervention, highly applicable to the desired population and to improve the quality of interventions $[41,48]$. Intervention mapping places specific emphasis on the input from social-cognitive determinants in the beginning of the development phases of an intervention. 
Although the survey was specifically designed for the target population (nurses and physical therapists) with specific behavior (encouraging physical activity) for a specific group of patients (at risk for cardiovascular disease), it seems plausible that the basics could be used for other research. One strength of the study reported here is its longitudinal design as this ruled out the possibility that behavior caused intention [42]. The study's sample size is an additional strength. A possible limitation is that all of the professionals included in this study were recruited from the same institute and this may limit generalization of the outcomes. The measure of behavior is self reported and probably not very explicitly operationalized, this is also a possible limitation.

\section{CONCLUSION}

In order to prevent and limit cardiovascular risk via the improvement of risk behavior in patients, it is imperative that we understand healthcare professionals' intention to encourage physical activity in cardiovascular patients and subsequent behavior of encouraging patients. A major implication of this study is that healthcare professionals' intention to promote physical activity in cardiovascular patients and self-reported behavior of encouraging patients can be predicted by social-cognitive determinants. This implies that efforts to change behavior and strengthen the intention-behavior relationship of healthcare professionals to encourage physical activity in cardiovascular patients can optimize the cardiovascular risk profile of patients. 
Table 4 - Overview scale: means for all items according to high versus low intention and presence versus absence of behavior encouraging physical activity in cardiovascular patients

\begin{tabular}{|c|c|c|c|c|c|c|}
\hline \multirow[t]{2}{*}{ 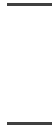 } & \multirow{2}{*}{\multicolumn{2}{|c|}{ Item }} & \multicolumn{2}{|c|}{ Intention T1 } & \multicolumn{2}{|l|}{ Behavior T2 } \\
\hline & & & Low & High & $\begin{array}{l}\text { No } \\
\text { encouragement }\end{array}$ & Encouragement \\
\hline \multirow[t]{3}{*}{ I } & & Behavior & $5.35 \pm 0.93$ & $6.23 \pm .0 .69 * * *$ & $4.92 \pm 0.68$ & $6.42 \pm .0 .36 * * *$ \\
\hline & 1 & $\begin{array}{l}\text { Do you encourage } \\
\text { cardiovascular } \\
\text { patients to become } \\
\text { physically active? }\end{array}$ & $5.75 \pm 0.98$ & $6.63 \pm 0.64 * * *$ & $5.39 \pm 0.89$ & $6.74 \pm 0.44 * * *$ \\
\hline & 2 & $\begin{array}{l}\text { In the past month, } \\
\text { how many of your } \\
\text { cardiovascular } \\
\text { patients did you } \\
\text { encourage to become } \\
\text { physically active? } \\
\text { (none-all) }\end{array}$ & $5.00 \pm 1.24$ & $5.87 \pm 0.97 * * *$ & $4.45 \pm 1.10$ & $6.12 \pm 0.57 * * *$ \\
\hline \multirow[t]{4}{*}{ II } & & Intention & $5.21 \pm 0.78$ & $6.97 \pm 0.07 * * *$ & $5.76 \pm 0.99$ & $6.52 \pm 0.70 * * *$ \\
\hline & 1 & $\begin{array}{l}\text { Do you intend to } \\
\text { encourage } \\
\text { cardiovascular } \\
\text { patients to become } \\
\text { physically active } \\
\text { tomorrow and the day } \\
\text { after tomorrow? }\end{array}$ & $5.34 \pm 0.92$ & $7.00 \pm 0.00 * * *$ & $5.83 \pm 1.06$ & $6.56 \pm 0.84 * * *$ \\
\hline & 2 & $\begin{array}{l}\text { Do you expect to } \\
\text { encourage } \\
\text { cardiovascular } \\
\text { patients to become } \\
\text { physically active } \\
\text { tomorrow and the day } \\
\text { after tomorrow? }\end{array}$ & $5.22 \pm 1.00$ & $7.00 \pm 0.00 * * *$ & $5.79 \pm 1.21$ & $6.46 \pm 0.85^{* * *}$ \\
\hline & 3 & $\begin{array}{l}\text { Of the first } 10 \\
\text { cardiovascular } \\
\text { patients you see, how } \\
\text { many do you intend to } \\
\text { encourage becoming } \\
\text { physically active? }\end{array}$ & $5.08 \pm 1.39$ & $6.92 \pm 0.22 * * *$ & $5.63 \pm 1.47$ & $6.55 \pm 0.85^{* * *}$ \\
\hline \multirow[t]{4}{*}{ III } & & Attitude & $5.81 \pm 0.62$ & $6.48 \pm 0.43 * * *$ & $6.06 \pm 0.62$ & $6.27 \pm 0.56 * *$ \\
\hline & 1 & $\begin{array}{l}\text { Encouraging } \\
\text { cardiovascular } \\
\text { patients is very useful } \\
\text { - very useless }\end{array}$ & $5.70 \pm 1.07$ & $6.68 \pm 0.68 * * *$ & $6.08 \pm 0.97$ & $6.38 \pm 0.96 *$ \\
\hline & 2 & $\begin{array}{l}\text { In my view, } \\
\text { encouraging } \\
\text { cardiovascular } \\
\text { patients to become } \\
\text { physically active is } \\
\text { very good - very bad }\end{array}$ & $6.17 \pm 0.72$ & $6.68 \pm 0.58^{* * *}$ & $6.33 \pm 0.71$ & $6.54 \pm 0.67^{*}$ \\
\hline & 3 & Is it useful to explain & $6.07 \pm 0.86$ & $6.57 \pm 0.78 * * *$ & $6.21 \pm 0.80$ & $6.41 \pm 0.94$ \\
\hline
\end{tabular}


the relationship

between the specific

health problem and

physical inactivity?

(very useful-not useful

at all)

Is it useful to assess

$5.87 \pm 1.03 \quad 6.24 \pm 1.05 * \quad 6.07 \pm 0.96$

$6.05 \pm 1.17$

patients' motivation

to become physically

active?

Is it useful to assess

the pros and cons of

physical activity?

Is it useful to teach

patients how to resist

social pressure

regarding physical

activity?

Is it useful to teach

patients specific skills

pertaining to physical

activity?

Is it useful to teach

patients how to

handle barriers in

regard physical

activity?

Is it useful to

$5.40 \pm 1.05 \quad 5.89 \pm 1.08^{*}$

$5.65 \pm 1.07$

$5.64 \pm 1.22$

$5.10 \pm 1.28 \quad 5.74 \pm 0.89 * * * \quad 5.37 \pm 1.16 \quad 5.46 \pm 1.06$

formulate physical

$5.73 \pm 1.11 \quad 6.17 \pm 0.95 * * \quad 5.92 \pm 0.99 \quad 5.96 \pm 1.14$

activity goals together

with patients?

Is it useful to teach

$5.66 \pm 0.936 .13 \pm 0.88^{* *}$

$5.79 \pm 0.97$

$6.04 \pm 0.85 *$

patients how to

handle relapses in

physical activity?

\begin{tabular}{|c|c|c|c|c|c|}
\hline IV & $\begin{array}{l}\text { Perceived behavioral } \\
\text { control }\end{array}$ & $4.76 \pm 0.56$ & $5.36 \pm 0.53 * * *$ & $4.89 \pm 0.57$ & $5.15 \pm 0.57 * * *$ \\
\hline 1 & $\begin{array}{l}\text { Do you think that you } \\
\text { have the skills and } \\
\text { knowledge to } \\
\text { encourage } \\
\text { cardiovascular } \\
\text { patients to become } \\
\text { physically active? }\end{array}$ & $5.35 \pm 1.00$ & $6.18 \pm 0.84 * * *$ & $5.50 \pm 0.97$ & $5.93 \pm 0.93^{* *}$ \\
\hline 2 & $\begin{array}{l}\text { Do you think you can } \\
\text { rely on your skills and } \\
\text { knowledge to } \\
\text { encourage } \\
\text { cardiovascular } \\
\text { patients to become } \\
\text { physically active? }\end{array}$ & $5.52 \pm 1.05$ & $6.39 \pm 0.74 * * *$ & $5.68 \pm 0.92$ & $6.09 \pm 0.98^{* *}$ \\
\hline
\end{tabular}




\begin{tabular}{|c|c|c|c|c|c|c|}
\hline & 3 & $\begin{array}{l}\text { Encouraging every } \\
\text { cardiovascular patient } \\
\text { to become physically } \\
\text { active is very difficult- } \\
\text { very easy }\end{array}$ & $3.83 \pm 1.18$ & $4.37 \pm 1.22 * *$ & $3.96 \pm 1.15$ & $4.12 \pm 1.24$ \\
\hline & \multirow[t]{8}{*}{4} & $\begin{array}{l}\text { It is very easy-very } \\
\text { difficult to explain the } \\
\text { relationship between } \\
\text { the specific health } \\
\text { problem and physical } \\
\text { inactivity }\end{array}$ & $5.27 \pm 1.03$ & $5.59 \pm 1.00 *$ & $5.22 \pm 0.99$ & $5.55 \pm 0.95 * *$ \\
\hline & & $\begin{array}{l}\text { It is very easy-very } \\
\text { difficult to assess } \\
\text { patients' motivation } \\
\text { to become physically } \\
\text { active. }\end{array}$ & $4.30 \pm 1.19$ & $4.79 \pm 1.14^{* *}$ & $4.45 \pm 1.10$ & $4.54 \pm 1.19$ \\
\hline & & $\begin{array}{l}\text { It is very easy-very } \\
\text { difficult to assess the } \\
\text { pros and cons of } \\
\text { physical activity. }\end{array}$ & $4.66 \pm 1.04$ & $5.04 \pm 1.05 * *$ & $4.84 \pm 0.94$ & $4.79 \pm 1.06$ \\
\hline & & $\begin{array}{l}\text { It is very easy-very } \\
\text { difficult to teach } \\
\text { patients how to resist } \\
\text { social pressure } \\
\text { regarding physical } \\
\text { activity. }\end{array}$ & $3.67 \pm 1.16$ & $3.96 \pm 1.20$ & $3.73 \pm 1.11$ & $3.76 \pm 1.16$ \\
\hline & & $\begin{array}{l}\text { It is very easy-very } \\
\text { difficult to teach } \\
\text { patients specific skills } \\
\text { pertaining to physical } \\
\text { activity. }\end{array}$ & $4.69 \pm 1.12$ & $4.97 \pm 1.12$ & $4.71 \pm 1.09$ & $4.88 \pm 1.10$ \\
\hline & & $\begin{array}{l}\text { It is very easy-very } \\
\text { difficult to teach } \\
\text { patients how to } \\
\text { handle barriers to } \\
\text { physical activity. }\end{array}$ & $4.06 \pm 1.12$ & $4.37 \pm 1.09 *$ & $3.95 \pm 1.04$ & $4.33 \pm 1.06^{* *}$ \\
\hline & & $\begin{array}{l}\text { It is very easy-very } \\
\text { difficult to formulate } \\
\text { physical activity goals } \\
\text { together with } \\
\text { patients. }\end{array}$ & $4.93 \pm 0.93$ & $5.08 \pm 1.07$ & $4.90 \pm 0.99$ & $5.00 \pm 1.04$ \\
\hline & & $\begin{array}{l}\text { It is very easy-very } \\
\text { difficult teach patients } \\
\text { how to handle } \\
\text { relapses in physical } \\
\text { activity. }\end{array}$ & $3.97 \pm 1.08$ & $4.18 \pm 1.22$ & $3.93 \pm 1.15$ & $4.03 \pm 1.10$ \\
\hline \multirow[t]{2}{*}{ V } & & $\underline{\text { Subjective norms }}$ & $5.28 \pm 0.73$ & $5.95 \pm 0.65 * * *$ & $5.43 \pm 0.78$ & $5.77 \pm 0.73 * * *$ \\
\hline & 1 & $\begin{array}{l}\text { Most colleagues who } \\
\text { are important to me } \\
\text { think I should } \\
\text { encourage }\end{array}$ & $4.97 \pm 1.31$ & $5.82 \pm 1.37 * * *$ & $5.20 \pm 1.22$ & $5.56 \pm 1.51^{*}$ \\
\hline
\end{tabular}




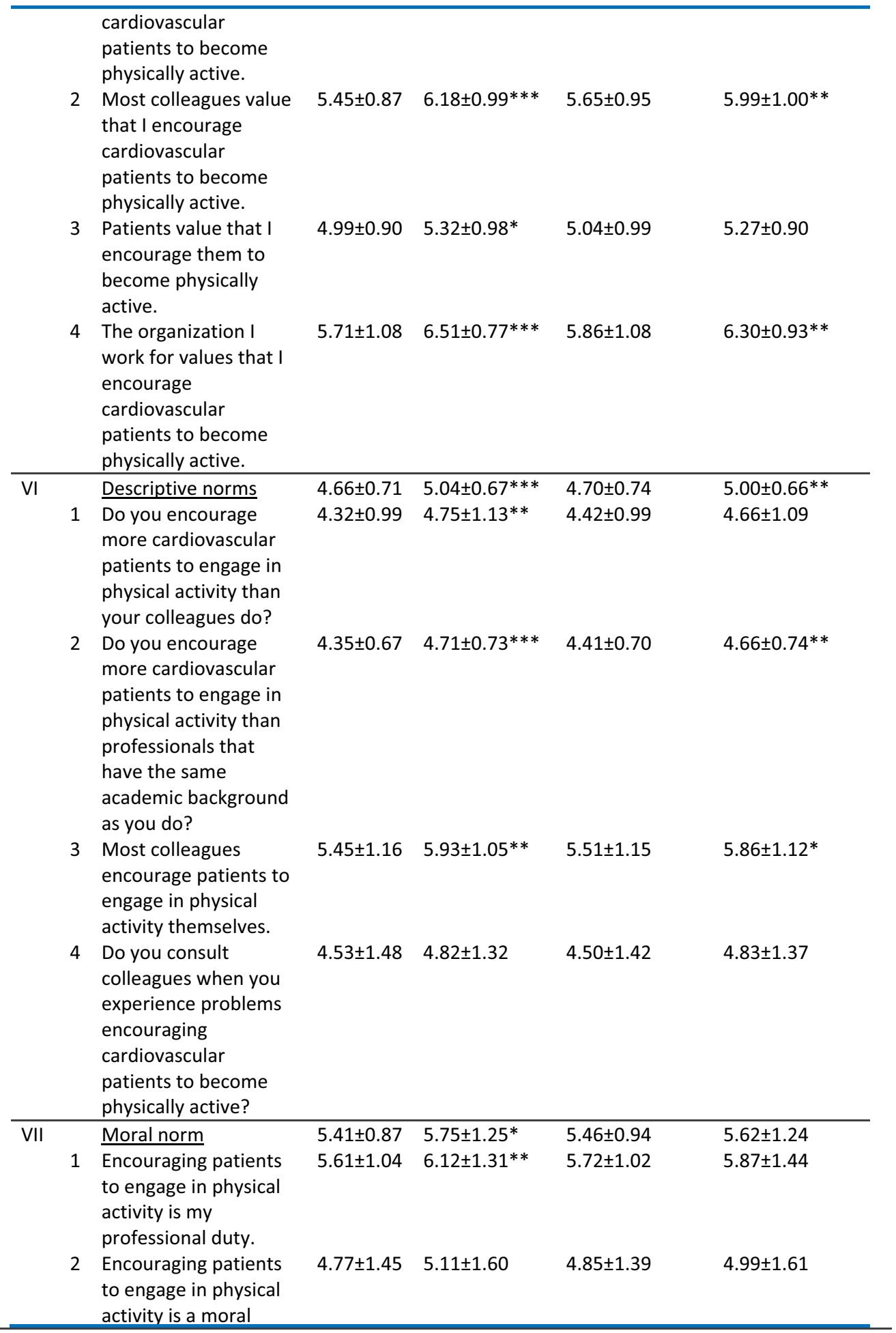




\begin{tabular}{|c|c|c|c|c|c|c|}
\hline & 3 & $\begin{array}{l}\text { obligation. } \\
\text { Encouraging patients } \\
\text { to engage in physical } \\
\text { activity is an obvious } \\
\text { part of my job. }\end{array}$ & $5.87 \pm 0.88$ & $6.03 \pm 1.59$ & $5.81 \pm 1.18$ & $6.02 \pm 1.38$ \\
\hline \multirow[t]{3}{*}{ VIII } & & Habit & $4.90 \pm 1.21$ & $5.64 \pm 1.15^{* * *}$ & $4.87 \pm 1.35$ & $5.51 \pm 1.10 * * *$ \\
\hline & 1 & $\begin{array}{l}\text { Encouraging patients } \\
\text { to be physically active } \\
\text { is something I do } \\
\text { without thinking. }\end{array}$ & $4.57 \pm 1.60$ & $5.44 \pm 1.58 * * *$ & $4.55 \pm 1.67$ & $5.25 \pm 1.55^{* *}$ \\
\hline & 2 & $\begin{array}{l}\text { Encouraging patients } \\
\text { to be physically active } \\
\text { is something I do } \\
\text { automatically }\end{array}$ & $5.25 \pm 1.11$ & $5.86 \pm 1.02 * * *$ & $5.21 \pm 1.34$ & $5.79 \pm 0.94 * * *$ \\
\hline \multirow[t]{3}{*}{ IX } & & Barriers & $3.05 \pm 0.89$ & $2.24 \pm 0.99 * * *$ & $2.96 \pm 0.87$ & $2.43 \pm 0.99 * * *$ \\
\hline & 1 & $\begin{array}{l}\text { I encourage patients } \\
\text { to become physically } \\
\text { active even when I am } \\
\text { busy (no, certainly } \\
\text { not-yes, certainly). }\end{array}$ & $2.74 \pm 1.17$ & $2.02 \pm 1.10 * * *$ & $2.69 \pm 1.13$ & $2.12 \pm 1.12 * * *$ \\
\hline & 2 & $\begin{array}{l}\text { I encourage patients } \\
\text { to become physically } \\
\text { active even when my } \\
\text { organization makes it } \\
\text { difficult to encourage } \\
\text { patients. }\end{array}$ & $3.31 \pm 1.13$ & $2.46 \pm 1.24 * * *$ & $3.16 \pm 1.08$ & $2.69 \pm 1.24 * *$ \\
\hline
\end{tabular}


STABILITY OF SOCIAL-COGNITIVE DETERMINANTS OVER TIME:

LONGITUDINAL STUDY

Chapter has been submitted. 


\section{ABSTRACT: StABILITY OF SOCIAL-COGNITIVE DETERMINANTS OVER TIME: A LONGITUDINAL STUDY}

Introduction: The Theory of Planned Behavior has extensively been studied to predict intention and behavior, for all kind of (health) problems and (healthcare) settings. The underlying assumption is that intention is an important predictor of behavior and that intention and behavior can be changed in a positive direction by implementing carefully designed behavior change interventions. We hypothesized that, if no intervention is implemented, social-cognitive determinants are stable over time. The objective of this study is to provide insight in the stability of social-cognitive determinants over time and the interdependence of social-cognitive determinants.

Method: In this longitudinal study, part of the Professionals' and Patients' Intention and Behavior (PIB2) study, 278 healthcare professionals completed online surveys. We measured relevant social-cognitive determinants of healthcare professionals' intention and the subsequent behavior of encouraging patients with cardiovascular risk factors to engage in physical activity, at two moments in time. No intervention took place.

Results: Paired samples t-tests showed no differences on all social-cognitive determinants measured at T1 compared to T2, except for the intention to encourage patients with cardiovascular risk factors to become physically active. By using structural equation modeling (SEM), we conducted a path analysis to test the Theory of Planned Behavior. The path model shows that we should accept the null hypothesis that the model fits the data $\left(\chi^{2}(5, N=278)=2.35, p=0.80 ;\right.$ RMSEA=0.00). We estimated the path model with (previous) behavior T1 being the exogenous variable and behavior T2, intention T1 and T2, attitude T1 and barriers T1 being the endogenous variables. The path model showed that (previous) behavior $\mathrm{T} 1(\beta=.58, \mathrm{p}<.001)$ and attitude $\mathrm{T} 1(\beta=.48, \mathrm{p}<.001)$, predicted intention $\mathrm{T} 1\left(\mathrm{R}^{2}=.57, \mathrm{p}=<0.001\right)$; that (previous) behavior $\mathrm{T} 1(\beta=.54, \mathrm{p}<.01)$ and barriers $\mathrm{T} 1(\beta=-.13$, $p<.01$ ) predicted behavior T2 (to encourage patients with cardiovascular risk factors to become physically active, $\left.R^{2}=.38, p=<.001\right)$; and that behavior $T 2(\beta=.60, p<.001)$, intention $\mathrm{T} 1(\beta=.19, p<.001)$ and attitudeT1 $(ß=.23, p<.01)$, predicted intention $\mathrm{T} 2\left(R^{2}=.60, p=<0.001\right)$.

Conclusion: Our findings revealed that social-cognitive determinants are, overall, stable over time, when no intervention is implemented, with only intention being less stable over time. When no intervention is implemented and the focus is on the influence of time, behavior is stable. In exploring the interdependence of social-cognitive determinants by using structural equation modeling, first we showed that intention T1 can be predicted by (previous) behavior $\mathrm{T} 1$; and we showed that behavior $\mathrm{T} 2$ can be predicted by (previous) behavior T1. Healthcare professionals are experienced in encouraging patients with cardiovascular risk factors to become physically active to decrease cardiovascular risk, and professionals probably have learned during education and in practice how to encourage patients. Previous behavior (experience and education) influences the healthcare 
professionals' intention T1 and behavior T2, endorsed by strong path coefficients. Secondly and different than expected, we showed that there is neither a direct nor an indirect path between the social-cognitive determinant intention T1 and behavior T2. Finally we showed in our path model, that intention $\mathrm{T} 2$ can be predicted by behavior T2, supported by a strong path coefficient (Trial ID: ECP-92).

\section{INTRODUCTION}

The Theory of Planned Behavior is a robust model, extensively studied and evaluated as an important model to predict intention and behavior, for all kinds of (health) problems and (healthcare) settings. People intend to engage in (health) behaviors when the behavior is evaluated as positive, when the behavior is considered to be under personal control and when one thinks that significant others find the behavior to be important. According to the Theory of Planned Behavior, (health) behavior can be predicted by the corresponding behavioral intention [1-14]. When the intention is strong, the behavior is more to be expected [3].The behavioral intention concerns the planning of the intended (health) behavior, and according to the theoretical background of the Theory of Planned Behavior, intention is an important predictor of the behavior.

This intention-behavior relationship is influenced by barriers and these can obstruct the behavior, even though the intention to engage in the behavior is positive. Habit can also predict behavior; it concerns the individuals' personal experience with a specific behavior in a stable context, and is an extension of the Theory of Planned Behavior $[15,16]$.

Behavioral intention can be explained by attitude, perceived behavioral control and subjective norm. The social-cognitive determinant attitude refers to the general evaluation of the behavior, and is determined by behavioral beliefs (perceptions regarding the advantages and disadvantages of the behavior) and perceptions regarding the consequences of the behavior. Perceived behavioral control is one's confidence in one's ability to perform a specific behavior. This social-cognitive determinant is determined by control beliefs that are based on perceptions of opportunities as well as perceived barriers and required resources [5]. The social-cognitive determinant subjective norm refers to the perceived social approval for the behavior, and is determined by expectations regarding whether important reference individuals or groups will approve of the behavior. In addition to the subjective norm, the descriptive norm can be considered as the behavior of others in the social environment. The descriptive norm is also an extension of the Theory of Planned Behavior from Bandura's Social Cognitive Theory [17]. The moral norm, also an extension of the Theory of Planned Behavior, is essential as the individuals' responsibility and the individuals' moral obligation towards the behavior to act in a specific way [12]. According to the Theory of Planned Behavior, the influence of general dispositions and sociodemographic factors are mediated by attitude, subjective norms and perceived behavioral control.

Nowadays it is common to use the Theory of Planned Behavior to facilitate the 
development of effective interventions, because we must understand what constitutes intention and (health) behavior before trying to intervene and change intention and (unhealthy) behavior. The assumption is that when we measure social-cognitive determinants and intention at T1 and behavior at T2, we will have a clear focus on the behavior under study [3]. Intention and behavior can be changed in a positive direction, for example a physical active lifestyle more conductive to health, by implementing carefully designed behavior change interventions $[18,19]$. We hypothesize that the social-cognitive determinants measured at time 1 will not differ much from those measured at time 2, when no intervention is implemented. For this, it is imperative that we gain a better understanding of the stability of the Theory of Planned Behavior over time, when no intervention is implemented.

Aim The objectives of this study were first to explore differences between the socialcognitive determinants measured at T1 compared with the social-cognitive determinants at T2. Secondly we investigated the interdependence of social-cognitive determinants to predict intention and behavior when measured at T1 and T2 (Trial ID: ECP-92).

\section{METHODS}

This longitudinal study is part of the Professionals' and Patients' Intention and Behavior (PIB2) study and described in detail elsewhere [20]. In a longitudinal design healthcare professionals were asked to participate in online surveys, and their intention, their self-reported behavior, the social-cognitive determinants of their intentions and behavior, and demographic variables were determined. Participants were recruited from the Department of Physiotherapy and the Department of Nursing at University of Applied Sciences in the Netherlands. Healthcare professionals with at least a Bachelor's degree in nursing (approximately $40 \%$ of the study group) or physiotherapy (60\% of the study group) and who conduct consultations with patients with cardiovascular risk factors, were included in the analyses. In total 739 were invited to complete the online survey, with three reminders send. 572 healthcare professionals completed the survey at time 1 (T1, April 2009) and of those, 278 professionals completed the survey at time 2 (T2, October 2009).

The construction of the questionnaire is, according to the Theory of Planned Behavior, specific to the definition of the behavior and the specification of the research population [3,19]. We collected data at $\mathrm{T} 1$ and $\mathrm{T} 2$, and all answers ranged on a seven-point scale from 'none/definitely not/very difficult/etc.' (1) to 'all/most definitely/very easy/etc.' (7). At T1 the baseline measurement, we measured all social-cognitive determinants, the intention to encourage patients with cardiovascular risk factors to become physically active and the behavior of encouraging patients. At T2 the follow-up measure, we measured again all social-cognitive determinants, the intention to encourage and the subsequent behavior.

We assessed behavior with two items: 'Do you encourage cardiovascular patients to become physically active?', and 'In the past month, how many of your cardiovascular patients did you encourage to become physically active?' (Cronbach's $\alpha=.64)$. Intention was 
indexed with three questions: 'Do you intend to encourage cardiovascular patients to become physically active tomorrow and the day after tomorrow?', 'Do you expect to encourage cardiovascular to become physically active tomorrow and the day after tomorrow?', and 'Of the first 10 cardiovascular patients you see, how many do you intend to encourage to become physically active?' (Cronbach's $\alpha=.82$ ). Habit was measured by two questions: 'Encouraging patients to be physically active is something I do without thinking', and ... something I do automatically' (Cronbach's $\alpha=.75$ ). Barriers were indexed by two questions that focused on encouraging patients 'even when one is busy' and 'even when one's organization makes it difficult to encourage patients' (Cronbach's $\alpha=.69$ ).

Attitude was assessed by asking: 'In my view, encouraging cardiovascular patients to become physically active is very good - very bad' and 'Encouraging cardiovascular patients is very useful - very useless'. Then we asked, 'Is it useful to: assess patients' motivation, assess the pros and cons of physical activity, teach patients how to resist social pressure, teach patients specific skills pertaining to physical activity, teach patients how to handle barriers in regard physical activity, formulate physical activity goals together with patients, teach patients how to handle relapses, and help patients understand the relationship between the specific health problem and physical inactivity?'. These eight items ('Is it useful to ...') were averaged and that score was averaged with the first two item scores to represent attitude (Cronbach's $\alpha=.63$ ).

Perceived behavioral control was assessed by the questions: 'Do you think that you have the skills and knowledge to encourage cardiovascular patients to become physically active?', 'Do you think you can rely on your skills and knowledge to encourage cardiovascular patients to become physically active?', and thirdly we asked; 'Encouraging every cardiovascular patients to become physically active is very difficult (1) -very easy (7)'. Perceived behavioral control was further assessed by an eight items that paralleled the eight items used for attitudes. 'It is very difficult (1) - very easy (7) to: assess patients' motivation, assess the pros and cons of physical activity, teach patients how to resist social pressure, teach patients specific skills pertaining to physical activity, teach patients how to handle barriers in regard physical activity, formulate physical activity goals together with patients, teach patients how to handle relapses, and help patients understand the relationship between the specific health problem and physical inactivity?'. Once again this scale score was calculated and combined with the previous three items as a measure of perceived behavioral control (Cronbach's $\alpha=.68$ ).

Subjective norm was measured by four items: 'Most colleagues who are important to me think I should encourage cardiovascular patients to become physically active', 'Most colleagues value that I encourage cardiovascular patients to become physically active', 'Patients value that I encourage them to become physically active', and 'The organization I work for values that I encourage cardiovascular patients to become physically active' (Cronbach's $\alpha=.73$ ).

Descriptive norm was indexed by three items: 'Do you encourage more cardiovascular patients to engage in physical activity than your colleagues do?', 'Do you 
encourage more cardiovascular patients to engage in physical activity than professionals with the same academic background do?', and; 'Most colleagues encourage patients to engage in physical activity themselves' (Cronbach's $\alpha=.47$ ). Moral norm was assessed by three questions: 'Encouraging patients to engage in physical activity is ... my professional duty/ a moral obligation/ an obvious part of my job' (Cronbach's $\alpha=.76$ ). A determinant score was calculated for every social-cognitive determinant.

Table 1 - Characteristics of the study population

\begin{tabular}{ll}
\hline$N=278$ & \\
\hline Male & $26.3 \%(73)$ \\
Female & $73.7 \%(205)$ \\
Age, years & $36.2 \pm 10.1$ \\
Professional experience, years & $8.58 \pm 7.70$ \\
Consultation time devoted to health education & $60.4 \%$ \\
\hline
\end{tabular}

Values are percentages (and numbers) or mean \pm SD.

\section{Statistical analysis}

To explore the differences between the social-cognitive determinants T1 compared with the social-cognitive determinants $\mathrm{T} 2$, we used paired samples t-tests. Subsequently we computed a correlation matrix of all social-cognitive determinants measured at T1 and all social-cognitive determinants measured at T2. (Hierarchical) regression analysis was applied to model healthcare professionals' intention T1 and intention T2. Regression analyses were also applied to model behavior T2 by using predictors of T1 and to model behavior T2 by using predictors of T1 as well as T2. To do this, we analyzed:

1) Dependent variable intention $T 1$ and the social-cognitive determinants 'as usual' on base of theory; entering as independent variables attitude $\mathrm{T} 1$, perceived behavior control T1 and subjective norm T1 in the first block, and entering descriptive norms T1 and moral norms T1 in the second block;

2) Dependent variable intention $T 2$ and independent variables attitude $T 2$, perceived behavioral control T2, subjective norm T2, intention T1 and behavior T1;

3) Dependent variable behavior T2 and the social-cognitive determinants 'as usual' on base of theory; entering as independent variables intention T1, perceived behavioral control $\mathrm{T} 1$, habit $\mathrm{T} 1$ and barriers T1, and;

4) 4) Dependent variable behavior $T 2$ and the independent variables behavior $T 1$, intention $\mathrm{T} 2$ and perceived behavioral control $\mathrm{T} 2$.

After this, we conducted structural equation modeling (SEM) to study the interdependence of social-cognitive determinants from the Theory of Planned Behavior. Structural equation modeling permits to examine direct, indirect, and total effects simultaneously in a single model and to test the validity of the underlying theory [21-24]. Structural equation modeling is based on trying to explain the covariance between measured variables. The question we tried to answer is how well a specific path model can 
describe the patterns of correlation for social-cognitive variables, intention and behavior. In constructing the model by using structural equation modeling, a distinction is made between exogenous and endogenous variables. An exogenous variable predicts other variables, but is not regressed on any other variable; endogenous variables are regressed on one or more other variables in the path diagram [21-23]. We conducted a path analysis with (previous) behavior T1 stated as the exogenous variable that predicts other social-cognitive determinants, but are not regressed on any other variable. Attitude T1, barriers T1, intention $\mathrm{T} 1$ and $\mathrm{T} 2$ and behavior $\mathrm{T} 2$ are endogenous variables and are regressed on one or more other variables in the path diagram. When we started conducting the path analysis to investigate the interdependence of social-cognitive determinants when measured at T1 and T2, we started from a theoretical model (Figure 1).

Standardized estimates of path coefficients were evaluated with t-test and a path was left out when it showed not to contribute to the model ( $t$-score $<2$ ). The variance of the residuals is a measure of the unexplained variance for the variable in question. Modification indices were used to decide which additional paths should be included. Structural equation modeling yields a chi-square value to test the null hypothesis that the model fits the data. In case of a large number of observations however, this Chi-square test considers even minor, uninteresting discrepancies as indicative of bad model fit. Because of this, the Root Mean Square Error of Approximation (RMSEA) is used as an indication of the adequacy of fit of the path model. The RMSEA is less affected by sample size and indicates a good fitting model when it is $\leq 0.05$; a value of zero indicates the best fit $[22,23]$. So, a fitting model can yield a significant Chi-square, but the RMSEA value should always be 0.05 or lower. Significance level was set at $\alpha<.05$. Statistical analyses were undertaken with SPSS version 17.0 (SPSS inc. 2009) and with LISREL version 8.80 (Jöreskog \& Sörbom 2004).

\section{RESULTS}

Table 1 presents descriptive statistics for the study sample. In total 278 healthcare professionals ( $73.7 \%$ female, mean age $36.2 \pm 10.1$ years) completed both measurements T1 and $\mathrm{T} 2$, incorporating social-cognitive determinants of the Theory of Planned Behavior.

\section{Stability in predictors of healthcare professionals' intention and behavior}

Analyses were undertaken to explore possible differences between social-cognitive determinants measured at T1 compared to the social-cognitive determinants measured at T2 (Table 2). No intervention took place between the measurement at T1 and T2. Paired samples t-tests showed no differences on all social-cognitive determinants measured at T1 compared to $\mathrm{T} 2$, except for intention. The lowest observed difference was 0.02 ; the highest was 0.09 , except for intention. The mean difference for intention T1 compared with T2 was 0.28 , meaning a lower intention at $\mathrm{T} 2$ to encourage patients with cardiovascular risk factors to become physically active. 
Table 2 - Differences between social-cognitive determinants measured at T1 and T2

\begin{tabular}{lllrr}
\hline$N=278$ & Time 1 & Time 2 & differences & t-test \\
\hline Behavior & $5.73 \pm 0.90$ & $5.77 \pm 0.90$ & +.04 & $\mathrm{~ns}$ \\
Intention & $6.20 \pm 0.93$ & $5.92 \pm 0.90$ & -.28 & $5.18^{* * *}$ \\
Attitude & $6.18 \pm 0.59$ & $6.16 \pm 0.58$ & -.02 & $\mathrm{~ns}$ \\
Perceived behavioral control & $5.05 \pm 0.69$ & $4.99 \pm 0.70$ & -.06 & $\mathrm{~ns}$ \\
Subjective norms & $5.62 \pm 0.77$ & $5.60 \pm 0.78$ & -.02 & $\mathrm{~ns}$ \\
Descriptive norms & $5.08 \pm 0.68$ & $5.07 \pm 0.55$ & -.01 & $\mathrm{~ns}$ \\
Moral norms & $5.55 \pm 1.12$ & $5.62 \pm 1.12$ & +.07 & $\mathrm{~ns}$ \\
Habit & $5.23 \pm 0.25$ & $5.14 \pm 1.16$ & -.09 & $\mathrm{~ns}$ \\
Barriers & $2.63 \pm 1.02$ & $2.69 \pm 1.01$ & +.06 & $\mathrm{~ns}$ \\
\hline
\end{tabular}

Values are mean $\pm S D$; Social-cognitive variables range 1-7.

The correlation matrix (Table 3 ) shows a strong association between healthcare professionals' behavior at T1 and T2 ( $r=.61)$, and intention at T1 and T2 ( $r=.53)$. Healthcare professionals' behavior at T2 shows a strong association with intention T2 ( $r=.73)$, but only a moderate association with intention T1 $(r=.44)$. Healthcare professionals' behavior at T1 shows a strong association with intention T2 ( $r=.57)$, and with intention T1 ( $r=.70)$.

Strong associations were found between attitude T1 and T2 ( $r=.53)$, between perceived behavioral control T1 and T2 ( $r=.60)$, between subjective norm T1 and T2 ( $r=.53)$, between descriptive norms T1 and T2 ( $r=.77)$, but not for moral norms between T1 and T2 $(r=.19)$. Strong associations were found between habit T1 and T2 $(r=.48)$, and barriers T1 and $\mathrm{T} 2(r=.50)$. 


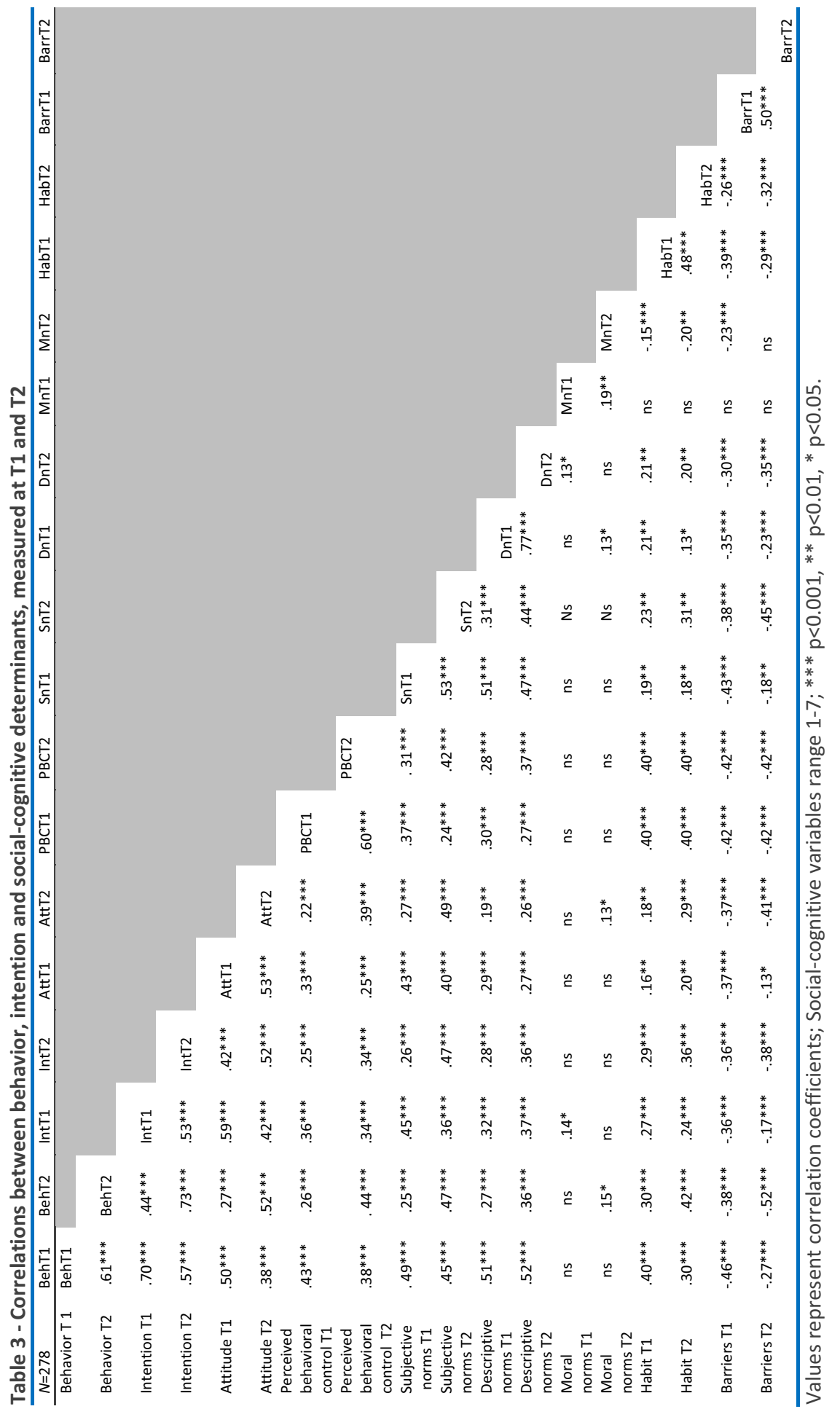




\section{Predictors of healthcare professionals' intention T1 and intention T2}

Regression analyses identified correlates of healthcare professionals' intention T1 and $\mathrm{T} 2$ to encourage physical activity among patients with cardiovascular risk factors (Table 4). The social-cognitive variables attitude $T 1$ ( $\beta=.455, p<.001)$, subjective norms $T 1$ ( $\beta=.207$, $p<.001)$, and perceived behavioral control T1 ( $\beta=.131, p<.05)$ accounted for $41 \%(p<.001)$ of the variance in intention $\mathrm{T} 1$. With respect to the self-reported intention $\mathrm{T} 1$, attitude showed to be a strong predictor to encourage patients with cardiovascular risk factors to become physically active.

The social-cognitive variables (previous) behavior T1 ( $\beta=.262, p<.001)$, intention T1 ( $\beta=.196, p<.01)$, attitude T2 ( $(=.284, p<.001)$, and subjective norms T2 ( $\beta=.141, p<.05)$, accounted for $48 \%(p<.001)$ of the variance in intention T2. Perceived behavioral control T2 did not contribute to the variance in intention $\mathrm{T} 2$. With respect to the self-reported intention T2, (previous) behavior T1 and attitude T2 showed to be strong predictors to encourage patients with cardiovascular risk factors to become physically active.

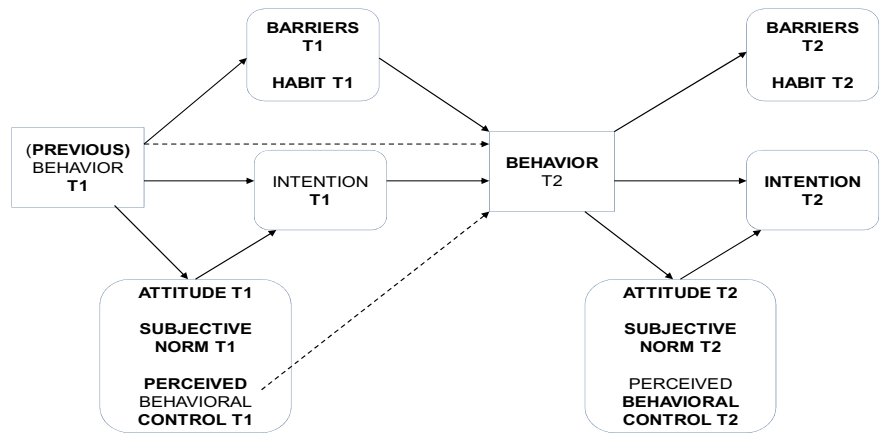

Figure 1 - Theoretical model of predictors of intention and behavior measured at T1 and T2

\section{Predictors of healthcare professionals' behavior T2}

Regression analyses identified correlates of healthcare professionals' behavior of encouraging patients with cardiovascular risk factors to become physically active (Table 4). The social-cognitive variables intention $\mathrm{T} 1(\beta=.311, \mathrm{p}<.001)$, next to habit $\mathrm{T} 1(\beta=.163, \mathrm{p}<.01)$ and barriers T1 $(\beta=-239, p<.001)$, accounted for $29 \%$ of the variance $(p<.001)$ in behavior T2. With respect to the self-reported behavior T2, intention T1 appeared to be the most important predictor, and additional predictors were the habit of encouraging patients to engage in physical activity and barriers that obstruct the encouragement of patients to engage in physical activity.

Social-cognitive variables accounted for $61 \%$ of the variance $(p<.001)$ in healthcare professionals' behavior T2 of encouraging patients with cardiovascular risk factors to become physically active, as the regression analysis identified in our longitudinal design. Healthcare professionals' behavior T2 was explained by (previous) behavior T1 ( $\beta=.232$, $p<.001)$, intention T2 ( $\beta=.546, p<.001)$, and perceived behavioral control T2 ( $\beta=.151$, $\mathrm{p}<.001$ ). With respect to the self-reported behavior T2, (previous) behavior T1 and intention 
T2 showed to be strong predictors for healthcare professionals to encourage patients with risk factors to become physically active.

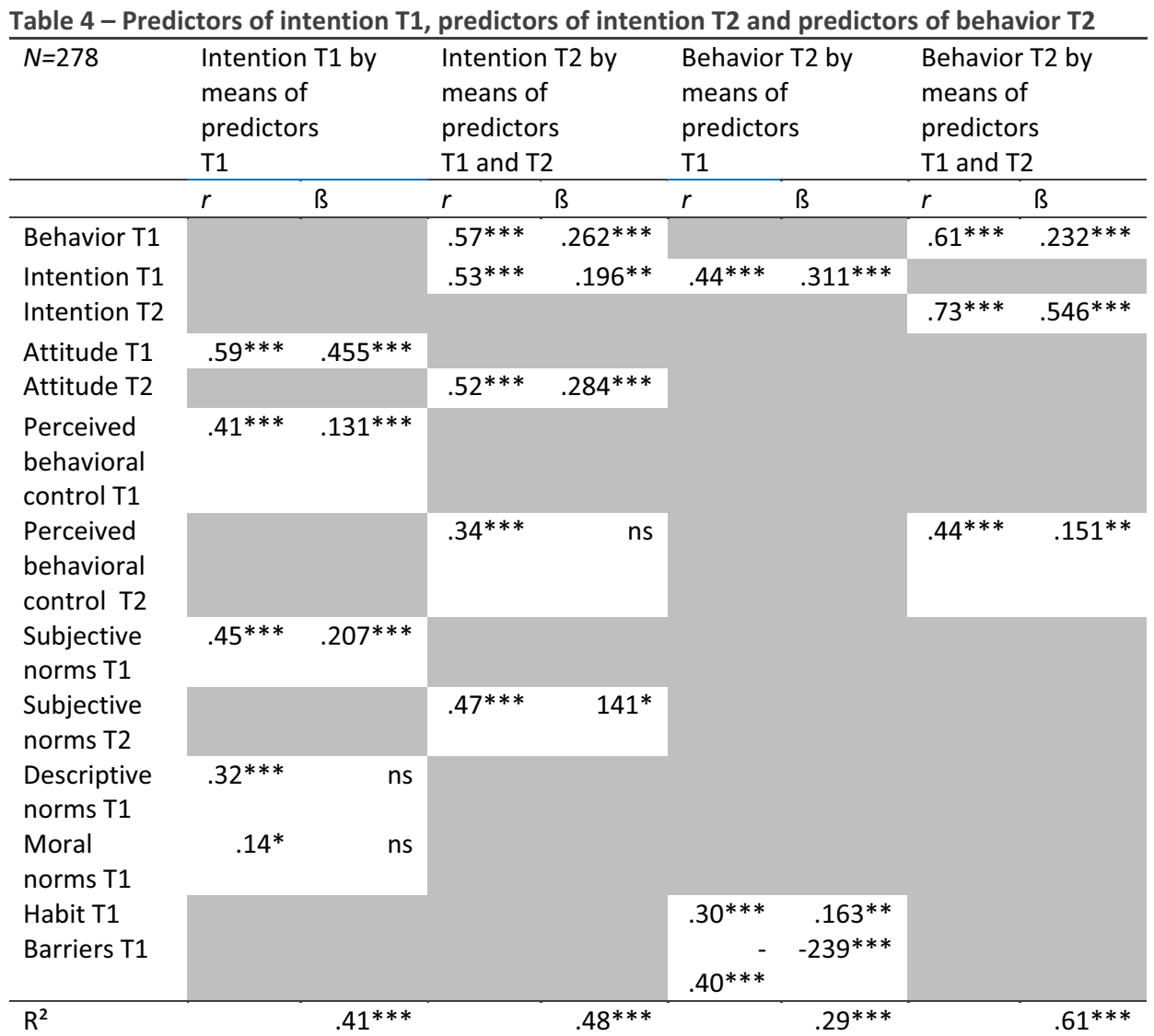

Regression analysis, ${ }^{* * *} p<.001,{ }^{* *} p<.01,{ }^{*} p<.05 ; r$ correlations; $\beta$ beta's.

Interdependence of social-cognitive determinants, structural equation modeling

Based on the above described findings and previous theoretical research, we examined direct, indirect and total effects by using structural equation modeling. The so conducted path model shows that we should accept the null hypothesis that the model fits the data $\left(\chi^{2}(5, N=278)=2.35, p=0.80 ; R M S E A=0.00\right)$. The RMSEA-value indicates that we created a good fitting model (Figure 2 ).

In this model, (previous) behavior T1 is the exogenous variable and behavior T2, intention $\mathrm{T} 1$ and $\mathrm{T} 2$, attitude $\mathrm{T} 1$ and barriers $\mathrm{T} 1$ are the endogenous variables. The hypothesized relationships in the model were supported, such that:

1) (Previous) behavior $T 1 \quad(\beta=.58, p<.001)$ and attitude $T 1 \quad(\beta=.48, p<.001)$, predicted intention $T 1$ (to intend and expect to encourage patients with cardiovascular risk factors to become physically active, $R^{2}=.57, p=<0.001$ );

2) (Previous) behavior $\mathrm{T} 1(\Omega=.54, \mathrm{p}<.01)$ and barriers $\mathrm{T} 1(\Omega=-.13, \mathrm{p}<.01)$, predicted behavior 
$T 2$ (to encourage patients with cardiovascular risk factors to become physically active, $\left.\mathrm{R}^{2}=.38, \mathrm{p}=<.001\right)$;

3) Behavior $\mathrm{T} 2(\beta=.60, \mathrm{p}<.001)$, intention $\mathrm{T} 1(\beta=.19, \mathrm{p}<.001)$ and attitude $\mathrm{T} 1(\beta=.23, \mathrm{p}<.01)$, predicted intention $T 2\left(R^{2}=.60, p=<0.001\right)$;

4) (Previous) behavior $T 1$ ( $\beta=-.52, p<.001)$, predicted barriers $T 1\left(R^{2}=.21, p=<0.001\right)$, and;

5) (Previous) behavior $\mathrm{T} 1(\beta=.27, p<.001)$ and barriers $\mathrm{T} 1 \quad(\beta=-.10, p<.01)$, predicted attitude $T 1\left(\mathrm{R}^{2}=.27, \mathrm{p}=<0.001\right)$.

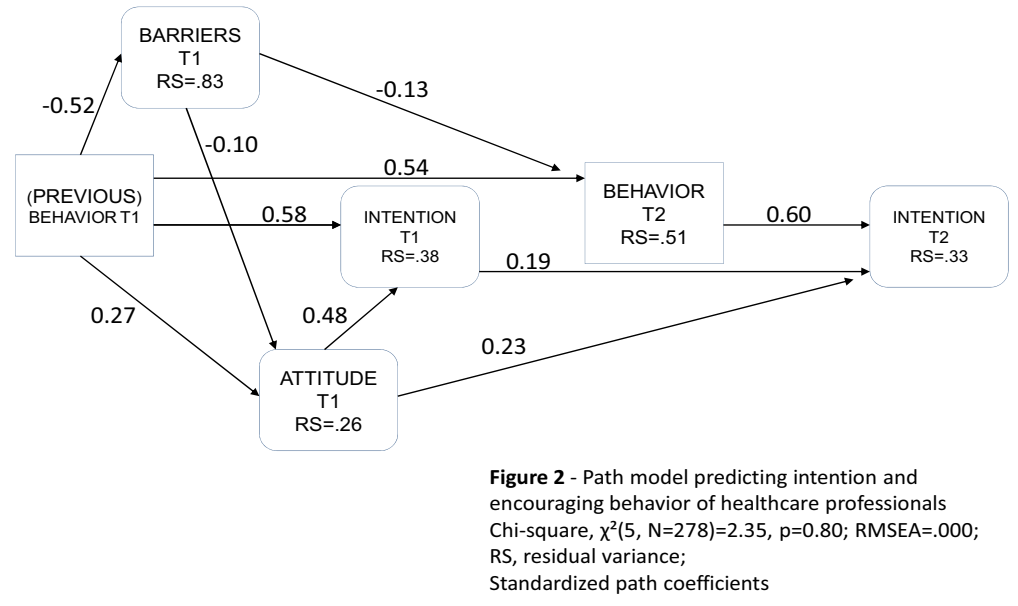

\section{DISCUSSION}

This study reports on the stability of social-cognitive determinants as the predictors of intention and behavior over time, by comparing the measurement of social-cognitive variables at $\mathrm{T} 1$ with the measurement of social-cognitive variables at $\mathrm{T} 2$. We also studied the interdependence of social-cognitive determinants according to the Theory of Planned Behavior, when measured at T1 and T2. By using structural equation modeling, we were able to examine direct, indirect, and total effects at the same time and to test the validity of the underlying theory, the Theory of Planned Behavior. The path model presented a good fit to the data, with all significant path effects.

Intention T1 could be predicted with (previous) behavior T1 and attitude T1; with no significant contribution detected in the path model for subjective norm T1 and perceived behavioral control T1. Our finding that intention T1 is largely predicted by attitude T1 corresponds with previous studies [1]. Attitude T1 showed to be especially important in the prediction of intention T1 and also T2 as compared with subjective norms T1 (also for T2), and as compared with perceived behavioral control T1 (also for T2). We explored behavior measured at T2, and found that particularly (previous) behavior T1, but also barriers T1 predicted behavior T2. There was not a significant contribution detected in the path model for barriers T2, or for habit T1 and T2.We explored intention T2, and found that intention T1 
and attitude $\mathrm{T} 1$ predicted intention T2, but that there was also an important contribution of behavior T2 in this relationship. Furthermore, (previous) behavior T1 predicted barriers T1; and (previous) behavior T1 and barriers T1 predicted attitude T1.

The standardized path coefficients showed that (previous) behavior T1 had a strong relationship with intention T1 (path coeff. =.58); that (previous) behavior T1 had a strong relationship with behavior T2 (path coeff. =.54), and also that behavior T2 had a strong relationship with intention $\mathrm{T} 2$ (path coeff. $=.60$ ).

According to the Theory of Planned Behavior, intention T1 is an important predictor of behavior T2. In the test of omitted paths using modification indices, we compared the full path model (with a path from intention T1 to behavior T2) with a reduced model (without a path from intention T1 to behavior T2). T-test indicated a weak relationship between intention T1 and behavior T2, and for this we omitted this path in our final path model. After omitting the path between intention T1 and behavior T2, t-test indicated all significant contributions of the endogenous variables. Also no previously unspecified paths (for intention T1) between variables were detected, when using modification indices. With respect to the relationship between intention $\mathrm{T} 1$ and behavior $\mathrm{T} 2$, we showed that no relationship between intention $\mathrm{T} 1$ and behavior $\mathrm{T} 2$ could be detected. In the path model, residuals for behavior $\mathrm{T} 2$ and intention $\mathrm{T} 2$ indicated that we explained an important part of the variance.

Table 5 - Structural equation modeling, underlying multivariate analyses

\begin{tabular}{|c|c|c|c|c|c|c|c|c|c|c|}
\hline \multirow[t]{2}{*}{$N=278$} & \multicolumn{2}{|c|}{ Behavior T2 } & \multicolumn{2}{|c|}{ Intention T2 } & \multicolumn{2}{|c|}{ Intention T1 } & \multicolumn{2}{|c|}{ Attitude T1 } & \multicolumn{2}{|c|}{ Barriers T1 } \\
\hline & $r$ & $\beta$ & $r$ & $\beta$ & $r$ & $\beta$ & $r$ & $\beta$ & $r$ & ß \\
\hline $\begin{array}{l}\text { Behavior } \\
\text { T2 }\end{array}$ & & & $.73 * * *$ & $.60 * * *$ & & & & & & \\
\hline $\begin{array}{l}\text { Behavior } \\
\text { T1 }\end{array}$ & $.61^{* * *}$ & $.54 * * *$ & & & $.70 * * *$ & $.58 * * *$ & $.50 * * *$ & $.27^{* * *}$ & $.46 * * *$ & $\begin{array}{r}- \\
.52 * * *\end{array}$ \\
\hline $\begin{array}{l}\text { Intention } \\
\text { T1 }\end{array}$ & & & $.53^{* * *}$ & $.19 * * *$ & & & & & & \\
\hline $\begin{array}{l}\text { Attitude } \\
\text { T1 }\end{array}$ & & & $.42 * * *$ & $.23 * * *$ & $.59 * * *$ & $.48 * * *$ & & & & \\
\hline $\begin{array}{l}\text { Barriers } \\
\text { T1 }\end{array}$ & $.38 * * *$ & $-.13^{*}$ & & & & & $.37^{* * *}$ & $-.10 *$ & & \\
\hline $\mathrm{R}^{2}$ & & $.38 * * *$ & & $.60 * * *$ & & $.57^{* * *}$ & & $.27^{* * *}$ & & $.21^{* * *}$ \\
\hline
\end{tabular}

Regression analysis, $* * * \mathrm{p}<.001, * * \mathrm{p}<.01, * \mathrm{p}<.05$; $r$ correlations; $ß$ beta's.

In the path model, (previous) behavior T1 is stated as the exogenous variables, because it can be specified as previous behavior already practiced by, in our study, healthcare professionals. Healthcare professionals are experienced in encouraging patients with cardiovascular risk factors to become physically active to decrease cardiovascular risk, and professionals probably have learned during education and in practice how to encourage patients. Though the path model supports essential prerequisites of the Theory of Planned Behavior, the model is slightly different from the findings in other studies.

Firstly, in the case of intention T1, the path model showed that the measure of the 
variable intention assessed a condition that began after the occurrence of previous behavior and we showed that intention T1 is predicted by (previous) behavior T1. Also, in the case of behavior T2, the path model showed that the behavior T2 is predicted by (previous) behavior T1. Secondly, we showed that there is no path between the socialcognitive determinant intention T1 and behavior T2; also an indirect path via another socialcognitive variable could not be detected. This finding, that behavior T2 is not influenced by the social-cognitive determinant intention T1 is different than expected on base of previous research. A meta-analytic review showed that intentions account for a considerable proportion of the variance in behavior [7]. The lack of a relationship in the structural equation model between intention T1 and behavior T2 is though provoking. Implications for changing the intention and behavior of healthcare professionals may be that the intention probably is less important when the behavior is stable (acquired through education and experience). Finally we showed in our path model, that there is a firm path from behavior $\mathrm{T} 2$ to the social-cognitive determinant intention $\mathrm{T} 2$.

Though not studied in a longitudinal design, previous correlation studies indicated that intentions occasionally predict previous behavior better than future behavior and that stating an intention brings to mind the previous behavior resulting in an intention more consistent with previous behavior $[3,25]$. Research indicated in a three factor path model (intention, and previous and future behavior) that routine behavior can be predicted from previous behavior, and intention, but with a stronger direct effect of previous behavior on future behavior than for intention [26]. As in our study, this research indicated that previous behavior appeared to be as an important predictor of behavior T2. Implications for changing the intention and behavior of healthcare professionals may be that (previous) behavior T1 should be determined and be taken into account for intervention design and implementation, because previous behavior can have a positive or negative influence on present or future behavior.

Social-cognitive variables accounted for $29 \%$ of the variance in behavior T2, and $41 \%$ of the variance in intention T1 and this corresponds with previous studies [4,7,10-12,27-29]. Social-cognitive variables accounted for $48 \%$ of the variables in intention $\mathrm{T} 2$, using predictors from $\mathrm{T} 1$ and $\mathrm{T} 2$; and for $61 \%$ of the variance in behavior $\mathrm{T} 2$, using predictors of $\mathrm{T} 1$ and $\mathrm{T} 2$.

We started our study by exploring the differences between social-cognitive determinants measured at T1 compared with social-cognitive determinants measured at T2. We hypothesized that there would be no differences between social-cognitive determinants measured at T1 compared with T2, when no intervention is implemented. We detected a discrepancy for intentions, showing a lower intention at T2 compared with T1, but behaviors stayed stable over time. If professionals have a strong intention to encourage patients to become physically active, the encouraging behavior is more to be expected; if professionals lower their intention, the encouraging behavior is less to be expected [3]. But in our study the intention planning the behavior decreases, and the corresponding 
encouraging behavior stayed unchanged.

Strengths of our study are its longitudinal design as this rules out the possibility that measurements at T2 influenced measurements at T1. An additional strength is that all social-cognitive variables were measured at $\mathrm{T} 1$ as well as $\mathrm{T} 2$, and on the same scale which increases the predictive validity of intention and behavior [3]. The study's sample size is an additional strength, because it was sufficiently large for all t-tests, tests of path coefficients in structural equation modeling and multiple regressions to be statistically significant with 95\% confidence intervals. Limitations of the study includes a possible restricted sample because all of the professionals included in this study were recruited from the same institute and this may limit generalization of the outcomes. Future studies are needed across different (sub) groups and different (health) behavior to further explore the influence of previous behavior, the undetected path from intention T1 to behavior T2 and the path from behavior T2 to intention T2. Probably it is desirable to better test the sequence of the intention and behavior related questions in the questionnaire. Another factor would probably be to ad measurements of social-cognitive variables at time 3 , possible only for (self-reported) behavior. Also the detection of additional, theoretically interesting, variables to incorporate in a path model is probably needed, to lower residual coefficients.

\section{CONCLUSION}

Our findings disclosed that social-cognitive determinants are stable over time, when no intervention is implemented, with only intention being less stable over time. In exploring the interdependence of determinants, we showed that intention T1 can be largely predicted by (previous) behavior T1; and behavior T2 by (previous) behavior T1. We also showed that there is neither a direct nor an indirect path between intention T1 and behavior T2. Finally, we showed that intention $\mathrm{T} 2$ can be largely predicted by behavior $\mathrm{T} 2$. 
CHAPTER 6

A WEB-BASED INTERVENTION FOR HEALTHCARE PROFESSIONALS AND PATIENTS TO DECREASE CVD RISK ATTRIBUTABLE TO PHYSICAL INACTIVITY

Chapter has been resubmitted as:

Barbara Sassen, Gerjo Kok, Ilse Mesters, Rik Crutzen, Anita Cremers, Luc Vanhees. A webbased intervention for healthcare professionals and patients to decrease CVD risk attributable to physical inactivity.

Journal of Medical Internet Research 
ABSTRACT: A WEB-BASED INTERVENTION FOR HEALTHCARE PROFESSIONALS AND PATIENTS TO DECREASE CVD RISK ATTRIBUTABLE TO PHYSICAL INACTIVITY

Introduction: The Intervention Mapping Protocol guided the development of the theory and evidence-based Internet-delivered Professional and Patient Intention and Behavior (PIB2) Intervention. According to the guidelines for cardiovascular risk management, healthcare professionals should encourage their patients to engage in physical activity. Patients with cardiovascular risk factors can reduce their risk of cardiovascular disease by increasing their physical activity and especially their physical fitness.

Objective: This article provides insight regarding the systematic development of the web-based PIB2-intervention for both healthcare professionals and patients by making use of the development method Intervention Mapping. The different steps of this development process are described to open up the black box of web-based intervention development and providing support for future web-based intervention development.

Methods: The development of the Professional and Patient Intention and Behavior Intervention (PIB2-intervention) was initiated with a needs assessment for both healthcare professionals and their patients with cardiovascular risk factors. We then formulated performance and change objectives. Subsequently, theory and evidence-based intervention methods and strategies were selected that were thought to affect the determinants of intention and behavior of healthcare professionals and patients. The rationale of the intervention was based on different behavioral change methods that allowed us to describe the scope and sequence of the intervention and produced the web-based intervention components. The intervention consisted of five theory and evidence-based modules, comprised of individualized messages and self-completion forms, as well as charts and tables for healthcare professionals and patients.

Results: The systematic and planned development of the PIB2-intervention resulted in a theory and evidence-based, internet-delivered behavior change intervention. The intervention was not developed as a substitute for face-to-face contact between professionals and patients, but as an application to complement and optimize health services. The intervention is based on the mutual exchange of information between the patient and their healthcare professional. The web-based intervention may improve socialcognitive determinants, intention, (health) behaviors and (health) maintenance for healthcare professionals as well as their patients, and long-term improvement in cardiovascular risk profiles. The main health outcome expected by the PIB2-intervention was that patients increased the (intensity) of their physical activity to impact cardiovascular risk factors.

Conclusion: The Intervention Mapping Protocol provided a systematic method for 
developing the intervention and each intervention design choice was carefully thought-out and justified. Although it is neither a rapid nor an easy method for developing an intervention, the protocol guides and directs the development process to open up the black box of web-based intervention development. The application of evidence-based behavior change methods used in our intervention offers insight regarding how an intervention may change intention and (health) behavior. Further research should test the effectiveness of the PIB2-intervention (Trial ID: ECP-92).

\section{INTRODUCTION}

Developing a web-based intervention is not just figuring out a well thought idea, but it needs a plan of how to design, implement and evaluate an intervention. Intervention Mapping provides a framework for building high quality interventions that are systematically planned and theory and evidence-based, and take perspectives of end users and intermediars into consideration [1-6]. Intervention Mapping places specific emphasis on the transparency of the translation of evidence-based behavior change techniques in intervention components not only to develop the specific intervention but also to explain its rationale [4].

Intervention Mapping is used throughout the entire process of creating an intervention (from diagnosis of the problem to problem solution), and includes collaborating iteratively with priority groups, stakeholders and experts in the field of health education and promotion. Intervention Mapping consists of six planning steps, whereby each step is a prerequisite for the next step and each step comprises different tasks. Each step in the Intervention Mapping process creates a product that is a guide for the subsequent step.

The first step of Intervention Mapping is a needs assessment of the study population. The questions explored in this step include: What is the problem? What are the causes? Are there detectable risk groups? The second step defines the program objectives and specifies the changes that are necessary, examining what determinants should be changed and why. The third step is the selection of theory-based intervention methods to effect these changes. In the fourth step an intervention is developed based on the integration of these theorybased methods of behavior change and the intervention is pre-tested. During the fifth step, an adoption and implementation plan for the intervention is created in order to facilitate sustained implementation. Finally, the process and the effects of the intervention are evaluated to determine if the intervention achieved the desired results [1,4]. Intervention Mapping has been found to be an effective protocol for developing an intervention [1,2,7$11]$.

In designing the intervention we focused on people with cardiovascular risk factors (abdominal obesity, high blood pressure, low HDL cholesterol (HDL-C), elevated triglycerides and elevated blood glucose levels). These factors increase the risk for cardiovascular disease, type 2 diabetes and overall mortality and morbidity [12-15]. Physical activity and particular intense physical activity improves cardio-vascular fitness associated with important cardiovascular health benefits $[13,16-18]$. Lifestyle interventions directed at increasing 
physical activity, thereby enhancing physical fitness, may improve the cardiovascular risk profile of patients. In designing the intervention we also comprised healthcare professionals, because they can and should encourage patients with cardiovascular risk factors to become and stay physically active. Healthcare professionals' intention to encourage physical activity among their patients with cardiovascular risk factors and subsequent behavioral modification by patients is crucial to the improvement of patients' cardiovascular risk profiles.

Aim This article provides insight into the systematic development of the web-based PIB2intervention to open up the black box of web-based intervention development and providing support for future web-based intervention development. This article focuses on the systematic development of the behavioral change intervention in order to facilitate program logic transparency, reproducibility and diffusion of the PIB2-intervention. The intervention sought to optimize behavioral coaching by healthcare professionals and encouraging previously physically inactive patients with cardiovascular risk factors to become physically active, following cardiovascular risk management guidelines with a potential for implementation in cardiovascular inpatient and outpatient care [19].

\section{METHODS}

We undertook a separate planning process to develop an intervention for healthcare professionals since they perform different behaviors with differing social-cognitive determinants related to the intention and behavior in question than their patients with cardiovascular risk factors do [20,21]. Within each step of the Intervention Mapping Protocol, the application for healthcare professionals is presented followed by the application for patients with cardiovascular risk factors. See figure 1 for an overview of the steps of Intervention Mapping, design, implementation and evaluation of the intervention.

\section{Intervention Mapping step 1 - Needs assessment}

Healthcare professionals

In the needs assessment, we performed a literature review, held focus-group interviews with healthcare professionals and studied the social-cognitive determinants of intention and behavior. The healthcare professionals in the study had a background in physiotherapy or nursing, and held at least a Bachelor degree. Focus-group interviews with healthcare professionals (7) revealed that encouraging patients to become physically active is seen as an integral part of their daily practice, and while relatively easy to do, the compliance of the patient is often a problem. In a former research we performed a quantitative study on the social-cognitive determinants of healthcare professionals to encourage patients with cardiovascular risk factors to become physically active [21]. We studied with a questionnaire social-cognitive determinants as posited by the Theory of Planned Behavior [22-30]. Results of this former study and input for the Intervention Mapping process were that, according to the Theory of Planned Behavior, healthcare professionals' encouragement of physical activity among cardiovascular patients can be 
predicted by high levels of intention to encourage physical activity among these patients, established habits of encouraging patients and low levels of barriers. The intention to encourage physical activity among cardiovascular patients is associated with attitudes, subjective norms and self-efficacy, and to a lesser extent, descriptive and moral norms. In exploring the relationship between intention and behavior, only $40 \%$ of the healthcare professionals had a positive intention and engaged in the actual encouraging behavior [21].

Figure 1 - Intervention Mapping: design, implementation and evaluation PIB2-intervention

\begin{tabular}{|c|c|c|c|c|}
\hline & & & Designing & \\
\hline \multirow[t]{2}{*}{ Step 1} & $\uparrow$ & $\rightarrow$ & $\downarrow$ Needs assessment & $\begin{array}{l}\text { Healthcare professionals: literature search; focusgop } \\
\text { interviews; assessment of social-cognitive } \\
\text { determinants of intention and behavior to encourage } \\
\text { physical activity }\end{array}$ \\
\hline & $\uparrow$ & & $\downarrow$ & $\begin{array}{l}\text { Patients with cardiovascular risk factors: literature } \\
\text { search; small group interviews; assessment of social- } \\
\text { cognitive determinantso ntention and behavior to } \\
\text { become physically active }\end{array}$ \\
\hline \multirow[t]{2}{*}{ Step 2} & $\uparrow$ & & $\begin{array}{l}\downarrow \text { Definition of } \\
\text { objectives and } \\
\text { specification of the } \\
\text { changes that are } \\
\text { needed }\end{array}$ & $\begin{array}{l}\text { Healthcare professionals: overall objective extending } \\
\text { the professional behavior; stating performance } \\
\text { objectives asteanticipated outcomes of the } \\
\text { intervention; stating change objectives }\end{array}$ \\
\hline & $\uparrow$ & & $\downarrow$ & $\begin{array}{l}\text { Patients with cardiovascular risk factors: overall } \\
\text { objective risk-reduction behavior; stating performance } \\
\text { objectives as the anticipated outcomes of the } \\
\text { intervention; stating chneobjectives }\end{array}$ \\
\hline \multirow[t]{2}{*}{ Step 3} & $\uparrow$ & & $\begin{array}{l}\downarrow \text { Theory-based } \\
\text { methods and } \\
\text { practical strategies }\end{array}$ & $\begin{array}{l}\text { Healthcare professionals: identification of theoretical } \\
\text { methods to change social-cognitive determinants of } \\
\text { the intention to encourage patients and the } \\
\text { corresponding behavior. }\end{array}$ \\
\hline & $\uparrow$ & & $\downarrow$ & $\begin{array}{l}\text { Patients with cardiovascular risk factors: identification } \\
\text { of theoretical methods to change social-cognitive } \\
\text { determinants of the intention to become physically } \\
\text { active and the corresponding behavior }\end{array}$ \\
\hline \multirow[t]{2}{*}{ Step 4} & $\uparrow$ & & $\downarrow$ Intervention & $\begin{array}{l}\text { Design, development and pre-testo he web-based } \\
\text { intervention }\end{array}$ \\
\hline & $\uparrow$ & & $\downarrow$ & \\
\hline \multirow[t]{2}{*}{ Step 5} & $\uparrow$ & & $\begin{array}{l}\downarrow \text { Adoption and } \\
\text { implementation plan }\end{array}$ & $\begin{array}{l}\text { Healthcare professionals: invited to participate via a } \\
\text { personalized letter sent by mail; instruction meeting; } \\
\text { telephone and mail support; rewarding certificate }\end{array}$ \\
\hline & $\uparrow$ & & $\downarrow$ & $\begin{array}{l}\text { Patients with cardiovascular risk factors: professionals } \\
\text { select patients }\end{array}$ \\
\hline \multirow[t]{2}{*}{ Step 6} & $\uparrow$ & & $\downarrow$ Evaluation plan & Pre and post test randomized controlled design \\
\hline & $\uparrow$ & & $\downarrow$ & \\
\hline \multicolumn{2}{|c|}{ Evaluation } & $\leftarrow$ & Implementation & \\
\hline
\end{tabular}

Patients with cardiovascular risk factors

A needs assessment for patients with cardiovascular risk factors was also performed. According to the classification of cardiovascular risk factors, people at risk for cardiovascular 
disease have one or more of the following risk factors: (1) abdominal obesity (men: waist circumference $>102 \mathrm{~cm}$; women: $>88 \mathrm{~cm}$ ); (2) high blood pressure (systolic $\geq 130 \mathrm{~mm} \mathrm{Hg}$ or diastolic $\geq 90 \mathrm{mmHg}$ ) or receiving antihypertensive drug treatment; (3) low HDL cholesterol (high-density lipoprotein, men $<1.03 \mathrm{mmol} / \mathrm{L}$, women $<1.30 \mathrm{mmol} / \mathrm{L}$ ) or being on medication that reduces HDL-C; (4) elevated triglycerides ( $\geq 1.70 \mathrm{mmol} / \mathrm{L}$ ) or being on medication that reduces triglycerides; and (5) elevated blood glucose ( $\geq 6.1 \mathrm{mmol} / \mathrm{L})$ or being on medication that reduces blood glucose $[12,13]$.

A search of the literature identified the importance of physical activity and physical fitness in preventing cardiovascular disease. Various 'guidelines' described and explained the optimal and recommended levels of physical activity and physical fitness. In a former study, we have investigated physical activity and physical fitness in an adult population and found that the intensity of physical activity is especially important in reducing cardiovascular risk factors [31].

Small group interviews (12 interviews with 3 patients each) revealed that patients with cardiovascular risk factors found being physically active a complex health behavior to incorporate into their daily living and that this behavior is difficult to maintain. In a former research, in accordance with the Theory of Planned Behavior, we performed a quantitative study [22-30]. We studied with a questionnaire the social-cognitive determinants of patients' physical activity intentions and the corresponding behavior. We found that behavior was predicted by high levels of intention, self-efficacy, descriptive norms and low levels of barriers. The intention to become physically active is strongly associated with attitude and self-efficacy. In exploring the relationship between intention and behavior, only $40 \%$ of the patients with cardiovascular risk factors had positive intentions and engaged in actual physically active behavior [20].

Intervention Mapping step 2 - Definition of objectives and specification of the changes that are needed

Healthcare professionals

The second step is defining the intervention objectives and specification of the changes that are needed [1,4]. In formulating our objectives, we defined the desired behavior of healthcare professionals as encouraging behavior conducive to the health of patients. Healthcare professionals should encourage patients with cardiovascular risk factors to become physically active at increased levels of intensity, as an extension of their professional behavior. This overall objective extension of professional behavior was specified as performance objectives. The performance objectives were directed at monitoring their encouraging behavior, formulating explicit plans to encourage and, in the end, maintain and habitually encourage physical activity among patients with cardiovascular risk factors, thereby preventing that patients relapse. These performance objectives are the anticipated behavioral outcomes of the intervention for healthcare professionals (table 1).

The performance objectives are linked with the social-cognitive determinants of intention and behavior, as described in step 1 of Intervention Mapping. The link between performance objectives and social-cognitive determinants resulted in a matrix displaying 
change objectives for healthcare professionals (table 2). The change objectives describe how the important social-cognitive determinants can be changed. For example the performance objective that professionals formulate explicit plans to encourage physical activity among patients with cardiovascular risk factors, is related to the change objectives that the professional knows that planning is important, that the professional can describe personal benefits for planning, feels confident in planning the encouragement in regard colleagues and describes when, where and how they will encourage patients to engage in physical activity.

Table 1 - Intervention mapping step 2: Performance objectives for healthcare professionals and patients with cardiovascular risk factors

Performance objectives

Healthcare Monitor the encouragement of physical activity among patients with

professionals cardiovascular risk factors is a prerequisite for a physically active patient

Formulate explicit plans to encourage physical activity among patients with cardiovascular risk factors

Identify solutions to diminish the barriers to encouraging physical activity among patients with cardiovascular risk factors

Formulate explicit plans to cope with difficult situations that occur while encouraging physical activity among patients with cardiovascular risk factors Maintain and habitually encourage physical activity among patients with cardiovascular risk factors, thereby preventing relapse

Patients with Monitor cardiovascular risks linked to (the intensity) of physical activity

cardiovascular Make explicit plans for physical activity

risk factors Identify solutions to diminish barriers to physically activity

Make explicit plans to cope with difficult situations that occur during physical activity

Maintain a lifestyle marked by physical activity, thereby preventing relapse

Patients with cardiovascular risk factors

In formulating our intervention objectives for patients with cardiovascular risk factors, we defined the desired behavior as risk-reduction behavior, assuming that if an intervention reduces the prevalence of risk factors, it can also reduce the prevalence of disease. Thus, for patients, not only should physical activity be encouraged but also the intensity of their physical activity resulting in healthy behaviors for patients with cardiovascular risk factors [31]. This overall objective of risk-reduction behavior of the patient was specified as performance objectives (table 1). The performance objectives were directed at monitoring cardiovascular risk linked to physical activity, make explicit plans and, in the end, maintain a lifestyle marked by physical activity, thereby preventing relapse in unhealthy behavior. The link between performance objectives and social-cognitive determinants resulted in a matrix displaying change objectives for patients with cardiovascular risk factors (table 3 ). Examples of change objectives related to the performance objective that patients maintain a lifestyle marked by physical activity, thereby preventing relapse, is related to the change objectives 
that patients indicate that relapse is part of changing lifestyle physical activity, state (health) benefits of physical activity, feel confident about handling negative social influence and about being able to perform physical activity, demonstrates restart and evaluate the behavior and, in the end, that the patient handles incidental situations that keep them from engaging in physical activity.

Intervention Mapping step 3 - Theory-based methods and practical strategies

The third step is the selection of theory-based intervention methods to change (determinants of) the health behavior of interest [1,4]. Acquiring insight into behavioral change methods to be used in intervention design is essential for evaluating the effectiveness of an intervention as it reveals not only why an intervention changed intention and/or (health) behavior, but also, if necessary, why it failed [32,33]. In step 2 we stated the performance and change objectives, and we know which social-cognitive determinants we should direct the intervention at. Important social-cognitive determinants detected were risk-perception, attitude, subjective norm as the social influence of others, perceived behavioral control and barriers. In step 3 we selected theory-based methods, looked at the considerations for using these methods and described conditions and strategies, for both healthcare professionals and patients (table 4).

We applied the theoretical method of risk-communication and risk-perception to encourage thinking about individual risk and personal vulnerability, followed by the generation of attitudinal change and outcome expectations by applying the method of decisional balance to list pro and cons [34]. We applied the theoretical method resistance to social pressure and mobilizing others for social support, encourage seeking social support [25]. Providing emotional support or supporting people with information and advice influences the performance of the behavior and is a protective factor for health outcomes [1]. Guided practice to encourage sub-skill enactment was also facilitated [30]. Interventions that maximize beneficial attitudes, subjective norms and perceived behavioral control have a substantial impact on intentions [35].

We applied the theoretical method of action and coping planning. Plan behavior change, make a plan and learn how to identify high-risk situations when putting into practice behavior change [36]. Action planning can initiate changes in intention. Interventions that provoke alterations in intention and response to their intention have a greater impact on (health) behavior [37-39]. Related to action planning, formulating implementation intentions by preparatory planning when, where, and how healthcare professionals would encourage physical activity among patients with cardiovascular risk factors, as well as determining when, where, and how patients would engage in a physical activity, was added to the intervention [40]. When healthcare professionals and patients formulate their own plans i.e. their own implementation intentions, they are more likely to attain the goal and to perform the planned behavior [41]. This strategy of implementation planning was found to generate a medium size effect on health behaviors [42].

Coping planning was initiated to allow health professionals vs. patients to better cope 
with putting behavior change into practice [36]. Coping planning was initiated where healthcare professionals vs. patients identified high-risk situations that might cause them to withdraw from the desired behavior [43]. In addition, healthcare professionals and patients were aided in making their own explicit plans to cope with potential difficult situations that would hinder them from engaging in encouraging health behavior or relapse [44].

In a systematic review and meta-analysis, it was found that the number of behavioral change techniques applied had a positive impact on the total effect size of the intervention $[6,45]$. The effectiveness of an intervention was reduced when the number of behavior change techniques decreased [45]. An overview of reviews on behavioral change techniques to promote behavior change found that risk communication, use of social support and selfmonitoring of behavior were all shown to be relatively effective [32]. Coping and action planning was found to have a sustainable effect on (health) behavior $[6,36,46]$. The intervention provided personalized text-messages (with individuals' names in headings, etc.) that were shown to be highly effective in encouraging interaction and support of behavioral change in interventions $[6,47]$.

Table 4 - Intervention mapping step 3 (theory-based methods): Social-cognitive determinants linked to theoretical methods and their conditions

\begin{tabular}{|c|c|c|c|}
\hline Determinant & $\begin{array}{l}\text { Theory-based } \\
\text { method }\end{array}$ & Considerations for use & $\begin{array}{l}\text { Conditions and } \\
\text { strategies }\end{array}$ \\
\hline $\begin{array}{l}\text { Risk-perception, } \\
\text { knowledge }\end{array}$ & $\begin{array}{l}\text { Risk } \\
\text { communication, } \\
\text { risk perception }\end{array}$ & $\begin{array}{l}\text { Requires knowledge } \\
\text { about the relationship } \\
\text { between (health) } \\
\text { problem and (risk vs. non } \\
\text { encouraging) behavior }\end{array}$ & $\begin{array}{lr}\text { Encourage thinking } \\
\text { about individual risk } \\
\text { and personal } \\
\text { vulnerability }\end{array}$ \\
\hline $\begin{array}{l}\text { Attitude, outcome } \\
\text { expectations }\end{array}$ & $\begin{array}{l}\text { Decisional } \\
\text { balance }\end{array}$ & $\begin{array}{l}\text { Requires consideration } \\
\text { and evaluation of } \\
\text { behavior }\end{array}$ & $\begin{array}{l}\text { Encourage listing pros } \\
\text { and cons of (not) } \\
\text { changing behavior in } \\
\text { the short and long } \\
\text { term }\end{array}$ \\
\hline \multirow[t]{2}{*}{$\begin{array}{l}\text { Social influence and } \\
\text { skills }\end{array}$} & $\begin{array}{l}\text { Resistance to } \\
\text { social pressure }\end{array}$ & $\begin{array}{l}\text { Requires social-skill } \\
\text { enactment with feedback }\end{array}$ & $\begin{array}{l}\text { Encourage to resist } \\
\text { social pressure }\end{array}$ \\
\hline & $\begin{array}{l}\text { Mobilizing others } \\
\text { for social support }\end{array}$ & $\begin{array}{l}\text { Requires a network that } \\
\text { can potentially support } \\
\text { (health) behavior }\end{array}$ & $\begin{array}{l}\text { Encourage to seek } \\
\text { social support }\end{array}$ \\
\hline \multirow{2}{*}{$\begin{array}{l}\text { Perceived behavioral } \\
\text { control } \\
\text { and skills }\end{array}$} & Guided practice & $\begin{array}{l}\text { Requires sub-skill } \\
\text { enactment with feedback }\end{array}$ & $\begin{array}{l}\text { Encourage sub-skills } \\
\text { practice }\end{array}$ \\
\hline & Action planning & $\begin{array}{l}\text { Requires specification of } \\
\text { when, where and how to } \\
\text { act }\end{array}$ & $\begin{array}{l}\text { Planning behavior } \\
\text { change, making a } \\
\text { behavior change plan }\end{array}$ \\
\hline $\begin{array}{l}\text { Barriers and skills to } \\
\text { cope }\end{array}$ & Coping planning & $\begin{array}{l}\text { Requires identification of } \\
\text { high-risk situations and } \\
\text { the practice of coping } \\
\text { responses }\end{array}$ & $\begin{array}{l}\text { Put into practice } \\
\text { behavior change }\end{array}$ \\
\hline
\end{tabular}


Intervention Mapping step 4-Intervention

On basis of the integration of the theory-based methods, conditions and strategies, we developed and tested the intervention in step 4. A web-based behavioral change intervention was considered the most appropriate, aimed at motivating healthcare professionals to encourage physical activity among their patients with cardiovascular risk factors. The intervention was not developed a substitute for face-to-face contact between the professional and the patient, but as an additional instrument to optimize health services [48]. Research has demonstrated the favorable effects of Internet-delivered interventions [49,50-52]. Computer-delivered interventions can not only improve social-cognitive determinants, but also enhance health behavior and general health maintenance [49]. An Internet-delivered behavioral change intervention facilitates the delivery of the intervention to a large group of professionals and patients. Using a website is appealing to the group of interest and has the benefits of making processes visible [46]. Internet-delivered physical activity interventions have been shown to be effective [53].

Several tests and interviews were conducted with experts and members of the target group (both health professionals and patients) in order to check the match between intervention components, the performance and change objectives and, theory-based methods, conditions for use and strategies. The PIB2-intervention embeds five modules, each comprising a sequential set of screens on the website (table 5 , table 6 , and figure 1 ).

Table 5 - Intervention mapping step 4 (intervention): Intervention components for healthcare professionals and patients with cardiovascular risk factors

\begin{tabular}{ll}
\hline Web-based PIB2-intervention \\
\hline Module 1 & $\begin{array}{l}\text { The healthcare professional coaches patients with cardiovascular risk factors } \\
\text { through a process of behavior change i.e. encourage the patient to become and stay } \\
\text { physically active. Module } 1 \text { consists of personalized messages with a feedback } \\
\text { system for the progress being made }\end{array}$ \\
\hline Module 2 & $\begin{array}{l}\text { Support system for healthcare professionals encouraging patients with } \\
\text { cardiovascular risk factors to become and stay physically active. The support system } \\
\text { follows parallel building module } 1 \text { and is about how to coach the patient with } \\
\text { cardiovascular risk factors through a process of behavior change i.e. encourage the } \\
\text { patient to become and stay physically active }\end{array}$ \\
\hline Module 3 & $\begin{array}{l}\text { To facilitate healthcare professionals to be a motivating and encouraging healthcare } \\
\text { professional, to generate a positive intention to encourage patients and to display } \\
\text { the corresponding behavior of encouraging the patient to become and stay } \\
\text { physically active }\end{array}$ \\
\hline Module 4 & $\begin{array}{l}\text { Internet forum directed at healthcare professionals with the aim to share } \\
\text { experiences with other healthcare professionals and find solutions for experienced } \\
\text { problems coaching patients with cardiovascular risk factors through a process of } \\
\text { behavior change i.e. encourage the patient to become and stay physically active }\end{array}$ \\
\hline Module 5 & $\begin{array}{l}\text { Patients' personal webpage where the patient can look back at the plans he made } \\
\text { with the healthcare professional and see if they are making progress in risk factors, } \\
\text { physical activity levels and the process of behavior change }\end{array}$ \\
\hline
\end{tabular}


In module 1 , the healthcare professional encourages the patient to become and stay physically active. Module 1 is designed to invite the patient to participate in the intervention, i.e. to use the intervention based on the mutual exchange of information between the healthcare provider and the patient, paralleling the performance and change objectives, the methods, conditions and strategies. It starts with the assessment of cardiovascular risk factors according to the guidelines for cardiovascular risk management [19]. Based on this assessment, a patient's cardiovascular risk factors are displayed in a pie chart and changes in the number of risk factors or risk factor levels are registered and (later) shown. During the assessment step, the level of physical activity and intensity and duration are assessed with the SQUASH-questionnaire and intensity (total, high, medium and low levels) of physical activity is displayed in a bar chart [54]. Changes in physical activity are registered and (later) shown. The social cognitive determinants of the patient are also gathered with a questionnaire and displayed in the health spider chart of the patient; changes are registered and (later) shown [20].

After the assessment, the healthcare professional starts to coach the patient with cardiovascular risk factors through a process of behavior change to become and to stay physically active. In the process of behavior change, the seven theory-based methods, conditions and strategies were put into practice in seven website screens. The process of behavior change starts with risk-perception, encouraging the patient to think about individual cardiovascular risk and personal vulnerability and the relationship between becoming (more) physically active and lower risk. Followed by listing the pros and cons of (not) changing the behavior in the short and long term, encouraging the patient to describe what his personal pro and cons are to become of not become physically active, in the short and long term. After this the patient is encouraged to resist social pressure and to seek support and practice the sub-skills needed to for being physically active. The process of behavior change ends with planning the behavior change, making a behavior change plan and put into practice behavior change. The patient is encouraged to specify when, where and how to become physically active in a plan. When the patient starts putting into practice the physical active lifestyle, high-risk situations and the practice of coping responses is encouraged.

A feedback system measures the progress in patient's cardiovascular risk factors, physical activity levels and the changes in the process of behavior change. The patients' profile is displayed when the professional is working with the patient and is visible on the left side of the screen (see figure 1). The healthcare professional can provide the patient with physical activity recommendations based on research to encourage physical activity and physical fitness $[31,55]$. The physical activity recommendations are shown in the patients' profile and can be changed by the professional when needed.

Module 2 is the support system for the healthcare professional. The support system parallels the seven website screens of module 1 and contains background information on how to coach the patient with cardiovascular risk factors through the process of behavior 
change. This module consists of explanations of the methods, conditions and strategies for the healthcare professional, scripts how to start conversations, etc. The professional can read for each method these background information and select parts of the information that are important (in advance or during the consultation with the patient). Once selected, the website can display the selected background information for all subsequent consultations with this and other patients by clicking a button 'show suggestions' in module 1 (table 6).

Module 3 facilitates the professional become a motivating and encouraging healthcare professional. In this process of behavior change, the seven theory-based methods, conditions and strategies were put into practice in seven website screens (table 6). Module 3 is designed to be a teaching and learning process for the healthcare professional consisting of specific questions and self-completion forms. The process of behavior change for healthcare professionals starts with 'risk'-communication, encouraging the professional to think about his encouraging behavior towards patients, and the relationship between encouraging patients and compliant patients. This is followed by listing the pro and cons of (not) encouraging patients, in the short and long term. After this the professional is encouraged to seek social support and look at the sub-skills needed to be an encouraging professional. The process of behavior change ends with planning the behavior change, making a behavior change plan and put into practice behavior change. The professional is encouraged to specify when, where and how to encourage patients in a plan. When the professional starts putting his encouraging behavior into practice, the identification of highrisk situations and the practice of coping responses is encouraged. In module 3 a feedback system is incorporated to enable the professional to evaluate their progress. At the initiation of the behavior change process, the healthcare professional fills in a questionnaire on socialcognitive determinants; progress is registered and made visible in the coaching spider chart [21].

Module 4 consists of an Internet forum directed at healthcare professionals. The healthcare professional can use the forum to share experiences with other healthcare professionals who are using the PIB2-intervention and find solutions for specific problems pertaining to the coaching of patients. A researcher responsible for the implementation process will respond to questions when other professionals do not respond or when responses are incorrect, however, the researcher refrains from interrupting on-line discussions (table 6). 
Table 6 - Intervention mapping step 4 (intervention): flow chart of the Intervention

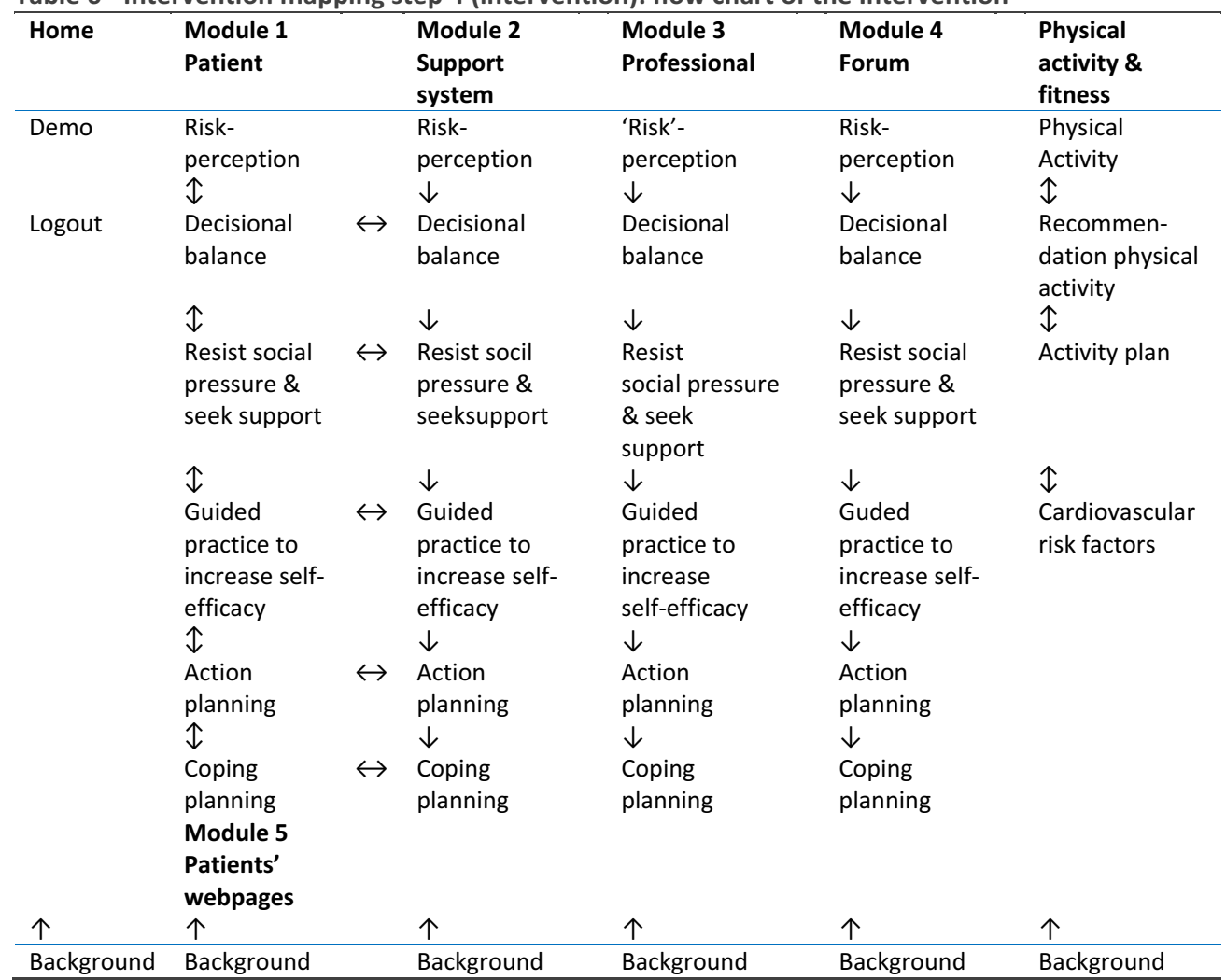

Module 4 consists of an Internet forum directed at healthcare professionals. The healthcare professional can use the forum to share experiences with other healthcare professionals who are using the PIB2-intervention and find solutions for specific problems pertaining to the coaching of patients. A researcher responsible for the implementation process will respond to questions when other professionals do not respond or when responses are incorrect, however, the researcher refrains from interrupting on-line discussions (table 6).

Module 5 facilitates the patient to look at the plans he made in conjunction with the healthcare professional in module 1 . The patient can examine the forms he or she filled in during module 1 and prepare for the next consultation with the professional. The patient receives personalized messages, underwritten with the name of the professional. The patient can see if he is making progress in reducing the number of cardiovascular risk factors, increasing his physical activity level, and implementing behavioral change, displayed in chart form in the same way as in module 1 . The patient can find the physical activity recommendations the healthcare professional has provided and practice them at home or elsewhere (table 6).

The healthcare professional can use all the modules of the PIB2-intervention as these 
are accessible with a login code. However, the patient can only access module 5 with a login code. Professionals can access background information on the PIB2-intervention as a whole, and are also given specific information for every module. Information on physical activity, physical fitness, general physical activity devices, making an activity plan and cardiovascular risk factors are accessible to the professional. For patients, information is given on the PIB2intervention as a whole and only specific information is provided for module 5 . Further, there is background information and a response form for members of the public visiting the website.

Intervention Mapping step 5 - Adoption and implementation plan

The fifth step is to develop a plan for the intervention to facilitate sustained implementation. Healthcare professionals were (former) students of the Department of Health and Lifestyle at the University of Applied Sciences. Participants with at least a Bachelor's degree in nursing or physiotherapy and who had consultations with cardiovascular patients were invited to participate via a personalized letter by mail. They were invited to attend a meeting at which the Web-based intervention was demonstrated and could be practiced. The Web-based intervention is self-explanatory; participants could choose not to attend the meeting and still use the demonstration tool on the website to familiarize themselves with the use of the website. During intervention, this was followed by telephone calls, emails and a meeting to provide the participants with personally relevant information [56]. We facilitated sustained implementation of the intervention by rewarding healthcare professionals for extensive use of the Web-based PIB2-intervention with a certificate of 10 European Credits.

The healthcare professionals selected which patients with cardiovascular risk factors they would work with. The healthcare professionals were strongly recommended to use the intervention for every patient with cardiovascular risk factors 'suitable' for intervention. The implementation of the PIB2-intervention was approved by the Ethics Committee at Maastricht University and was registered in the Dutch Trial Register (Trial ID: ECP-92).

\section{Intervention Mapping step 6 - Evaluation plan}

And at last, in step 6 the anticipation on the evaluation of the intervention is planned to determine if the intervention achieved the planned results. When building the website, we designed it from the bottom up and began by determining the data needed to measure the effectiveness of the Web-based intervention [46]. The evaluation of the PIB2intervention will be designed according to the CONSORT criteria for reporting a randomized controlled trial [57]. The intervention will be evaluated by using a pre and posttest randomized control trial design consisting of an intervention group and a waiting-list control group (see table 7). Continuous data collection will be part of the Web-based intervention for a follow-up period of 10 months. 
Table 7 - Intervention mapping step 5 (adoption and implementation plan): Overview of the timeinterval design

\begin{tabular}{|c|c|c|c|c|c|c|}
\hline \multirow{3}{*}{$\begin{array}{l}\text { Group: } \\
\text { Healthcare } \\
\text { professionals }\end{array}$} & \multirow[b]{2}{*}{$\begin{array}{l}\text { Intervention } \\
\text { group } 1\end{array}$} & \multicolumn{3}{|c|}{ Design: } & & \\
\hline & & T1 & $\begin{array}{l}\text { T2 Start } \\
\text { intervention, } \\
\text { continuous } \\
\text { measurement }\end{array}$ & $\begin{array}{l}\text { T3 } \\
\text { At } 5 \\
\text { months }\end{array}$ & & \\
\hline & $\begin{array}{l}\text { Control } \\
\text { group A }\end{array}$ & T1 & & $\mathrm{T} 2$ & $\begin{array}{l}\text { T3 } \\
\text { Start } \\
\text { intervention, } \\
\text { continuous } \\
\text { measurement }\end{array}$ & $\begin{array}{l}\text { T4 } \\
\text { At } 10 \\
\text { months }\end{array}$ \\
\hline $\begin{array}{l}\text { Patients with } \\
\text { cardiovascular } \\
\text { risk factors }\end{array}$ & $\begin{array}{l}\text { Intervention } \\
\text { group } 2\end{array}$ & T1 & $\begin{array}{l}\text { T2 Start } \\
\text { intervention, } \\
\text { continuous } \\
\text { measurement }\end{array}$ & $\begin{array}{l}\text { T3 } \\
\text { At } 5 \\
\text { months }\end{array}$ & & \\
\hline & $\begin{array}{l}\text { Control } \\
\text { group B }\end{array}$ & & & T1 & $\begin{array}{l}\text { T2 } \\
\text { Start } \\
\text { intervention, } \\
\text { continuous } \\
\text { measurement }\end{array}$ & $\begin{array}{l}\text { T3 } \\
\text { At } 10 \\
\text { months }\end{array}$ \\
\hline
\end{tabular}

The effect evaluation will be performed to verify whether the PIB2-intervention was successful in strengthening the encouraging behavior of healthcare professionals, i.e. if methods, conditions and strategies to use these methods were successfully applied to change performance and change objectives. The effect evaluation will also be performed to verify whether the intervention was successful in strengthening the physical active behavior of patients with cardiovascular risk factors, i.e. if we attained the performance and change objectives. For patients the main outcome measure is improvement in cardiovascular risk profiles, i.e. patients decrease their number of cardiovascular risk factors by at least one risk factor and/or decrease their levels of cardiovascular risk factors at the end of the intervention. The process evaluation will be performed during implementation of the PIB2intervention via the collection of data on the use and usability of the PIB2-intervenion modules.

\section{RESULTS}

The systematic and planned development of the PIB2-intervention resulted in a theory and evidence-based, internet-delivered behavior change intervention. The intervention was not developed as a substitute for face-to-face contact between professionals and patients, but as an application to complement and optimize health services. The intervention is based on the mutual exchange of information between the patient and their healthcare professional. The web-based intervention may improve socialcognitive determinants, intention, (health) behaviors and (health) maintenance for healthcare professionals as well as their patients, and long-term improvement in cardiovascular risk profiles. Step 1 Intervention Mapping, the needs assessment for 
healthcare professionals resulted in that we could state the problem that they do not (always) encourage patients with cardiovascular risk factors to become and/or stay physically active. The risk group here is professionals with low intentions to encourage patients and/or who do not display the corresponding behavior to encourage patients with cardiovascular risk factors to become and remain physically active. The outcome measure for healthcare professionals was to increase their intention to encourage physical activity among cardiovascular patients and the subsequent behavior of encouraging patients. The problem for patients at risk for cardiovascular disease is their low intention towards, and inadequate levels of physical activity and physical fitness. The health outcome measure for patients was to improve their cardiovascular risk profile and we directed our efforts towards enforcing the intention to become physically active and subsequent behavior of physical activity, and increasing the (intensity) of physical activity to impact cardiovascular risk factors.

Step 2 Intervention Mapping, definition of objectives and specification of the changes needed, resulted in a matrix with performance objectives for both healthcare professionals and patients, and the matrix with change objectives that shows how these performance objectives are linked with important social-cognitive determinants. Step 3 Intervention mapping resulted in the linking of important social-cognitive determinants of intention and behavior, performance and change objectives with theory-based methods, and conditions and strategies to use these methods, based on results of previous studies. We selected the theory-based methods that will constitute the intervention. In step 4 of Intervention mapping we designed the website consisting of different modules, and the pre-testing of the website. Step 5 Intervention mapping resulted in the adoption and implementation plan how to select and invite the healthcare professionals and patients with cardiovascular risk factors to take part in the intervention. Step 6 Intervention mapping resulted in the evaluation design for the intervention and a plan how to evaluate the intervention.

\section{DISCUSSION}

The PIB2-intervention was developed guided by the Intervention Mapping protocol. After the needs assessment, we specified the performance and change objectives of the intervention. We selected the methods to affect these objectives and developed on base of these methods the intervention. After this we created the adoption and implementation plan for the intervention, and finally the evaluation plan. The intervention was not developed as a substitute for face-to-face contact between professionals and patients, but as an application to complement and optimize health services. The Intervention Mapping Protocol guided the development of the theory and evidence-based internet-delivered Professional and Patient Intention and Behavior Intervention.

The intervention was developed to complement face-to-face contact between the healthcare professional and the patient by encouraging the mutual exchange of information to optimize health services. The intervention was designed to invite patients with cardiovascular risk factors to participate in the communication process with their healthcare 
professional. The Web-based PIB2-intervention aimed, on the one hand, to help healthcare professionals encourage patients with cardiovascular risk factors to become and stay physically active while, at the same time, it sought to motivate healthcare professionals so that they could enhance their professional behavior when communicating with patients.

Changing intentions and behavior among both healthcare professionals and patients is a complex process with many inhibiting factors. By assessing the needs of both healthcare professionals and patients, we could define important and changeable social-cognitive determinants. Using evidence-based behavior change techniques in the development process of the intervention is important as they provide insight regarding how socialcognitive determinants of healthcare professionals' and patients' behavior may be changed. In the longer term, it also provides information on how intention and (health) behavior can be affected. Although influencing the professional behavior for healthcare professionals and the physical activity behavior for patients with cardiovascular risk factors is difficult to achieve, the Intervention Mapping protocol provided us with tools to handle this complicated process.

Furthermore, although we carefully developed and tested the web-based intervention in close cooperation with healthcare professionals and patients with cardiovascular risk factors, much of its success depends on its feasibility and usefulness in the healthcare professionals' daily practice, and on whether there is sufficient time and expertise to use the intervention during the consultation period. 
Figure 2 - Multimedia appendix of supplementary file www.gezondheidsbevordering.eu

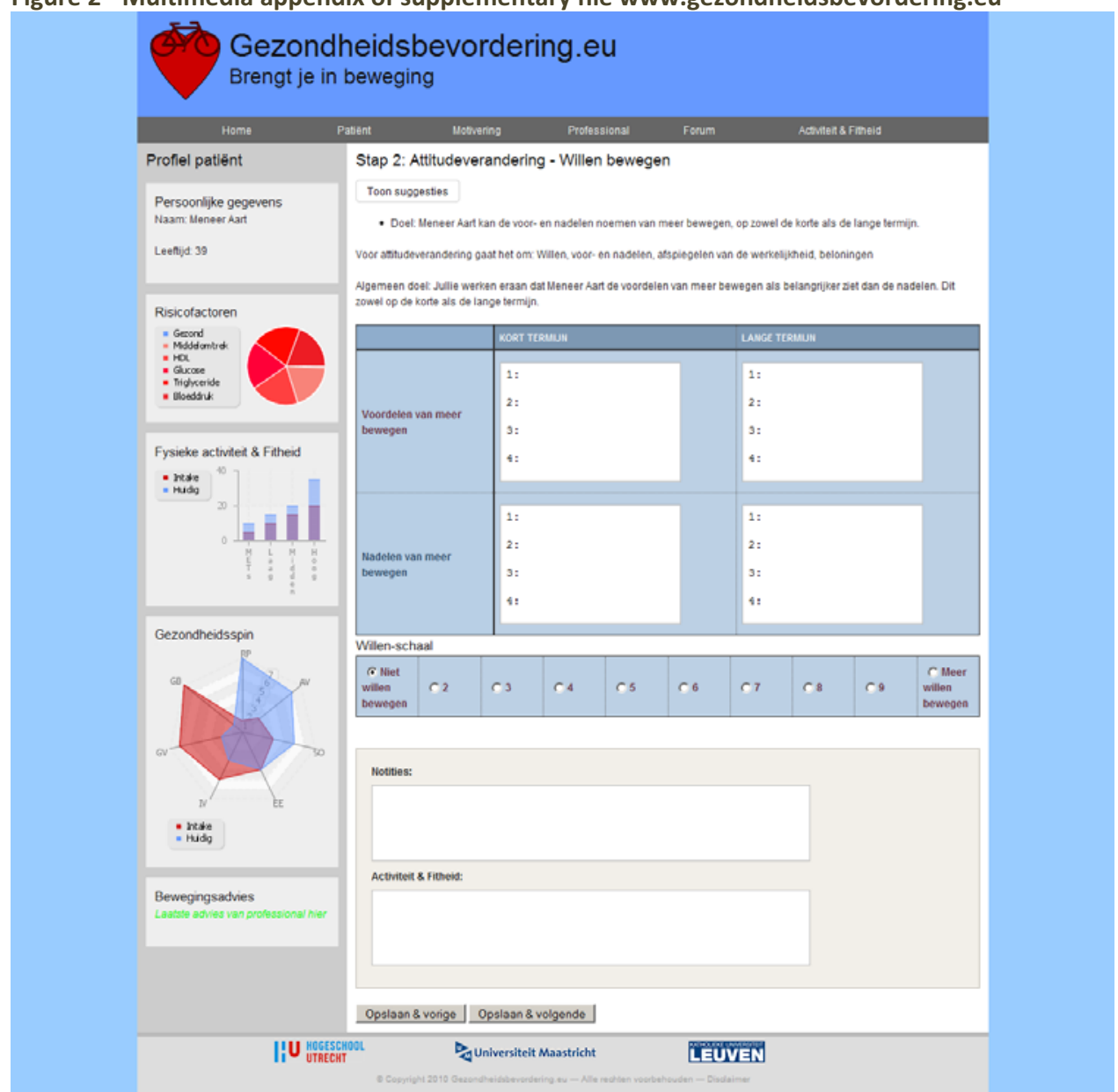

Acknowledgement

The authors would like to thank Ir. Lex Verheesen for his contribution in the development of the website www.Gezondheidsbevordering.eu. 


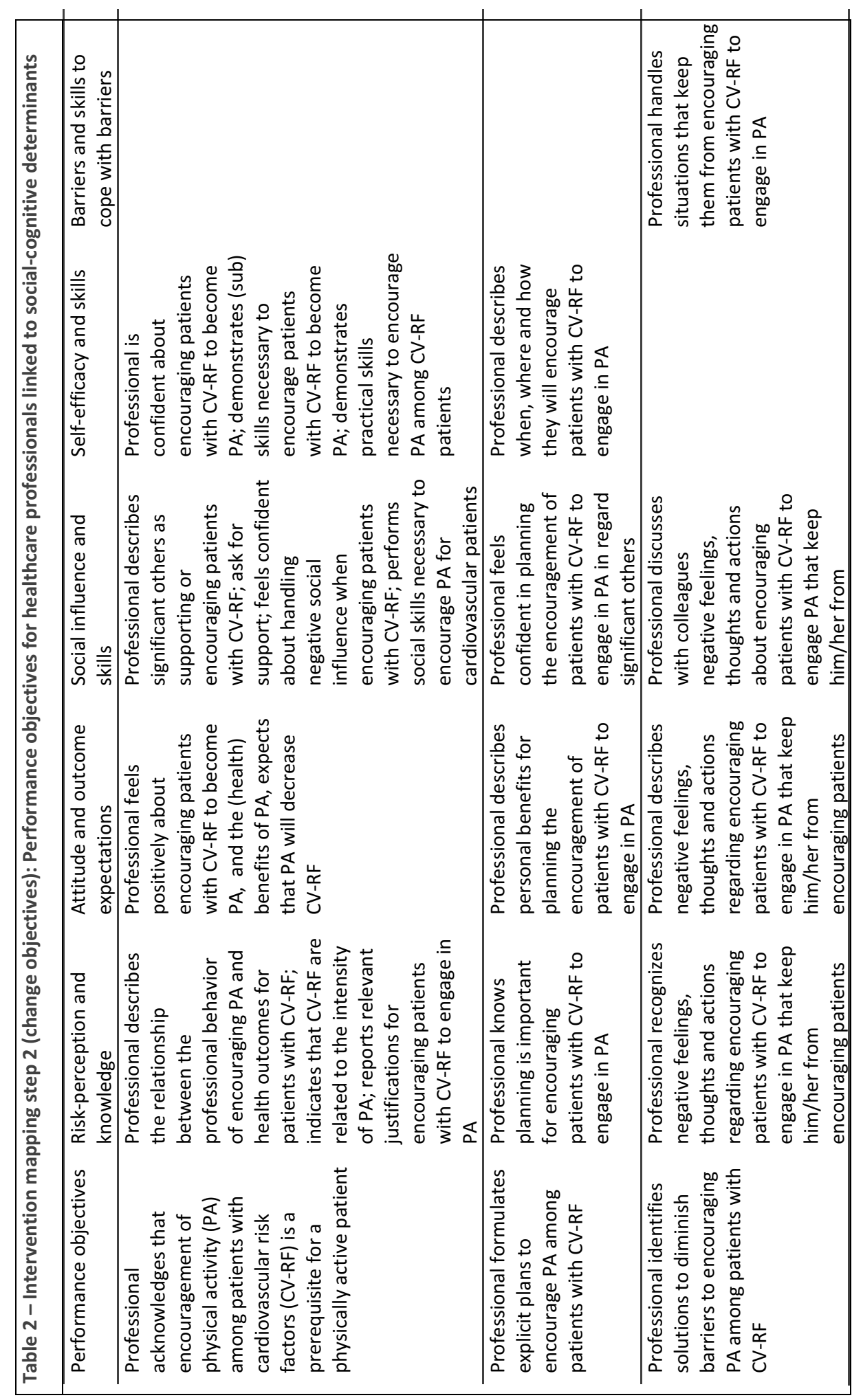




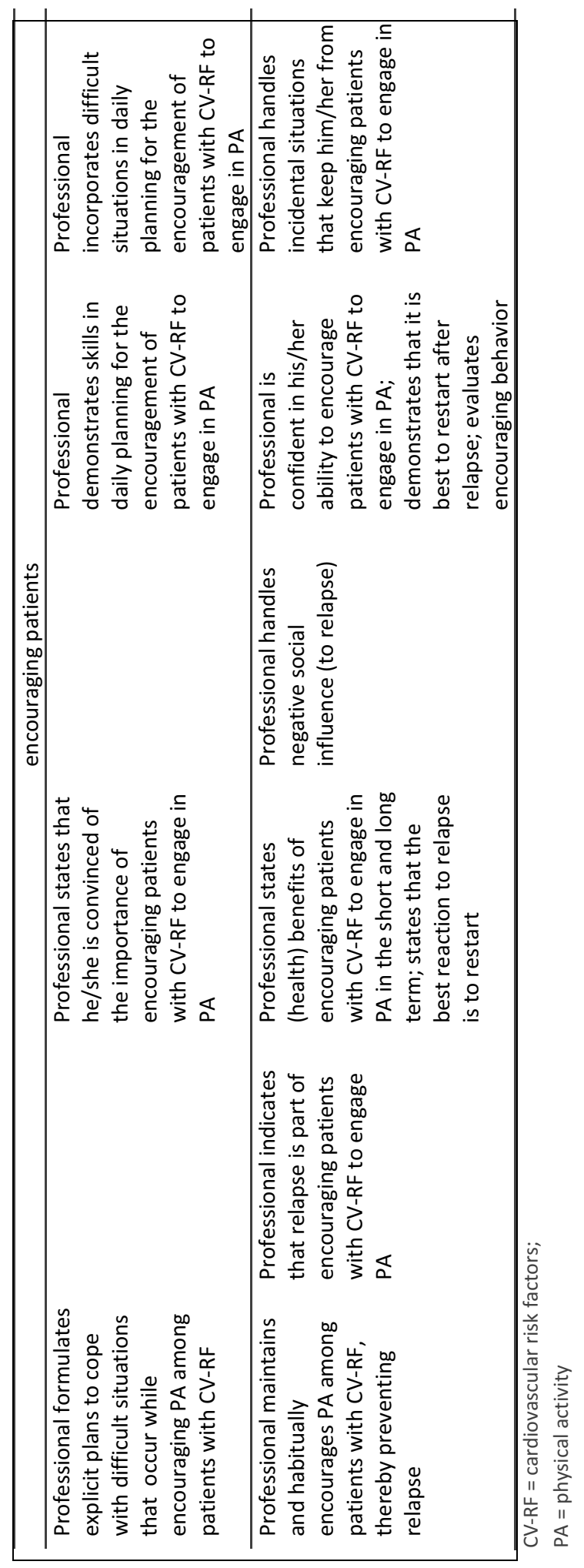




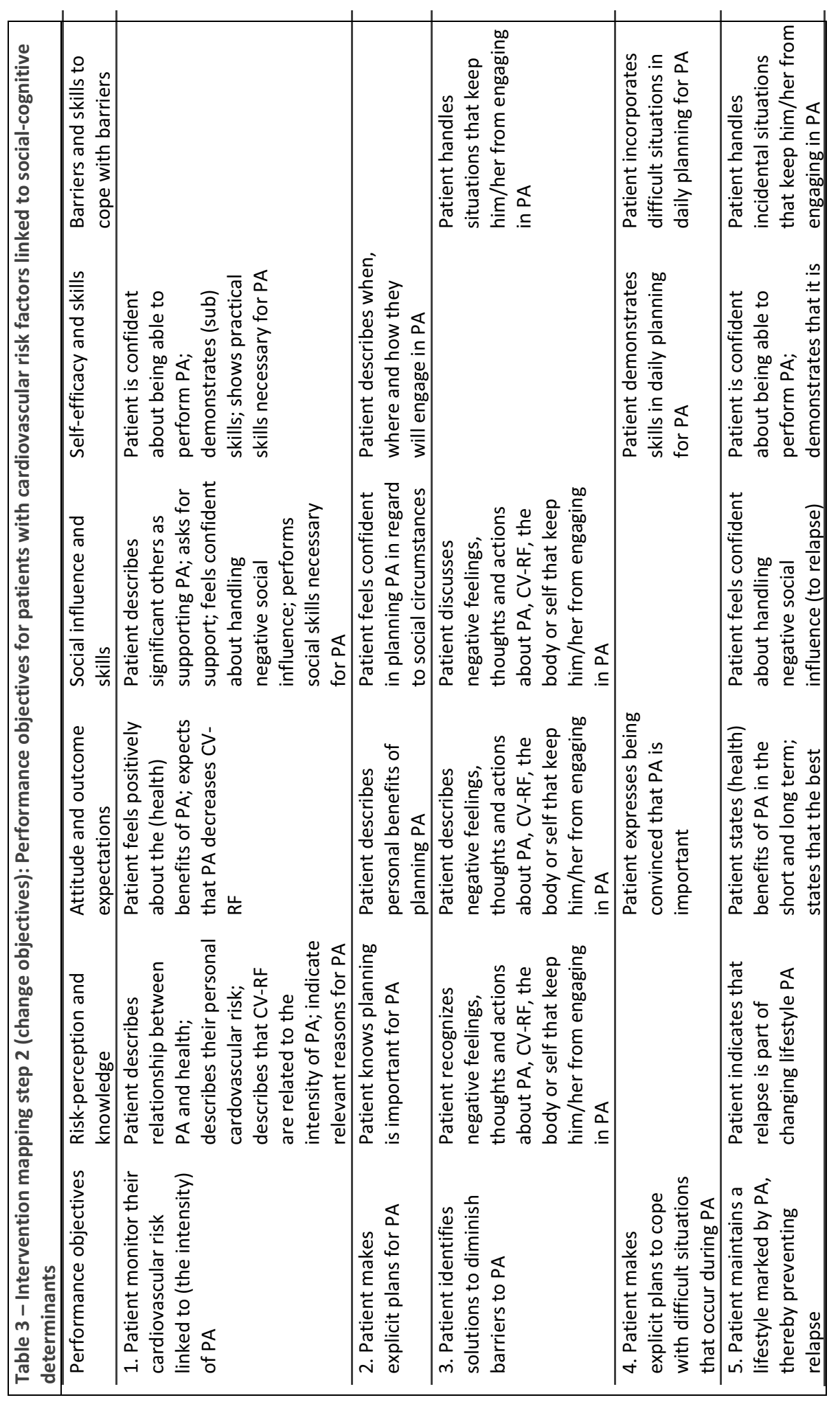




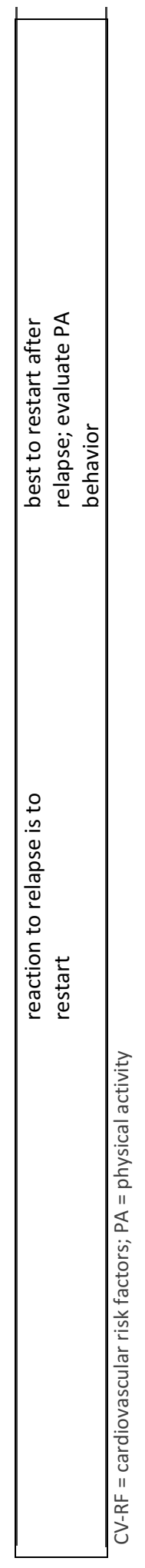


CHAPTER

General discussion 


\section{GENERAL DISCUSSION}

In this dissertation the following aims were objects of interest and study. The first aim of this dissertation was to explore the relative importance of characteristics of physical activity (i.e. intensity, duration and volume) in relation to cardiovascular risk factors, next to explore physical fitness in comparison with components of physical activity in controlling cardiovascular risk factors, and to elucidate the pathway of the relation between physical activity, physical fitness and cardiovascular risk score. The second aim was to explore the relative importance of social-cognitive variables and the intention to engage in physical activity, physical active behavior, the intensity of physical activity, and physical fitness (peak $\left.\mathrm{VO}_{2}\right)$; and to investigate the congruence between a high and low intention to engage in physical activity vs. having physical active or inactive behavior for people with cardiovascular risk factors. The third aim was to explore the relative importance of socialcognitive variables in relation to healthcare professionals' intention and behavior, and also the congruence between healthcare professionals' intention to encourage physical activity in cardiovascular risk patients and their self-reported behavior of encouraging patients. The fourth aim was to explore differences between the social-cognitive determinants measured at time 1 compared with the social-cognitive determinants at time 2 , and also the interdependence of social-cognitive determinants to predict intention and behavior. Finally, the fifth aim was to open up the black box of web-based intervention development and to provide support for future web-based intervention development.

\section{FINDINGS OF THE STUDIES}

This dissertation showed principal findings and implications, categorized in four sections. In the first section findings related to cardiovascular risk factors, physical fitness and physical activity are presented. In the second section findings related to (health) behavior of both people with cardiovascular risk factors and healthcare professionals encouraging those people to become physically active are displayed. In the third section results related to the stability over time and the interdependence of (predictors of) intention and behavior are displayed. Finally, in the fourth section findings related to the development and implementation of the web-based intervention are described.

Section 1. We aimed to investigate the relative importance of physical activity in relation to cardiovascular risk factors, of physical fitness in controlling cardiovascular risk factors, and to clarify the pathway between physical activity, physical fitness and cardiovascular risk score. Chapter 2 reported on how physical fitness and physical activity both influences cardiovascular risk factors. Findings of this study were that $18.6 \%$ of a Dutch working population had 3 or more cardiovascular risk factors with a prevalence of $22.5 \%$ in men and $10.6 \%$ in women. $\mathbf{7 8 . 7 \%}$ of the total population had one or more cardiovascular risk factor(s). Principal findings of the study were that, after adjustment for age and gender, physical activity (in intensity, duration, and volume) and physical fitness were each associated with reduced odds of the metabolic syndrome. Analyses further showed an inverse association between total cardiovascular risk score and physical activity intensity, 
the hours of physical activity performed at high intensity and physical fitness; but no relation with total hours or the hours of physical activity performed at low or moderate intensity. When we adjusted our analyses for physical fitness, the relations with the components of physical activity became non-significant. An additional finding of this study was that by using pathway analysis, we found that physical fitness mediated $78 \%$ of the effect of average physical activity intensity and $93 \%$ of the effect of the hours performed at high intensity on total cardiovascular risk score. We therefore postulated that physical activity interventions should aim at increasing cardiorespiratory fitness in order to influence the cardiovascular risk profile.

Section 2. We aimed to explore the relative importance of social-cognitive variables and the intention to engage in physical activity, physical active behavior, the intensity of physical activity, and physical fitness; and to investigate the congruence between a high and low intention to engage in physical activity vs. having physical active or inactive behavior for people with cardiovascular risk factors. We also aimed to explore the relative importance of social-cognitive variables in relation to healthcare professionals' intention and behavior, and also the congruence between healthcare professionals' intention to encourage physical activity in cardiovascular risk patients and their self-reported behavior of encouraging patients. Chapter 3 and 4 explored how the intention and behavior can be predicted by clarifying social-cognitive determinants.

For people with one or more cardiovascular risk factors, main findings of the study were that social-cognitive variables accounted for $39 \%$ of the variance in the intention to engage in physical activity for 60 minutes every day. Important correlates of intention to engage in physical activity were attitude, self-efficacy, descriptive norm and barriers. Socialcognitive variables accounted for $52 \%$ of the variance in physical active behavior (being physical active for 60 minutes every day). The intention to engage in physical activity and self-efficacy were, in turn, important correlates of physical active behavior.

In addition to the prediction of intention to engage in physical activity and physical active behavior, we explored the impact of the intensity of physical activity. A finding of this study was that the intensity of physical activity was only slightly significantly related to physical active behavior (6\%). Next to this, we investigated the relationship between physical fitness, the intensity of physical activity and social-cognitive variables. Physical fitness (23\%) was positively associated with physical active behavior, self-efficacy and the intensity of physical activity. Also we investigated the congruence between the intention to engage in physical activity and physical active behavior. For people with one or more cardiovascular risk factors, $39.9 \%$ had positive intentions to engage in physical activity and were also physically active, and $10.5 \%$ had low intentions but were physically active; $37.7 \%$ had low intentions and were physically inactive, and about $11.9 \%$ had high intentions but were physically inactive.

For healthcare professionals, principal findings of the study on social-cognitive determinants were that determinants accounted for $41 \%$ of the variance in healthcare professionals' intention to encourage physical activity among cardiovascular patients. 
Important correlates of intention were attitude, subjective norms and perceived behavioral control. With respect to the self-reported behavior of encouraging patients, social-cognitive determinants accounted for $29 \%$ of the variance. Intentions, habit, and barriers were significant correlates of professionals' behavior of encouraging patients to engage in physical activity. We explored the congruence between healthcare professionals' intention to encourage patients and the self-reported behavior of encouraging patients. An additional finding was that intention and behavior were congruent in $39.7 \%$ of the healthcare professionals. The intention to encourage and the corresponding behavior of encouraging was incongruent in $31.7 \%$ of the healthcare professionals.

Section 3. We aimed to explore the differences and interdependence between social-cognitive determinants measured at two time moments (T1 and T2). Chapter 5 reported on the stability of predictors of intention and behavior over time and their interdependence. Principal findings of this study were that predictors of intention and behavior showed to be relatively stable over time, except for the intention to encourage patients with cardiovascular risk factors to become physically active. So, while the behavior was stable, the intention related to the encouraging behavior was not. Principal findings of this study were also, when we constituted a test of the Theory of Planned Behavior, Social Cognitive Theory and other health behavior theories, first that (previous) behavior and attitude at T1 predicted intention T1. Intention assessed a condition that began after the occurrence of previous behavior and we showed that intention T1 is predicted by previous behavior (behavior at T1). Another important finding in this study was that (previous) behavior and barriers at T1 predicted behavior $\mathrm{T} 2$ to encourage patients with cardiovascular risk factors to become physically active. We showed that there is no path between the social-cognitive determinant intention T1 and behavior T2; also an indirect path via another social-cognitive variable could not be detected. The last principal finding from this study wass that behavior T2, intention $\mathrm{T} 1$ and attitudeT1 predicted intention $\mathrm{T} 2$.

Section 4. We aimed to open up the black box of web-based intervention development and to provide support for future web-based intervention development. Chapter 6 revealed the development of the PIB2-intervention. The systematic and planned development of the PIB2-intervention resulted in an internet-delivered behavior change intervention. The intervention was not developed as a substitute for face-to-face contact between professionals and patients, but as an application to complement and optimize health services. The intervention is based on the mutual exchange of information between the patient and their healthcare professional. Principal results are that we could state the (health) problem, could state the overall, performance and change objectives linked with important social-cognitive determinants, could link these with theory-based methods, and conditions and strategies to use these methods based on results of previous studies, could design the website consisting of five different modules, and at last could state the implementation and evaluation plan. The web-based intervention may improve socialcognitive determinants, intention, (health) behaviors and (health) maintenance for healthcare professionals as well as their patients, and long-term improvement in 
cardiovascular risk profiles. The main health outcome expected by the PIB2-intervention is that patients increase the (intensity) of their physical activity to impact cardiovascular risk factors.

\section{REFLECTIONS ON METHODOLOGY}

Several methodological issues of the studies will be presented. First the strengths and limitations of the studies on cardiovascular risk factors, physical fitness and physical activity (chapter 2 ) and on the social-cognitive predictors of intention and health behavior of people with cardiovascular risk factors, physical fitness and physical activity (chapter 3 ) will be presented. Strengths of these studies include its sample size, the inclusion of socialcognitive variables and the simultaneous assessment of physical fitness (measured as $\mathrm{VO}_{2}$ peak) and physical activity. Limitations are the cross-sectional design that limits causal inferences; therefore, longitudinal data are undoubtedly required. It is also possible that those participants who reported low levels of moderate and vigorous activity may have reduced their activity as a result of having more cardiovascular risk factors. Further, the selfadministered questionnaire to assess physical activity may under- or overestimate levels of physical activity intensity and hours, influenced by the perception of the subject. However, the reproducibility and validity of the questionnaire have been proved to be fairly reproducible and reasonably valid. Also, the self-administered questionnaire to assess social-cognitive determinants, intention and behaviour may under- or overestimate their intention and the behaviour of being physically active for 60 minutes a day. Finally, the study findings involved healthy middle-aged men and women of a cohort of police employees and they may therefore not be generalized to other groups.

Secondly, strengths and limitations of the studies on social-cognitive predictors of intention and health behavior of healthcare professionals (chapter 4) and on the stability and interdependence of social-cognitive predictors of intention and behavior (chapter 5) will be presented. Strengths include the longitudinal design so that we could differentiate between measured predictors, intention and behavior at time 1 and compare these with measures at time 2; this ruled out the possibility that measurements at T2 influenced measurements at T1. Strengths also include that all social-cognitive variables were measured on the same scale which increases the predictive validity of intention and behavior. The survey was specifically designed for the target population (nurses and physical therapists) with specific behavior (encouraging physical activity) for a specific group of patients (at risk for cardiovascular disease), and it seems plausible that the basics could be used for other research. The study's sample size is an additional strength, because it was sufficiently large for all t-tests, tests of path coefficients in structural equation modeling and multiple regressions to be statistically significant with $95 \%$ confidence intervals. Limitations of the study include a possible restricted sample because all of the professionals included in this study were recruited from the same institute and this may limit generalization of the outcomes. Future studies are needed for the research on the interdependence of socialcognitive determinants across different (sub) groups and different (health) behavior to 
further explore the influence of previous behavior, the undetected path from intention T1 to behavior T2 and the path from behavior T2 to intention T2. Probably it is desirable to better test the sequence of the intention and behavior related questions in the questionnaire. Another factor would probably be to add measurements of social-cognitive variables at time 3, possible only for (self-reported) behavior. Also the detection of additional, theoretical interesting, variables to incorporate in a path model is probably needed, to lower residual coefficients.

Finally the strengths and limitations of the study related to the development and implementation of the web-based PIB2-intervention are presented in this paragraph. Although we carefully developed and tested the web-based intervention in close cooperation with healthcare professionals and patients with cardiovascular risk factors, much of its success depends on its feasibility and usefulness in the healthcare professionals' daily practice, and on whether there is sufficient time and expertise to use the intervention during the consultation period. Although the professional behavior of healthcare professionals and the physical activity behavior of patients with cardiovascular risk factors is difficult to achieve, the Intervention Mapping protocol provided us with tools to handle this complicated, time-consuming process.

Overall. Limitations related to the transition of findings from the studies on cardiovascular risk factors, physical fitness and physical activity (chapter 2), and on socialcognitive predictors of intention and health behavior of people with cardiovascular risk factors, physical fitness and physical activity (chapter 3), to the study related to the development and implementation of the web-based PIB2-intervention (chapter 5) are presented. Though the patients' characteristics in our study (chapter 2 and 3) are very similar to those in other, international studies, it is possible that the patients encouraged to become physically active in in- or outpatient care by healthcare professionals in the PIB2intervention, could be different from the people with cardiovascular risk factors studied in the police cohort.

\section{IMPLICATIONS OF THE STUDIES}

What are the implications for people with one or more cardiovascular risk factors?

From the first study in this dissertation the implication is that the intensity of being physically active is especially important for the health of people with cardiovascular risk factors. When people can be encouraged to become physical active on an adequate level of intensity and cardiovascular fitness is improved, it impacts the number as well as the levels of cardiovascular risk factors. The implication is that physical activity should preferably increase health-related fitness $\left(\mathrm{VO}_{2}\right.$ peak) in order to maximally influence cardiovascular risk factors. It can also be concluded that the duration of physical activity is less important and that being physically active at a moderate and lower level of intensity does not contribute to a more positive cardiovascular profile. From this study, it can be concluded that physical activity and physical fitness are inversely associated with the clustering of cardiovascular risk factors. With regard to physical activity, it seems that intensity and more specifically higher intensity is the main characteristic of physical activity; (higher) intensity determines 
its effect on cardiovascular risk factors. However, compared to physical activity, physical fitness exerts greater effects on each individual cardiovascular risk factor and also on the combination of cardiovascular risk factors. The implication of this study is that in daily practice physical activity should preferably increase physical fitness in order to "maximize" its effect on the prevention of cardiovascular risk factors and which is most likely achieved by exercise at higher intensity.

From the second study of this dissertation the implication is that cardiovascular risk profiles can be optimized and an important association between physical fitness and socialcognitive variables could be demonstrated. Cardiovascular physical fitness (measured as $\mathrm{VO}_{2}$ peak) can be predicted by social cognitive determinants from the Theory of Planned Behavior, Social Cognitive Theory and other health behavior theories. Physical fitness can be predicted by physical active behavior as well as by self-efficacy and the intensity of physical activity, and the latter by physical active behavior. Social-cognitive determinants are consequently expected to be key objectives for cardiovascular morbidity-reducing interventions. The implication is that these three variables are therefore likely to be important objectives for interventions directed at deceasing cardiovascular morbidity and mortality. The implication is also that, in order to optimize the preventive effect of physical fitness, efforts to encourage behavior change by strengthening behavioral intention, strengthen self-efficacy and then later adding intensity to physical activity are worthwhile.

Physical active behavior can be predicted by intention, self-efficacy, descriptive norms and barriers. The implications of these results are that people with positive intentions and high levels of self-efficacy are more likely to engage in physical active behavior. They also suggest investing in efforts to develop the skills necessary to overcome barriers.

The intention to engage in physical activity can be predicted by attitude, selfefficacy, descriptive norms and barriers. Our findings revealed that people who are physically active have more positive attitudes, have higher self-efficacy and, are more likely to have positive intentions about physical activity. People with one or more cardiovascular risk factors and who are physically active, perceived more advantages than disadvantages to engage in regular physical activity. Interventions should therefore endeavor to highlight and clarify the advantages of engaging in physical activity while providing solutions for the disadvantages. Also, self-efficacy was associated with intention thus suggesting that, for people with cardiovascular risk factors and who are physically active, physical activity is perceived as relatively easy to adopt and that interventions should gradually add intensity to physical activity as physical activity levels improve. Interventions should also support the development of control over physical activity. Subjective norm appeared to be less important. The descriptive norm as the influence of significant others was found to impact the intention to engage in physical activity for 60 minutes every day. Interventions should therefore be directed at both learning skills necessary to handle negative social influence and strengthening positive social support. An important input for lifestyle changes for people with one or more cardiovascular risk factors was that for ca. $40 \%$ of the population 
the intention to engage in physical activity was in line with their actual physical active behavior. The probability of physical active behavior is higher when the intention to be physically active is high. The implication of this study is that the incongruence between intentions and behavior can obstruct behavior change and should be taken into consideration in intervention development

\section{What are the implications for healthcare professionals?}

The social-cognitive determinants of healthcare professionals are consequently expected to be key objectives for interventions directed at the reduction of cardiovascular risk. Implications of the study described in chapter 4, are that attention should be directed at increasing healthcare professionals' intention to encourage physical activity in cardiovascular patients and the corresponding behavior of encouraging patients. The socialcognitive determinants of behaviors (predictors were intentions, habit, and barriers) and intentions (predictors were attitudes, subjective norms and perceived behavioral control) may be changed in a more positive direction by planned interventions, deciding which determinants need to be changed, reinforced, and/or introduced.

The implications are that, in order to optimize healthcare professionals' behavior, strengthening both behavioral intention and habit next to reducing the barriers is worthwhile. The implication is also that professionals with more positive attitudes, more positive subjective norms, and higher perceived behavioral control were more likely to have positive intentions to encourage physical activity in cardiovascular patients. Professionals perceived more advantages than disadvantages encouraging cardiovascular patients to become physically active. Interventions should therefore endeavor to emphasize and explain the advantages of encouraging patients while providing explanations for the disadvantages. Healthcare professionals should get convinced that being physically active is important for patients with cardiovascular risk factors. Also, subjective norms were in our study found to be associated with intention, thus suggesting that professionals who felt that encouraging patients is expected and also done by other healthcare professionals had more positive intentions. Interventions should therefore be directed at seeking positive social support from other healthcare professionals, and learn to communicate the importance of encouraging patients to engage in physical activity with other healthcare professionals. In our study, perceived behavioral control was found to be associated with the intention to encourage physical activity in cardiovascular patients, thus suggesting that professionals who encourage patients felt competent to perform the behavior and that encouraging patients was perceived as relatively easy to do. Interventions should support the feeling of competence and teach skills necessary to handle difficult situations encouraging patients to become or stay physically active. The habit of encouraging patients can also contribute to the behavior of encouraging patients and should therefore be consolidated via environmental interventions that strengthen such habits. Our results suggest that to invest in the development of the skills necessary to overcome barriers, is worthwhile. The lack of congruence between high versus low intention and the behavior of encouraging patients 
versus not encouraging patients is an important input for interventions.

If professionals have a strong intention to encourage patients to become physically active, the encouraging behavior is more to be expected; if professionals lower their intention, the encouraging behavior is less to be expected. In chapter 5 we described that the intention planning the behavior decreases, and the corresponding encouraging behavior stayed unchanged. The implication of this study is that all social-cognitive predictors and behavior showed a marked stability, but intention did not.

In the same study, we explored the interdependence of social-cognitive determinants. An important implication of this study is that the previous behavior at T1 of healthcare professionals appeared to be as an important predictor of their behavior at T2. Healthcare professionals are experienced in encouraging patients with cardiovascular risk factors to become physically active to decrease cardiovascular risk, and professionals probably have learned during education and in practice how to encourage patients. The study results showed that the measure of the variable intention assessed a condition that began after the occurrence of behavior. We showed that intention T1 is predicted by (previous) behavior T1; and behavior T2 is also predicted by (previous) behavior T1.

The results also indicated that, different from our theoretical assumptions, there is no path between the social-cognitive determinant intention T1 and behavior T2; and that no indirect path via another social-cognitive variable could be detected. This lack of a relationship in the structural equation model between intention T1 and behavior T2 is thought provoking. Implications for changing the intention and behavior of healthcare professionals may be that the intention probably is less important when the behavior is stable (acquired through education and experience). An additional implication of this study is that there is a firm path from behavior $\mathrm{T} 2$ to the social-cognitive determinant intention $\mathrm{T} 2$.

The implications of these results are that previous behavior at T1 appeared to be an important predictor of behavior at T2. Implications for changing the intention and behavior of healthcare professionals may be that the (previous) behavior T1 should be determined and be taken into account for intervention design and implementation, because previous behavior can have a positive or negative influence on behavior at $\mathrm{T} 2$. The implication is that social-cognitive variables measured at $\mathrm{T} 1$ and $\mathrm{T} 2$ contribute to the prediction of behavior $\mathrm{T} 2$ and intention $\mathrm{T} 1$ for healthcare professionals encouraging patients with cardiovascular risk factors to become physically active.

What are the implications for in- and outpatient care?

From the fifth study of this dissertation it can be concluded that the Intervention Mapping Protocol provided a systematic method to develope the PIB2-intervention. The implication of this study is that the protocol guides and directs the development process to open up the black box of web-based intervention development and provides support for future web-based intervention development. The implication is that the application of evidence-based behavior change methods used in our intervention offers insight regarding 
how an intervention may change intention and (health) behavior. The implication of this study is also that it showed applicable to develop an intervention aimed at healthcare professionals and patients with cardiovascular risk factors, with different overall, performance and change objectives. We defined the desired behavior of healthcare professionals as encouraging behavior conducive to the health of patients. The application is directed as a tool for healthcare professionals to encourage patients with cardiovascular risk factors to become physically active while, at the same time, it sought to motivate healthcare professionals so that they could extend their professional behavior when communicating with patients. We defined the desired behavior as risk-reduction behavior for patients with cardiovascular risk factors, assuming that if an intervention reduces the prevalence of risk factors it can also reduce the prevalence of disease. The application is directed as a tool for patients so that they feel invited to participate in the communication process, while at the same time, it sought to motivate patients so that they can reduce their cardiovascular risk.

On the basis of the integration of the theory-based methods, conditions and strategies, we developed and tested the intervention, developed a plan for the intervention to facilitate sustained implementation, and in the anticipation on the evaluation, the intervention is implemented to determine if the intervention achieved the planned results. The intervention will be evaluated according to the criteria for reporting a randomized controlled trial.

Preliminary process evaluation of the PIB2-intervention showed that healthcare professionals working with the PIB2-intervention experienced difficulties to combine the intervention with usual professional activity. Healthcare professionals experienced difficulties regarding starting to use the intervention, and difficulties regarding continuing to use the intervention. The web-based PIB2-intervention was developed in a way that healthcare professionals only needed a short instruction, a demonstration-version of the website and a login code to start. Though a large group judged the PIB2-intervention as relatively easy, attractive, and suitable for the purpose of encouraging patients with cardiovascular risk factors to become physically active and matching with usual professional care, they hesitated to start the PIB2-intervention. Other important inhibiting factors were the amount of (administrative) tasks and the need to be productive, the influence of colleague's and private circumstances. Healthcare professionals were detached in asking patients to start, or started with a single patient and included the next patient after finishing the first. Extra meetings, telephone calls and systematic email contact on progress evaluation data were added to educate the healthcare professionals to work according the principles of the PIB2-intervention. The PIB2-intervention was scheduled for 6 month, because of slow inclusion rate another 6 months had to be added.

The PIB2-intervention will be evaluated and, when effectiveness is proven, has potential to be implemented in the usual care of healthcare professionals, encouraging people with cardiovascular risk factors to become physically active. Healthcare organizations should actively embrace evidence-based interventions directed at supplying 
there human resources with tools to encourage changes in lifestyle behavior and handle non-adherence to recommendations. Professional organizations can be a factor of importance in the implementation of evidence-based interventions. Implementation and adoption of interventions to handle adherence to recommendations, also depends on the education of healthcare professionals.

\section{RECOMMENDATIONS FOR FUTURE RESEARCH}

For the studies investigating cardiovascular risk factors, physical fitness and physical activity (chapter 2) and the social-cognitive predictors of intention and health behavior of people with cardiovascular risk factors, physical fitness and physical activity (chapter 3), a recommendation can be made. In the UP-LIFT study we studied the subjects in a crosssectional design and assessed social-cognitive predictors of intention and behavior, physical fitness and physical activity. Future research using a longitudinal design will reasonable improve the findings, when we could use social-cognitive predictors of intention and behavior, physical fitness and physical activity at time 1 and time 2 .

Also for the studies on social-cognitive predictors of intention and encouraging behavior of healthcare professionals (chapter 4), a recommendation can be made. Studies on the encouraging behavior of healthcare professionals are scarce; thát healthcare professionals are an important chain in the risk-reduction behavior of people with cardiovascular risk factors is known, but how we can motivate them to become and stay encouraging towards patients, should probably also be the focus of further research. The survey was specifically designed for the target population (nurses and physical therapists) with specific behavior (encouraging physical activity) for a specific group of patients (at risk for cardiovascular disease), it seems plausible that the basics could be used for other research.

The study investigating the stability and interdependence of social-cognitive predictors of intention and behavior (chapter 5), showed that future studies are needed to further explore the interdependence of social-cognitive determinants across different (sub) groups and different (health) behavior. These studies are needed to further explore the influence of previous behavior, the undetected path from intention T1 to behavior T2 and the path from behavior T2 to intention T2. Probably it is also desirable to better test the sequence of the intention and behavior related questions in the measurement instrument. Another factor would probably be to ad measurements of social-cognitive variables at time 3 , possible only for (self-reported) behavior. Also the detection of additional, theoretically interesting, variables to incorporate in a path model is probably needed, to lower residual coefficients.

Finally, recommendations can be made regarding the study that described the development and implementation of the web-based PIB2-intervention. In line with the recommendation described in section 3 , the process and effect evaluation has to show if the PIB2-intervention is sufficient to achieve the overall, performance and change objectives and if the application complements and optimizes health services. The process- 
and effect evaluation has to show if the intervention is sufficient to achieve changes in important social-cognitive determinants i.e. that the theory-based methods were effective; and also, if professionals' employed the five modules of the PIB2-intervention. The implementation of the evaluation plan will show if we were able to extent professional behavior of healthcare professionals conductive to the health of patients, and to extent the risk-reduction behavior for patients with cardiovascular risk factors i.e. to reduce the prevalence of risk factors and of cardiovascular disease in the population.

\section{CONCLUDING REMARKS}

Increasing cardiovascular, health-related fitness is a complex task, and difficult to achieve. Health-related fitness can be affected by lifestyle behavior and habitual physical activity. Working on this dissertation I thought it would be important to experience this myself, and like the patients with cardiovascular risk factors explained in the small group interviews, increasing physical activity to improve health-related physical fitness is a complex health behavior that is difficult to incorporate in daily living and difficult to maintain. But from the perspective of health, disease prevention and especially the prevention of cardiovascular and metabolic diseases, lifestyle behavior and physical activity, influencing fitness, can have a beneficial effect.

Behavior change is a complex process; it is the starting point for healthcare professionals when a patient with risk factors for cardiovascular disease visits them for the first time. We demonstrated that the previous behavior of healthcare professionals was an important predictor of their behavior at a later time. Previous behavior is behavior performed frequently and in the same professional context. Parallel we showed that the intention to encourage patients with cardiovascular risk factors to become physically active and their corresponding behavior is suboptimal. This probably implies that, though healthcare professionals encourage patients with cardiovascular risk factors to become physically active to decrease cardiovascular risk, intensifying their health education professional skills during their bachelor and/or during their working career, better prepares them to be motivated healthcare professionals who encourage patients (with risk factors for cardiovascular disease), (to become and stay physically active) and improve the health of their patients (and decrease cardiovascular risk). Healthcare professionals need adequate communication skills, competencies in understanding the complexity of health and lifestyle behavior and strategies to handle and change health and lifestyle behavior. Healthcare professionals and organizations should incorporate cardiovascular prevention following cardiovascular risk management guidelines and implement evidence-based health education interventions.

Scientific findings should be applied in clinical practice, not only to decrease the prevalence of cardiovascular diseases, not only to decrease the cardiovascular risk of an individual patient, but also to lower the burden of healthcare costs. Scientific findings should be applied in clinical practice to improve the health status of people with risk factors for cardiovascular disease and especially their quality of life. And additionally, if healthcare 
professionals extent their professional behavior and are intrinsically motivated and competent to perform health education in patient care, they are able to respond adequately on the difficulties of behavior change of patients and, understand why changing behavior and maintain healthy or healthier lifestyle behavior is so difficult for patients. If this computerized intervention tool would be proven effective for healthcare professionals, the approach to patients with cardiovascular risk factors would change drastically. 
I

References 
1. Graham I, Atar D, Borch-Johnsen K, Boysen G, Burell G, Cifkova R, Dallongeville J, De Backer G, Ebrahim S, Gjelsvik B, Herrmann-Lingen C, Hoes A, Humphries S, Knapton M, Perk J, Priori SG, Pyorala K, Reiner Z, Ruilope L, Sans-Menendez S, Scholte op Reimer W, Weissberg P, Wood D, Yarnell J, Zamorano JL, Walma E, Fitzgerald T, Cooney MT, Dudina A; European Society of Cardiology (ESC) Committee for Practice Guidelines (CPG). European guidelines on cardiovascular disease prevention in clinical practice. Fourth Joint Task Force of the European Society of Cardiology and other societies on cardiovascular disease prevention in clinical practice (constituted by representatives of nine societies and by invited experts). Eur J Cardiovasc Prev Rehabil. 2007: 2:S1-113

2. Yusuf S, Hawken S, Ounpuu S, Dans T, Avezum A, Lanas F, McQueen M, Budaj A, Pais $\mathrm{P}$, Varigos J, Lisheng L; INTERHEART Study Investigators. Effect of potentially modifiable risk factors associated with myocardial infarction in 52 countries (the INTERHEART study): case-control study. Lancet. 2004:(9438):937-52

3. Lakka H, Laaksonen DE, Lakka TA, Niskanen LK, Kumpusalo E, Tuomilehto J, et al. The metabolic syndrome and total and cardiovascular disease mortality in middle-aged men. JAMA 2002;288:2709-2716

4. Third Report of the National Cholesterol Education Program (NCEP): Expert Panel on Detection, evaluation and treatment of high blood cholesterol in adults (Adult Treatment Panel III). Final report. National Institutes of Health 2002

5. Grundy SM, Cleeman JL, Daniels SR, Donato KA, Eckel RH, Franklin BA, Gordon DJ, Krauss RM, Savage PJ, Smith SC, Spertus JA, Costa F: Diagnosis and management of the metabolic syndrome: An American Heart Association/National Heart and Lung, and Blood Institute Scientific Statement. Circulation 2005, 112:2735-52

6. Chobanian, AV, Bakris GL, Black HR, Crushman WC, Green LA, Izzo JL, Jonas DW, Materson BJ, Oparil S, Wright JT, Roccella EJ: the National High Blood Pressure Education Program Coordinating Committee: Seventh report of the joint national committee on prevention, detection, evaluation and treatment of high blood pressure. Hypertension 2003, 42:1206-52

7. Sofi F, Capalbo A, Cesari F, Abbate R, Gensini GF. Physical activity during leisure time and primary prevention of coronary heart disease: an updated meta-analysis of cohort studies. Eur J Cardiovasc Prev Rehabil 2008;15:247-57

8. Nocon M, Hiemann T, Müller-Riemenschneider F, Thalau F, Roll S, Willich SN. Association of physical activity with all-cause and cardiovascular mortality: a 
systematic review and meta-analysis. Eur J Cardiovasc Prev Rehabil 2008;15:239-46

9. Cornelissen VA, Fagard RH. Effects of endurance training on blood pressure, blood pressure-regulating mechanisms, and cardiovascular RF. Hypertension 2005; 46:667675

10. Halbert JA, Silagny CA, Finucane P, Withers RT, Hamdorf PA. Exercise training and blood lipids in hyperlipidemic and normolipidemic adults: a meta-analysis of randomized, controlled trials. Eur J Clin Nut 1999;53:514-22

11. Gill JM. Physical activity, cardiorespiratory fitness and insulin resistance: a short update. Curr Opin Lipidol 2007;18:47-52

12. Shaw K, Gennat H, O'Rourke P, Del Mar C. Exercise for overweight or obesity. Cochrane Database Syst Rev 2006;4:CD003817

13. Rennie KL, McCarthy N, Yazdgerdi S, Marmot M, Brunner E. Association of the metabolic syndrome with both vigorous and moderate physical activity. Int J Epidemiol 2003;32:600-6

14. Ekelund U, Brage S, Franks PW, Hennings S, Emms S, Wong MY, et al. Physical activity energy expenditure predicts changes in body composition in middle-aged healthy whites: effect modification by age. Am J Clin Nutr 2005;81:964-9

15. Petrella RJ, Lattanzio CN, Demeray A, Varello V, Blore R. Can adoption of regular exercise later in life prevent metabolic risk for cardiovascular disease? Diabetes Care 2005;28:694-701

16. Hu G, Lakka TA, Kipeläinen TO, Tuomilehto J. Epidemiological studies of exercise in diabetes prevention. Appl Physiol Nutr Metab 2007; 32:583-95

17. Lakka TA, Laaksonen DE, Lakka HM, Männikö N, Niskanen LK, Rauramaa R, et al. Sedentary lifestyle, poor cardiorespiratory fitness, and the metabolic syndrome. Med Sci Sports Exerc 2003; 35:1279-86

18. Lamonte MJ, Barlow CE, Jurca R, Kampert JB, Church TS, Blair SN. Cardiorespiratory fitness is inversely associated with the incidence of metabolic syndrome: a prospective study of men and women. Circulation 2005;112:505-12

19. Bouchard C, Shephard RJ. Physical activity, fitness and health the model and key concepts. In: Bouchard C, Stephard RJ, Stephens T. Physical activity, fitness and health. Champaign, IL: Human Kinetics 1994

20. Buckland GG, Salas-Salvado J, Serra-Majem L, Castell C, Cabré J, Salleras-Sanmarit L. Increase in metabolic syndrome as defined by ATPIII from 1992-1993 to 2002-2003 
in a Mediterranean population. Nutrition Reviews 2009; 67: S117-S125

21. Manson JE, Frank B, Rich-Edwards JW, Colditz GA, Stampfer MJ, Willett WC, et al. A prospective study of walking as compared with vigorous exercise in the prevention of coronary heart disease in women. New Eng J Med 1999; 341:650-658

22. Gami AS, Witt BJ, Howard DE, Erwin PJ, Gami LA, Somers VK, et al. Metabolic syndrome and risk of incident cardiovascular events and death: a systematic review and meta-analysis of longitudinal studies. J Am Coll Cardiol. 2007;49:403-14

23. Kok G, Schaalma H, Ruiter RA, van Empelen P, Brug J: Intervention mapping: protocol for applying health psychology theory to prevention programmes. J Health Psychol 2004, 9:85-98

24. Bartholomew LK, Parcel GS, Kok G, Gottlieb NH, Fernández ME. Planning health promotion programs: An Intervention Mapping approach. San Francisco, CA: Jossey; 2011

25. Schaalma H, Kok G. Decoding health education interventions: the times are achangin'. Psychol Health 2009 Jan;24(1):5-9

26. Williams PT. Physical fitness and activity as separate heart disease RF: a metaanalysis. Med Sci Sports Exerc 2001; 33: 754-761

27. Ajzen I: The theory of planned behavior. Organizational Behavior and human Decision Processes 1991, 50:179-211

28. Ajzen I: Perceived behavioral control, self-efficacy, locus of control, and the theory of planned behavior. J of Appl Social psychology 2002, 32:665-683

29. Godin G, Kok G: The theory of planned behavior: a review of its applications to health-related behaviors. Am J Health Promot 1996, 11:87-98

30. Armitage CJ, Conner M: Sociale Cognitive determinants of blood donation. J of Appl Social psychology 2001, 31:1-28

31. Sheeran P, Trafimow D, Armitage CJ: Predicting behaviour from perceived behavioural control: tests of the accuracy assumption of the theory of planned behaviour. Br J Soc Psychol 2003, 42:393-410

32. Rhodes RE, Courneya KS: Investigating multiple components of attitude, subjective norm, and perceived control: an examination of the theory of planned behaviour in the exercise domain. Br J Soc Psychol 2003, 42:129-46

33. Rodgers WM, Conner M, Murray TC: Distinguishing among perceived control, perceived difficulty, and self-efficacy as determinants of intentions and behaviours. 
Br J Soc Psychol 2008, 47:607-30

34. Bandura A: Self-efficacy: The exercise of control. New York: Freeman. 1997

35. Grimshaw JM, Thomas RE, MacLennan G, Fraser C, Ramsay CR, Vale L, Whitty P, Eccles MP, Matowe L, Shirran L, Wensing M, Dijkstra R, Donaldson C. Effectiveness and efficiency of guideline dissemination and implementation strategies. Health Technol Assess. 2004, 8:1-72

36. Hrisos S, Eccles MP, Francis JJ, Bosch M, Dijkstra R, Johnston M, Grol R, Kaner EF, Steen IN: Using psychological theory to understand the clinical management of type 2 diabetes in Primary Care: a comparison across two European countries. BMC Health Serv Res 2009. 9:140

37. Perkins MB, Jensen PS, Jaccard J, Gollwitzer P, Oettingen G, Pappadopulos E, Hoagwood KE: Applying theory-driven approaches to understanding and modifying clinicians' behavior: what do we know? Psychiatr Serv 2007. 58:342-8

38. Fishbein M, Ajzen I: Predicting and changing behavior : the reasoned action approach. New York : Psychology Press 2010

39. Bartholomew LK, Parcel GS, Kok G, Gottlieb NH: Planning Health Promotion Programs: An Intervention Mapping Approach. San Francisco, CA: Jossey-Bass; 2006

40. van Bokhoven MA, Kok G, van der Weijden T. Designing a quality improvement intervention: a systematic approach. Qual Saf Health Care 2003 Jun;12(3):215-20

41. Webb TL, Joseph J, Yardley L, Michie S. Using the internet to promote health behavior change: a systematic review and meta-analysis of the impact of theoretical basis, use of behavior change techniques, and mode of delivery on efficacy. J Med Internet Res. 2010 Feb 17;12(1):e4

42. Van Kesteren NM, Kok G, Hospers HJ, Schippers J, De Wildt W. Systematic development of a self-help and motivational enhancement intervention to promote sexual health in HIV-positive men who have sex with men. AIDS Patient Care STDS. 2006 Dec;20(12):858-75

43. Alewijnse D, Mesters IE, Metsemakers JF, van den Borne BH. Program development for promoting adherence during and after exercise therapy for urinary incontinence. Patient Educ Couns 2002 Oct -Nov;48(2):147-60

44. Heinen MM, Bartholomew LK, Wensing M, van de Kerkhof $P$, van Achterberg $T$. Supporting adherence and healthy lifestyles in leg ulcer patients: systematic development of the Lively Legs program for dermatology outpatient clinics. Patient Educ Couns. 2006 May;61(2):279-91 
45. Wolfers ME, van den Hoek C, Brug J, de Zwart O. Using Intervention Mapping to develop a programme to prevent sexually transmittable infections, including HIV, among heterosexual migrant men. BMC Public Health. 2007 Jul 5;7:141

46. Van Stralen MM, Kok G, de Vries H, Mudde AN, Bolman C, Lechner L. The Active plus protocol: systematic development of two theory- and evidence-based tailored physical activity interventions for the over-fifties.BMC Public Health. 2008 Dec 4;8:399

47. Portnoy DB, Scott-Sheldon LA, Johnson BT, Carey MP. Computer-delivered interventions for health promotion and behavioral risk reduction: a meta-analysis of 75 randomized controlled trials, 1988-2007. Prev Med. 2008 Jul;47(1):3-16.

48. Kroeze W, Werkman A, Brug J. A systematic review of randomized trials on the effectiveness of computer-tailored education on physical activity and dietary behaviors. Ann Behav Med. 2006 Jun;31(3):205-23

49. Noar SM, Benac CN, Harris MS. Does tailoring matter? Meta-analytic review of tailored print health behavior change interventions. Psychol Bull. 2007 Jul;133(4):673-93

50. Wantland DJ, Portillo CJ, Holzemer WL, Slaughter R, McGhee EM. The effectiveness of Web-based vs. non-Web-based interventions: a meta-analysis of behavioral change outcomes. J Med Internet Res. 2004 Nov 10;6(4):e40

51. Crutzen R, de Nooijer J, Brouwer W, Oenema A, Brug J, de Vries NK. A conceptual framework for understanding and improving adolescents' exposure to Internetdelivered interventions. Health Promot Int. 2009 Sep;24(3):277-84

52. Van den Berg MH, Schoones JW, Vliet Vlieland TP. Internet-based physical activity interventions: a systematic review of the literature. J Med Internet Res. 2007 Sep 30;9(3):e26

53. Kwaliteitsinstituut voor de Gezondheidszorg $\mathrm{CBO}$ en Nederlands Huisartsen Genootschap. Multidisciplinaire richtlijn Cardiovasculair risicomanagement. Utrecht: 2006

\section{CHAPTER 2 REFERENCES}

1. Sofi F, Capalbo A, Cesari F, Abbate R, Gensini GF. Physical activity during leisure time and primary prevention of coronary heart disease: an updated meta-analysis of cohort studies. Eur J Cardiovasc Prev Rehabil 2008;15:247-57

2. Nocon M, Hiemann $T$, Müller-Riemenschneider $F$, Thalau $F$, Roll $S$, Willich $S N$. Association of physical activity with all-cause and cardiovascular mortality: a systematic review and meta-analysis. Eur J Cardiovasc Prev Rehabil 2008;15:239-46

3. Myers J, Prakash M, Froelicher V, Do D, Partington S, Atwood JE. Exercise capacity and mortality among men referred for exercise testing. NEJM 2002; 14: 346: 793-801 
4. Cornelissen VA, Fagard RH. Effects of endurance training on blood pressure, blood pressure-regulating mechanisms, and cardiovascular RF. Hypertension 2005; 46:667675

5. Halbert JA, Silagny CA, Finucane P, Withers RT, Hamdorf PA. Exercise training and blood lipids in hyperlipidemic and normolipidemic adults: a meta-analysis of randomized, controlled trials. Eur J Clin Nut 1999;53:514-22

6. Gill JM. Physical activity, cardiorespiratory fitness and insulin resistance: a short update. Curr Opin Lipidol 2007;18:47-52

7. Shaw K, Gennat H, O'Rourke P, Del Mar C. Exercise for overweight or obesity. Cochrane Database Syst Rev 2006;4:CD003817

8. Third Report of the National Cholesterol Education Program (NCEP), Expert Panel on Detection, evaluation and treatment of high blood cholesterol in adults (Adult Treatment Panel III). Final report 2002, National Institutes of Health

9. Lakka H, Laaksonen DE, Lakka TA, Niskanen LK, Kumpusalo E, Tuomilehto J, et al. The metabolic syndrome and total and cardiovascular disease mortality in middle-aged men. JAMA 2002;288:2709-2716

10. Rennie KL, McCarthy N, Yazdgerdi S, Marmot M, Brunner E. Association of the metabolic syndrome with both vigorous and moderate physical activity. Int J Epidemiol 2003;32:600-6

11. Ekelund U, Brage S, Franks PW, Hennings S, Emms S, Wong MY, et al. Physical activity energy expenditure predicts changes in body composition in middle-aged healthy whites: effect modification by age. Am J Clin Nutr 2005;81:964-9

12. Petrella RJ, Lattanzio CN, Demeray A, Varello V, Blore R. Can adoption of regular exercise later in life prevent metabolic risk for cardiovascular disease? Diabetes Care 2005;28:694-701

13. Hu G, Lakka TA, Kipeläinen TO, Tuomilehto J. Epidemiological studies of exercise in diabetes prevention. Appl Physiol Nutr Metab 2007; 32:583-95

14. Lakka TA, Laaksonen DE, Lakka HM, Männikö N, Niskanen LK, Rauramaa R, et al. Sedentary lifestyle, poor cardiorespiratory fitness, and the metabolic syndrome. Med Sci Sports Exerc 2003; 35:1279-86

15. Lamonte MJ, Barlow CE, Jurca R, Kampert JB, Church TS, Blair SN. Cardiorespiratory fitness is inversely associated with the incidence of metabolic syndrome: a prospective study of men and women. Circulation 2005;112:505-12

16. Williams PT. Physical fitness and activity as separate heart disease RF: a meta- 
analysis. Med Sci Sports Exerc 2001; 33: 754-761

17. Vanhees L, Lefevre J, Phillippaerts R, Martens M, Huygens W, Troosters T, et al. How to assess physical activity? How to assess physical fitness? Eur J Cardiovasc Prev Rehabil 2005;12:102-14

18. Wendel-Vos GCW, Schuit AJ, Saris WHM, Kromhout D. Reproducibility and relative validity of the Short Questionnaire to Assess Health enhancing physical activity. J Clin Epid 2003;56:1163-69

19. Ainsworth BE, Haskell WL, Whitt MC, Irwin ML, Swartz AM, Strath SJ, et al. Compendium of physical activities: an update of activity codes and MET intensities. Med Sci Sports Exerc 2000;32: 498-504

20. Selvin S. Statistical Analysis for Epidemiologic Data. New York: Oxford University Press Inc; 1996

21. Buckland GG, Salas-Salvado J, Serra-Majem L, Castell C, Cabré J, Salleras-Sanmarit L. Increase in metabolic syndrome as defined by ATPIII from 1992-1993 to 2002-2003 in a Mediterranean population. Nutrition Reviews 2009; 67: S117-S125

22. Moebus S, Hanish JY, Aidelsburger P, Bramlage P, Wasem J, Jöckel KH. Impact of 4 different definitions used for the assessment of the prevalence of the metabolic syndrome in primary healthcare: the german metabolic and cardiovascular risk projects (GEMCAS). Cardiovasc Diabetology 2007; 6: 22-32

23. Gami AS, Witt BJ, Howard DE, Erwin PJ, Gami LA, Somers VK, et al. Metabolic syndrome and risk of incident cardiovascular events and death: a systematic review and meta-analysis of longitudinal studies. J Am Coll Cardiol. 2007;49:403-14

24. Carroll S, Cooke CB, Butterly RJ. Metabolic clustering, physical activity and fitness in nonsmoking middle-aged men. Med Sci Sports Exerc 2000; 32:2079-2086

25. Manson JE, Frank B, Rich-Edwards JW, Colditz GA, Stampfer MJ, Willett WC, et al. A prospective study of walking as compared with vigorous exercise in the prevention of coronary heart disease in women. New Eng J Med 1999; 341:650-658

26. Orakzai RH, Orakzai SH, Nasir K, Roguin A, Pimentel I, Carvalho JAM, et al. Association of increased cardiorespiratory fitness with low risk for clustering of metabolic syndrome components in asymptomatic men. Archives of Medical Research 2006; 37:522-528

27. Blaha MJ, Bansal S, Rouf R, Golden SH, Blumenthal RS, Defilippis AP. A practical ABCDE approach to the metabolic syndrome. Mayo Clin Proc 2008; 83:932-943

28. Tanasescu M, Leitzmann MF, Rimm EB, Willett WC, Stampfer MJ, Hu FB. Exercise 
type and intensity in relation to coronary heart disease in men. JAMA 2002; 288:1994-2000

29. Swain PD, Franklin BA. Comparison of cardioprotective benefits of vigorous versus moderate intensity aerobic exercise. Am J Cardiol 2006; 97:141-147

30. Laukkanen JA, Kurl S, Salonen R, Rauramaa R, Salonen JT. The predictive value of cardiorespiratory fitness for cardiovascular events in men with various risk profiles: a prospective population-based cohort study. Eur Heart J 2004; 25:1428-1437

31. Durstine LJ, Grandjeann PW, Davis PG, Ferguson MA, Alderson NL, DuBose KD. Blood lipid and lipoprotein adaptations to exercise: a quantitative analysis. Sports Med 2001; 31:1033-1062

32. Dvorak RV, Tchernof A, Starling RD, Ades PA, DiPietro L, Poehlman ET. Respiratory fitness, freel living physical activity and cardiovascular disease risk in older individuals: a double labeled water study. J Clin Endocrinol Metab 2000; 85:957-963

33. Talbot LA, Morrell CH, Metter EJ, Fleg JL. Comparison of cardiorespiratory fitness versus leisure time physical activity as predictors of coronary events in men aged < or $=65$ years and $>65$ years. Am J Cardiol 2002; 89: 1187-1192

\section{CHAPTER 3 REFERENCES}

1. Grundy SM, Cleeman JL, Daniels SR, Donato KA, Eckel RH, Franklin BA, Gordon DJ, Krauss RM, Savage PJ, Smith SC, Spertus JA, Costa F: Diagnosis and management of the metabolic syndrome: An American Heart Association/National Heart and Lung, and Blood Institute Scientific Statement. Circulation 2005, 112:2735-52

2. Eckel RH, Grundy SM, Zimmet PZ: The metabolic syndrome. Lancet 2005, 365:141528

3. Chobanian, AV, Bakris GL, Black HR, Crushman WC, Green LA, Izzo JL, Jonas DW, Materson BJ, Oparil S, Wright JT, Roccella EJ: the National High Blood Pressure Education Program Coordinating Committee: Seventh report of the joint national committee on prevention, detection, evaluation and treatment of high blood pressure. Hypertension 2003, 42:1206-52

4. Third Report of the National Cholesterol Education Program (NCEP): Expert Panel on Detection, evaluation and treatment of high blood cholesterol in adults (Adult Treatment Panel III). Final report. National Institutes of Health 2002

5. Lakka H, Laaksonen DE, Lakka TA, Niskanen LK, Kumpusalo E, Tuomilehto J, Salonen $\mathrm{T}$ : The metabolic syndrome and total and cardiovascular disease mortality in middleaged men. JAMA 2002, 288:2709-16 
6. Berlin JA and Colditz GA: A meta-analysis of physical activity in the prevention of coronary heart disease. Am J Epidemiol 1990, 132:612-628

7. Manson JE, Greenland $P$, LaCroix AZ, Stefanick ML, Mouton CP, Oberman A, Perii MG, Sheps DS, Pettinger MB, Siscovick DS: Walking compared with vigorous exercise for the prevention of cardiovascular events in woman. NEJM 2002, 347:716-17

8. Sofi F, Capalbo A, Cesari F, Abbate R, Gensini GF: Physical activity during leisure time and primary prevention of coronary heart disease: an updated meta-analysis of cohort studies. Eur J Cardiovasc Prev Rehabil 2008, 15:247-57

9. Nocon M, Hiemann T, Müller-Riemenschneider F, Thalau F, Roll S, Willich SN: Association of physical activity with all-cause and cardiovascular mortality: a systematic review and meta-analysis. Eur J Cardiovasc Prev Rehabil 2008, 15:239-46

10. Myers J, Prakash M, Froelicher V, Do D, Partington S, Atwood JE: Exercise Capacity and Mortality among Men Referred for Exercise Testing. N Eng J Med 2002, 346(11):793-801

11. Church TS, Earnest CP, Skinner JS, Blair SN: Effects of different doses of physical activity on cardiorespiratory fitness among sedentary, overweight or obese postmenopausal women with elevated blood pressure: a randomized controlled trial. JAMA 2007, 297(19):2081-91

12. Löllgen $H$, Böckenhoff $A$, Knapp G: Physical activity and all-cause mortality: an updated meta-analysis with different intensity categories. Int J Sports Med 2009, 30:213-24

13. Blair SN, Cheng $\mathrm{Y}$, Holder JS: Is physical activity or physical fitness more important in defining health benefits? Med Sci Sports Exerc 2001, 33(6 Suppl):S379-99

14. Vanhees L, Lefevre J, Phillippaerts R, Martens M, Huygens W, Troosters T, Beunen G: How to assess physical activity? How to assess physical fitness? Eur J Cardiovasc Prev Rehabil 2005, 12:102-14

15. Cornelissen VA, Fagard RH: Effects of endurance training on blood pressure, blood pressure-regulating mechanisms, and cardiovascular risk factors. Hypertension 2005, 46:667-75

16. Halbert JA, Silagny CA, Finucane P, Withers RT, Hamdorf PA: Exercise training and blood lipids in hyperlipidemic and normolipidemic adults: a meta-analysis of randomized, controlled trials. Eur J Clin Nut 1999, 53:514-22

17. Gill JM: Physical activity, cardiorespiratory fitness and insulin resistance: a short update. Curr Opin Lipidol 2007, 18:47-52 
18. Shaw K, Gennat H, O'Rourke P, Del Mar C: Exercise for overweight or obesity. Cochrane Database Syst Rev 2006, 4:CD003817

19. Rennie KL, McCarthy N, Yazdgerdi S, Marmot M, Brunner E: Association of the metabolic syndrome with both vigorous and moderate physical activity. Int J Epidemiol 2003, 32:600-6

20. Ekelund U, Brage S, Franks PW, Hennings S, Emms S, Wareham NJ: Physical activity energy expenditure predicts changes in body composition in middle-aged healthy whites: effect modification by age. Am J Clin Nutr 2005, 81:964-9

21. Petrella RJ, Lattanzio CN, Demeray A, Varello V, Blore R: Can adoption of regular exercise later in life prevent metabolic risk for cardiovascular disease? Diabetes Care 2005, 28:694-701

22. Hu G, Lakka TA, Kippeläinen TO, Tuomilehto J: Epidemiological studies of exercise in diabetes prevention. Appl Physiol Nutr Metab 2007, 32:583-95

23. Lakka TA, Laaksonen DE, Lakka HM, Männikö N, Niskanen LK, Rauramaa R, Salonen JT: Sedentary lifestyle, poor cardiorespiratory fitness, and the metabolic syndrome. Med Sci Sports Exerc 2003, 35:1279-86

24. Lamonte MJ, Barlow CE, Jurca R, Kampert JB, Church TS, Blair SN: Cardiorespiratory fitness is inversely associated with the incidence of metabolic syndrome: a prospective study of men and women. Circulation 2005, 112:505-12

25. Sassen B, Cornelissen V, Kiers H, Wittink H, Kok GJ, Vanhees L: Physial fitness matters more than physical activity in controlling cardiovascular disease risk factors. Eur J Cardiovasc Prev Rehabil 2009, 16:667-683

26. Bartholomew LK, Parcel GS, Kok G, Gottlieb NH: Planning Health Promotion Programs: An Intervention Mapping Approach. San Francisco, CA: Jossey-Bass; 2006

27. Kok G, Schaalma H, Ruiter RA, van Empelen P, Brug J: Intervention mapping: protocol for applying health psychology theory to prevention programmes. J Health Psychol 2004, 9:85-98

28. Ajzen I: The theory of planned behavior. Organizational Behavior and human Decision Processes 1991, 50:179-211

29. Ajzen I: Perceived behavioral control, self-efficacy, locus of control, and the theory of planned behavior. J of Appl Social psychology 2002, 32:665-683

30. Godin G, Kok G: The theory of planned behavior: a review of its applications to health-related behaviors. Am J Health Promot 1996, 11:87-98 
31. Armitage CJ, Conner M: Sociale Cognitive determinants of blood donation. J of Appl Social psychology 2001, 31:1-28

32. Sheeran P, Trafimow D, Armitage CJ: Predicting behaviour from perceived behavioural control: tests of the accuracy assumption of the theory of planned behaviour. Br J Soc Psychol 2003, 42:393-410

33. Rhodes RE, Courneya KS: Investigating multiple components of attitude, subjective norm, and perceived control: an examination of the theory of planned behaviour in the exercise domain. Br J Soc Psychol 2003, 42:129-46

34. Rhodes RE, Courneya KS, Blanchard CM, Plotnikoff RC: Prediction of leisure-time walking: an integration of social cognitive, perceived environmental, and personality factors. Int J Behav Nutr Phys Act 2007, 31:4:51

35. Rodgers WM, Conner M, Murray TC: Distinguishing among perceived control, perceived difficulty, and self-efficacy as determinants of intentions and behaviours. Br J Soc Psychol 2008, 47:607-30

36. Bandura A: Self-efficacy: The exercise of control. New York: Freeman. 1997

37. Bandura A: Social foundations of thought and action: A social cognitive theory. New York: Prentice Hall. 1987

38. Wendel-Vos GCW, Schuit AJ, Saris WHM, Kromhout D: Reproducibility and relative validity of the Short Questionnaire to Assess Health enhancing physical activity. J Clin Epid 2003, 56:1163-69

39. Ainsworth BE, Haskell WL, Whitt MC, Irwin ML, Swartz AM, Strath SJ: Compendium of physical activities, an update of activity codes and MET intensities. Medicine \& Science in Sports \& Exercise 2000, 9:S498-S516

40. Boudreau F, Godin G: Using the Theory of Planned Behaviour to predict exercise intention in obese adults. Can J Nurs Res 2007, 39:112-25

41. Amireault S, Godin G, Vohl MC, Pérusse L: Moderators of the intention-behaviour and perceived behavioural control-behaviour relationships for leisure-time physical activity. Int J Behav Nutr Phys Act 2008, 1:5-7

42. Armitage CJ, Conner M: Efficacy of the Theory of Planned Behaviour: a meta-analytic review. Br J Soc Psychol 2001, 40:471-99

43. Webb TL, Sheeran P: Does changing behavioral intentions engender behavior change? A meta-analysis of the experimental evidence. Psychol Bull 2006, 132:24968 
44. Fishbein M, Ajzen I: Predicting and changing behavior : the reasoned action approach. New York : Psychology Press 2010

\section{CHAPTER 4 REFERENCES}

1. Eccles MP, Hrisos S, Francis J, Kaner EF, Dickinson HO, Beyer F, Johnston M: Do selfreported intentions predict clinicians' behaviour: a systematic review. Implement Sci 2006, 21:1-28

2. Foley KA, Vasey J, Alexander CM, Markson LE: Development and validation of the hyperlipidemia: attitudes and beliefs in treatment (HABIT) survey for physicians. J Gen Intern Med 2003.18:984-90

3. Grimshaw JM, Eccles MP, Walker AE, Thomas RE: Changing physicians' behavior: what works and thoughts on getting more things to work. J Contin Educ Health Prof 2002, 22:237-43

4. Grimshaw JM, Thomas RE, MacLennan G, Fraser C, Ramsay CR, Vale L, Whitty P, Eccles MP, Matowe L, Shirran L, Wensing M, Dijkstra R, Donaldson C. Effectiveness and efficiency of guideline dissemination and implementation strategies. Health Technol Assess. 2004, 8:1-72

5. Hrisos S, Eccles MP, Francis JJ, Bosch M, Dijkstra R, Johnston M, Grol R, Kaner EF, Steen IN: Using psychological theory to understand the clinical management of type 2 diabetes in Primary Care: a comparison across two European countries. BMC Health Serv Res 2009. 9:140

6. Yeazel MW, Lindstrom Bremer KM, Center BA: A validated tool for gaining insight into clinicians' preventive medicine behaviors and beliefs: the preventive medicine attitudes and activities questionnaire (PMAAQ). Prev Med 2006.43:86-91

7. Perkins MB, Jensen PS, Jaccard J, Gollwitzer P, Oettingen G, Pappadopulos E, Hoagwood KE: Applying theory-driven approaches to understanding and modifying clinicians' behavior: what do we know? Psychiatr Serv 2007. 58:342-8

8. Third Report of the National Cholesterol Education Program (NCEP): Expert Panel on Detection, evaluation and treatment of high blood cholesterol in adults (Adult Treatment Panel III). Final report. National Institutes of Health 2002

9. Grundy SM, Cleeman JL, Daniels SR, Donato KA, Eckel RH, Franklin BA, et al: Diagnosis and management of the metabolic syndrome: An American Heart Association/National Heart and Lung, and Blood Institute Scientific Statement. Circulation 2005, 112:2735-2752

10. Chobanian, AV, Bakris GL, Black HR, Crushman WC, Green LA, Izzo JL, et al. and the 
National High Blood Pressure Education Program Coordinating Committee: Hypertension 2003, 42:206-1252

11. Lakka H, Laaksonen DE, Lakka TA, Niskanen LK, Kumpusalo E, Tuomilehto J, et al: The metabolic syndrome and total and cardiovascular disease mortality in middle-aged men. JAMA 2002, 288:2709-2716

12. Eckel RH, Grundy SM, Zimmet PZ: The metabolic syndrome. Lancet 2005, 365:141528

13. Berlin JA and Colditz GA: A meta-analysis of physical activity in the prevention of coronary heart disease. Am J Epidemiol 1990, 132:612-628

14. Manson JE, Greenland P, LaCroix AZ, Stefanick ML, Mouton CP, Oberman A, Perii MG, Sheps DS, Pettinger MB, Siscovick DS: Walking compared with vigorous exercise for the prevention of cardiovascular events in woman. NEJM 2002, 347:716-7

15. Sofi F, Capalbo A, Cesari F, Abbate R, Gensini GF: Physical activity during leisure time and primary prevention of coronary heart disease: an updated meta-analysis of cohort studies. Eur J Cardiovasc Prev Rehabil 2008, 15:247-57

16. Nocon M, Hiemann T, Müller-Riemenschneider F, Thalau F, Roll S, Willich SN: Association of physical activity with all-cause and cardiovascular mortality: a systematic review and meta-analysis. Eur J Cardiovasc Prev Rehabil 2008, 15:239-46

17. Myers J, Prakash M, Froelicher V, Do D, Partington S, Atwood JE: Exercise Capacity and Mortality among Men Referred for Exercise Testing. N Eng J Med 2002, 346(11):793-801

18. Cornelissen VA, Fagard RH: Effects of endurance training on blood pressure, blood pressure-regulating mechanisms, and cardiovascular risk factors. Hypertension 2005, 46:667-675

19. Halbert JA, Silagny CA, Finucane P, Withers RT, Hamdorf PA: Exercise training and blood lipids in hyperlipidemic and normolipidemic adults: a meta-analysis of randomized, controlled trials. Eur J Clin Nut 1999, 53:514-22

20. Gill JM: Physical activity, cardiorespiratory fitness and insulin resistance: a short update. Curr Opin Lipidol 2007, 18:47-52.

21. Shaw K, Gennat H, O'Rourke P, Del Mar C: Exercise for overweight or obesity. Cochrane Database Syst Rev 2006, 4:CD003817

22. Rennie KL, McCarthy N, Yazdgerdi S, Marmot M, Brunner E: Association of the metabolic syndrome with both vigorous and moderate physical activity. Int J 
Epidemiol 2003, 32:600-6

23. Ekelund U, Brage S, Franks PW, Hennings S, Emms S, Wong MY, et al: Physical activity energy expenditure predicts changes in body composition in middle-aged healthy whites: effect modification by age. Am J Clin Nutr 2005, 81:964-9

24. Petrella RJ, Lattanzio CN, Demeray A, Varello V, Blore R: Can adoption of regular exercise later in life prevent metabolic risk for cardiovascular disease? Diabetes Care 2005, 28:694-701

25. Hu G, Lakka TA, Kippeläinen TO, Tuomilehto J: Epidemiological studies of exercise in diabetes prevention. Appl Physiol Nutr Metab 2007, 32:583-95

26. Lakka TA, Laaksonen DE, Lakka HM, Männikö N, Niskanen LK, Rauramaa R, et al: Sedentary lifestyle, poor cardiorespiratory fitness, and the metabolic syndrome. Med Sci Sports Exerc 2003, 35:1279-86

27. Lamonte MJ, Barlow CE, Jurca R, Kampert JB, Church TS, Blair SN: Cardiorespiratory fitness is inversely associated with the incidence of metabolic syndrome: a prospective study of men and women. Circulation 2005, 112:505-12

28. Sassen B, Cornelissen V, Kiers H, Wittink H, Kok GJ, Vanhees L: Physial fitness matters more than physical activity in controlling cardiovascular disease risk factors. Eur J Cardiovasc Prev Rehabil 2009, 16:667-683

29. Godin G, Kok G: The theory of planned behavior: a review of its applications to health-related behaviors. Am J Health Promot 1996, 11:87-98

30. Godin G, Bélanger-Gravel A, Eccles M, Grimshaw J: Healthcare professionals' intentions and behaviours: A systematic review of studies based on social cognitive theories. Implement Sci 2008, 16:3-36

31. Ajzen I: The theory of planned behavior. Organizational Behavior and human Decision Processes 1991, 50:179-211

32. Ajzen I: Perceived behavioral control, self-efficacy, locus of control, and the theory of planned behavior. J of Appl Social psychology 2002, 32:665-683

33. Fishbein $M$, Ajzen I: Predicting and changing behavior : the reasoned action approach. New York : Psychology Press 2010

34. Armitage CJ, Conner M: Social Cognitive determinants of blood donation. J of Appl Social psychology 2001, 31:1-28

35. Sheeran P, Trafimow D, Armitage CJ: Predicting behaviour from perceived behavioural control: tests of the accuracy assumption of the theory of planned 
behaviour. Br J Soc Psychol 2003, 42:393-410

36. Rhodes RE, Courneya KS: Investigating multiple components of attitude, subjective norm, and perceived control: an examination of the theory of planned behaviour in the exercise domain. Br J Soc Psychol 2003, 42:129-46

37. Rodgers WM, Conner M, Murray TC: Distinguishing among perceived control, perceived difficulty, and self-efficacy as determinants of intentions and behaviours. Br J Soc Psychol 2008, 47:607-30

38. Bandura A: Self-efficacy: The exercise of control. New York: Freeman. 1997

39. Bandura A: Social foundations of thought and action: A social cognitive theory. New York: Prentice Hall. 1987

40. Verplanken B, Wood W: Interventions to break and create consumer habits. J Public Policy Mark 2006, 25:90-103

41. Kok G, Schaalma H, Ruiter RA, van Empelen P, Brug J: Intervention mapping: protocol for applying health psychology theory to prevention programmes. J Health Psychol 2004, 9:85-98

42. Webb TL, Sheeran P: Does changing behavioral intentions engender behavior change? A meta-analysis of the experimental evidence. Psychol Bull 2006, 132:24968

43. Rhodes RE, Courneya KS, Blanchard CM, Plotnikoff RC: Prediction of leisure-time walking: an integration of social cognitive, perceived environmental, and personality factors. Int J Behav Nutr Phys Act 2007, 31:4:51

44. Godin G, Conner M: Intention-behavior relationship based on epidemiologic indices: an application to physical activity. Am J Health Promot 2008, 22:180-2

45. Hagger MS, Chatzisarantis N, Biddle SJH: The influence of self-efficacy and past behavior on the physical activity intentions of young people. J Sports Sci 2001, 19:711-23

46. Boudreau F, Godin G: Using the Theory of Planned Behaviour to predict exercise intention in obese adults. Can J Nurs Res 2007, 39:112-25

47. Brug J, de Vet E, de Nooijer J, Verplanken B: Predicting fruit consumption: cognitions, intention, and habits. J Nutr Educ Behav 2006. 38:73-81

48. Bartholomew LK, Parcel GS, Kok G, Gottlieb NH: Planning Health Promotion Programs: An Intervention Mapping Approach. San Francisco, CA: Jossey-Bass; 2006 
1. Ajzen I: The theory of planned behavior. Organizational Behavior and human Decision Processes 1991, 50:179-211

2. Ajzen I: Perceived behavioral control, self-efficacy, locus of control, and the theory of planned behavior. J of Appl Social psychology 2002, 32:665-683

3. Fishbein $M$, Ajzen I: Predicting and changing behavior : the reasoned action approach. New York : Psychology Press 2010

4. Godin G, Kok G: The theory of planned behavior: a review of its applications to health-related behaviors. Am J Health Promot 1996, 11:87-98

5. Bandura A: Self-efficacy: The exercise of control. New York: Freeman. 1997

6. Conner M, Armitage CJ: Extending the Theory of Planned Behavior: A review and avenues for further research. J Appl Soc Psychol 1998, 28:1429-1464

7. Armitage CJ, Conner M. Efficacy of the Theory of Planned Behaviour: a meta-analytic review. Br J Soc Psychol. 2001 Dec;40(Pt 4):471-99

8. Armitage $\mathrm{CJ}$, Conner M: Social Cognitive determinants of blood donation. J of Appl Social psychology 2001, 31:1-28

9. Rodgers WM, Conner M, Murray TC: Distinguishing among perceived control, perceived difficulty, and self-efficacy as determinants of intentions and behaviours. Br J Soc Psychol 2008, 47:607-30

10. Godin G, Conner M: Intention-behavior relationship based on epidemiologic indices: an application to physical activity. Am J Health Promot 2008, 22:180-2

11. Sheeran P, Trafimow D, Armitage CJ: Predicting behaviour from perceived behavioural control: tests of the accuracy assumption of the theory of planned behaviour. Br J Soc Psychol 2003, 42:393-410

12. Godin G, Bélanger-Gravel A, Eccles M, Grimshaw J: Healthcare professionals' intentions and behaviours: A systematic review of studies based on social cognitive theories. Implement Sci 2008, 16:3-36

13. Rhodes RE, Courneya KS: Investigating multiple components of attitude, subjective norm, and perceived control: an examination of the theory of planned behaviour in the exercise domain. Br J Soc Psychol 2003, 42:129-46

14. Hagger MS, Chatzisarantis N, Biddle SJH: The influence of self-efficacy and past behavior on the physical activity intentions of young people. J Sports Sci 2001, 19:711-23 
15. Verplanken B, Wood W: Interventions to break and create consumer habits. J Public Policy Mark 2006, 25:90-103

16. Brug J, de Vet E, de Nooijer J, Verplanken B: Predicting fruit consumption: cognitions, intention, and habits. J Nutr Educ Behav 2006. 38:73-81

17. Bandura A: Social foundations of thought and action: A social cognitive theory. New York: Prentice Hall. 1987

18. Bartholomew LK, Parcel GS, Kok G, Gottlieb NH, Fernández ME: Planning Health Promotion Programs: An Intervention Mapping Approach. San Francisco, CA: JosseyBass; 2011

19. Kok G, Schaalma H, Ruiter RA, van Empelen P, Brug J: Intervention mapping: protocol for applying health psychology theory to prevention programmes. J Health Psychol 2004, 9:85-98

20. Sassen B. Predictors of healthcare professionals' intention and behavior to encourage physical activity in patients with cardiovascular risk factors. BMC Public Health. 2011,19;246

21. Cole DA, Maxwell SE. Testing mediational models with longitudinal data: questions and tips in the use of structural equation modeling. J Abnorm Psychol. 2003, 112(4):558-77

22. Bryan A, Schmiege SJ, Broaddus MR. Mediational analysis in HIV/AIDS research: estimating multivariate path analytic models in a structural equation modeling framework. AIDS Behav. 2007 May;11(3):365-83

23. Kline RB. Principles and practice of structural equation modeling. New York/London: The Guilford press; 2011

24. Bentler PM. SEM with simplicity and accuracy. J Consum Psychol. 2010, 20(2):215220

25. Albarracín D, Wyer RS Jr. The cognitive impact of past behavior: influences on beliefs, attitudes, and future behavioral decisions. J Pers Soc Psychol. 2000 79(1):522

26. Ouelette JA, Wood W. Habit and intention in everyday life: the multiple processes by which past behavior predict future behavior. Psychological Bulletin 1998. 124:54-74

\section{CHAPTER 6 REFERENCES}

1. Bartholomew LK, Parcel GS, Kok G, Gottlieb NH. Planning Health Promotion Programs: An Intervention Mapping Approach. San Francisco, CA: Jossey-Bass; 2006 
2. Bartholomew LK, Parcel GS, Kok G, Gottlieb NH, Fernández ME. Planning health promotion programs: An Intervention Mapping approach. San Francisco, CA: Jossey; 2011

3. Kok G, Schaalma H, Ruiter RA, van Empelen P, Brug J. Intervention mapping: protocol for applying health psychology theory to prevention programmes. J Health Psychol 2004, 9:85

4. Schaalma H, Kok G. Decoding health education interventions: the times are achangin'. Psychol Health 2009 Jan;24(1):5-9

5. van Bokhoven MA, Kok G, van der Weijden T. Designing a quality improvement intervention: a systematic approach. Qual Saf Health Care 2003 Jun;12(3):215-20

6. Webb TL, Joseph J, Yardley L, Michie S. Using the internet to promote health behavior change: a systematic review and meta-analysis of the impact of theoretical basis, use of behavior change techniques, and mode of delivery on efficacy. J Med Internet Res. 2010 Feb 17;12(1):e4

7. Van Kesteren NM, Kok G, Hospers HJ, Schippers J, De Wildt W. Systematic development of a self-help and motivational enhancement intervention to promote sexual health in HIV-positive men who have sex with men. AIDS Patient Care STDS. 2006 Dec;20(12):858-75

8. Alewijnse D, Mesters IE, Metsemakers JF, van den Borne BH. Program development for promoting adherence during and after exercise therapy for urinary incontinence. Patient Educ Couns 2002 Oct -Nov;48(2):147-60

9. Heinen $M M$, Bartholomew LK, Wensing $M$, van de Kerkhof $P$, van Achterberg $T$. Supporting adherence and healthy lifestyles in leg ulcer patients: systematic development of the Lively Legs program for dermatology outpatient clinics. Patient Educ Couns. 2006 May;61(2):279-91

10. Wolfers ME, van den Hoek C, Brug J, de Zwart O. Using Intervention Mapping to develop a programme to prevent sexually transmittable infections, including HIV, among heterosexual migrant men. BMC Public Health. 2007 Jul 5; 7:141

11. Van Stralen MM, Kok G, de Vries H, Mudde AN, Bolman C, Lechner L. The Active plus protocol: systematic development of two theory- and evidence-based tailored physical activity interventions for the over-fifties.BMC Public Health. 2008 Dec 4;8:399

12. Third Report of the National Cholesterol Education Program (NCEP): Expert Panel on Detection, evaluation and treatment of high blood cholesterol in adults (Adult Treatment Panel III). Final report. National Institutes of Health 2002 
13. Grundy SM, Cleeman JL, Daniels SR, Donato KA, Eckel RH, Franklin BA, et al. Diagnosis and management of the metabolic syndrome: An American Heart Association/National Heart and Lung, and Blood Institute Scientific Statement. Circulation 2005, 112:2735-2752

14. Chobanian, AV, Bakris GL, Black HR, Crushman WC, Green LA, Izzo JL, et al. and the National High Blood Pressure Education Program Coordinating Committee. Hypertension 2003, 42:206-1252

15. Lakka H, Laaksonen DE, Lakka TA, Niskanen LK, Kumpusalo E, Tuomilehto J, et al. The metabolic syndrome and total and cardiovascular disease mortality in middle-aged men. JAMA 2002, 288:2709-2716

16. Sofi F, Capalbo A, Cesari F, Abbate R, Gensini GF. Physical activity during leisure time and primary prevention of coronary heart disease: an updated meta-analysis of cohort studies. Eur J Cardiovasc Prev Rehabil 2008, 15:247-57

17. Nocon M, Hiemann T, Müller-Riemenschneider F, Thalau F, Roll S, Willich SN. Association of physical activity with all-cause and cardiovascular mortality: a systematic review and meta-analysis. Eur J Cardiovasc Prev Rehabil 2008, 15:239-46

18. Lakka TA, Laaksonen DE, Lakka HM, Männikö N, Niskanen LK, Rauramaa R, et al. Sedentary lifestyle, poor cardio-respiratory fitness, and the metabolic syndrome. Med Sci Sports Exerc 2003, 35:1279-86

19. Kwaliteitsinstituut voor de Gezondheidszorg $\mathrm{CBO}$ en Nederlands Huisartsen Genootschap. Multidisciplinaire richtlijn Cardiovasculair risicomanagement. Utrecht: 2006

20. Sassen B, Kok G, Schaalma H, Kiers H, Vanhees L. Cardiovascular risk profile: crosssectional analysis of motivational determinants, physical fitness and physical activity. BMC Public Health 2010,10:592

21. Sassen B. Predictors of healthcare professionals' intention and behaviour to encourage physical activity in patients with cardiovascular risk factors. BMC Public Health. 2011,19;246

22. Ajzen I. The theory of planned behavior. Organizational Behavior and human Decision Processes 1991, 50:179-211

23. Fishbein M, Ajzen I. Predicting and changing behavior : the reasoned action approach. New York : Psychology Press 2010

24. Godin G, Kok G. The theory of planned behavior: a review of its applications to health-related behaviors. Am J Health Promot 1996, 11:87-98 
25. Bandura A. Social foundations of thought and action: A social cognitive theory. New York: Prentice Hall. 1987

26. Armitage CJ, Conner M. Sociale cognitive determinants of blood donation. J of Appl Social psychology 2001, 31:1-28

27. Sheeran P, Trafimow D, Armitage CJ. Predicting behaviour from perceived behavioural control: tests of the accuracy assumption of the theory of planned behaviour. Br J Soc Psychol 2003, 42:393-410

28. Rhodes RE, Courneya KS. Investigating multiple components of attitude, subjective norm, and perceived control: an examination of the theory of planned behaviour in the exercise domain. Br J Soc Psychol 2003, 42:129-46

29. Rodgers WM, Conner M, Murray TC. Distinguishing among perceived control, perceived difficulty, and self-efficacy as determinants of intentions and behaviours. Br J Soc Psychol 2008, 47:607-30

30. Bandura A. Self-efficacy: The exercise of control. New York: Freeman. 1997

31. Sassen B, Cornelissen V, Kiers H, Wittink H, Kok GJ, Vanhees L. Physial fitness matters more than physical activity in controlling cardiovascular disease risk factors. Eur J Cardiovasc Prev Rehabil 2009, 16:667-683

32. Van Achterberg T, Huisman-de Waal GG, Ketelaar NA, Oostendorp RA, Jacobs JE, Wollersheim HC. How to promote healthy behaviours in patients? An overview of evidence for behaviour change techniques. Health Promot Int. 2010 Aug 25

33. Abraham C, Michie S. A taxonomy of behavior change techniques used in interventions. Health Psychol. 2008 May;27(3):379-87

34. Weinstein ND. The precaution-adoption process. Health Psychology. 1988. 7:355-86

35. Fife-Schaw C, Sheeran P, Norman P. Simulating behaviour change interventions based on the theory of planned behaviour: Impacts on intention and action. Br J Soc Psychol. 2007 Mar;46(Pt 1):43-68

36. Sniehotta FF, Scholz U, Schwarzer R. Action plans and coping plans for physical exercise: A longitudinal intervention study in cardiac rehabilitation. $\mathrm{Br} \mathrm{J}$ Health Psychol. 2006 Feb;11(Pt 1):23-37

37. Webb TL, Sheeran P. Does changing behavioral intentions engender behavior change? A meta-analysis of the experimental evidence. Psychol Bull 2006, 132:24968

38. Godin G, Conner M. Intention-behavior relationship based on epidemiologic indices: 
an application to physical activity. Am J Health Promot. 2008 Jan-Feb;22(3):180-2

39. Godin G, Bélanger-Gravel A, Amireault S, Gallani MC, Vohl MC, Pérusse L. Effect of implementation intentions to change behaviour: moderation by intention stability. Psychol Rep. 2010 Feb;106(1):147-59

40. Gollwitzer PM, Schaal B: Metacognition in action: the importance of implementation intentions. Pers Soc Psychol Rev. 1998;2(2):124-36

41. Achtziger A, Gollwitzer PM, Sheeran P. Implementation intentions and shielding goal striving from unwanted thoughts and feelings. Pers Soc Psychol Bull. 2008 Mar;34(3):381-93

42. Sheeran P, Webb TL, Gollwitzer PM. The interplay between goal intentions and implementation intentions. Pers Soc Psychol Bull. 2005 Jan;31(1):87-98

43. Sniehotta FF. Towards a theory of intentional behaviour change: plans, planning, and self-regulation. Br J Health Psychol. 2009 May;14(Pt 2):261-73

44. Marlat GA, Gordon JR. Relapse prevention: maintenance strategies in the treatment of addictive behaviors. New York: 1985

45. de Bruin M, Viechtbauer W, Schaalma HP, Kok G, Abraham C, Hospers HJ. Standard care impact on effects of highly active antiretroviral therapy adherence interventions: A meta-analysis of randomized controlled trials. Arch Intern Med. 2010 Feb 8;170(3):240-50

46. Crutzen R, de Nooijer J, Brouwer W, Oenema A, Brug J, de Vries NK. A conceptual framework for understanding and improving adolescents' exposure to Internetdelivered interventions. Health Promot Int. 2009 Sep;24(3):277-84

47. Hawkins RP, Kreuter M, Resnicow K, Fishbein M, Dijkstra A. Understanding tailoring in communicating about health. Health Educ Res. 2008 Jun;23(3):454-66

48. Griffiths F, Lindenmeyer A, Powell J, Lowe $P$, Thorogood $M$. Why are health care interventions delivered over the internet? A systematic review of the published literature. J Med Internet Res. 2006 Jun 23;8(2):e10

49. Kroeze W, Werkman A, Brug J. A systematic review of randomized trials on the effectiveness of computer-tailored education on physical activity and dietary behaviors. Ann Behav Med. 2006 Jun;31(3):205-23

50. Noar SM, Benac CN, Harris MS. Does tailoring matter? Meta-analytic review of tailored print health behavior change interventions. Psychol Bull. 2007 Jul;133(4):673-93 
51. Wantland DJ, Portillo CJ, Holzemer WL, Slaughter R, McGhee EM. The effectiveness of Web-based vs. non-Web-based interventions: a meta-analysis of behavioral change outcomes. J Med Internet Res. 2004 Nov 10;6(4):e40

52. Van den Berg MH, Schoones JW, Vliet Vlieland TP. Internet-based physical activity interventions: a systematic review of the literature. J Med Internet Res. 2007 Sep 30;9(3):e26

53. SQUASH Wendel-Vos GCW, Schuit AJ, Saris WHM, Kromhout D: Reproducibility and relative validity of the Short Questionnaire to Assess Health enhancing physical activity. J Clin Epid 2003, 56:1163-69

54. Haskell WL, Lee IM, Pate RR, Powell KE, Blair SN, Franklin BA, Macera CA, Heath GW, Thompson PD, Bauman A; American College of Sports Medicine; American Heart Association. Physical activity and public health: updated recommendation for adults from the American College of Sports Medicine and the American Heart Association. Circulation 2007 Aug 28;116(9):1081-93

55. Brouwer W, Oenema A, Crutzen R, de Nooijer J, de Vries NK, Brug J. An exploration of factors related to dissemination of and exposure to webbased behavior change interventions aimed at adults: a Delphi study approach. J Med Internet Res. 2008 Apr 16;10(2):e10

56. Schulz KF, Altman DG, Moher D, for the CONSORT Group. CONSORT 2010 Statement: updated guidelines for reporting parallel group randomised trials. Ann Int Med 2010;152 


\section{REFERENCES IN ALFABETIC ORDER}

1. van Achterberg T, Huisman-de Waal GG, Ketelaar NA, Oostendorp RA, Jacobs JE, Wollersheim HC. How to promote healthy behaviours in patients? An overview of evidence for behaviour change techniques. Health Promot Int. 2010 Aug 25

2. Abraham C, Michie S. A taxonomy of behavior change techniques used in interventions. Health Psychol. 2008 May;27(3):379-87

3. Achtziger A, Gollwitzer PM, Sheeran P. Implementation intentions and shielding goal striving from unwanted thoughts and feelings.Pers Soc Psychol Bull. 2008 Mar;34(3):381-93

4. Ainsworth BE, Haskell WL, Whitt MC, Irwin ML, Swartz AM, Strath SJ: Compendium of physical activities, an update of activity codes and MET intensities. Medicine \& Science in Sports \& Exercise 2000, 9:S498-S516

5. Ajzen I. The theory of planned behavior. Organizational Behavior and human Decision Processes 1991, 50:179-211

6. Ajzen I: Perceived behavioral control, self-efficacy, locus of control, and the theory of planned behavior. J of Appl Social psychology 2002, 32:665-683

7. Albarracín D, Wyer RS Jr. The cognitive impact of past behavior: influences on beliefs, attitudes, and future behavioral decisions. J Pers Soc Psychol. 2000 79(1):522

8. Alewijnse D, Mesters IE, Metsemakers JF, van den Borne BH. Program development for promoting adherence during and after exercise therapy for urinary incontinence. Patient Educ Couns 2002 Oct -Nov;48(2):147-60

9. Amireault S, Godin G, Vohl MC, Pérusse L: Moderators of the intention-behaviour and perceived behavioural control-behaviour relationships for leisure-time physical activity. Int J Behav Nutr Phys Act 2008, 1:5-7

10. Armitage CJ, Conner M. Efficacy of the Theory of Planned Behaviour: a meta-analytic review. Br J Soc Psychol. 2001 Dec;40(Pt 4):471-99

11. Armitage CJ, Conner M. Sociale cognitive determinants of blood donation. J of Appl Social psychology 2001, 31:1-28

12. Bandura A. Self-efficacy: The exercise of control. New York: Freeman. 1997

13. Bandura A. Social foundations of thought and action: A social cognitive theory. New York: Prentice Hall. 1987 
14. Bartholomew LK, Parcel GS, Kok G, Gottlieb NH. Planning Health Promotion Programs: An Intervention Mapping Approach. San Francisco, CA: Jossey-Bass; 2006

15. Bartholomew Bartholomew LK, Parcel GS, Kok G, Gottlieb NH, Fernández ME. Planning health promotion programs: An Intervention Mapping approach. San Francisco, CA: Jossey; 2011

16. Bentler PM. SEM with simplicity and accuracy. J Consum Psychol. 2010, 20(2):215220

17. Berlin JA and Colditz GA: A meta-analysis of physical activity in the prevention of coronary heart disease. Am J Epidemiol 1990, 132:612-628

18. Blaha MJ, Bansal S, Rouf R, Golden SH, Blumenthal RS, DeFilippis AP. A practical ABCDE approach to the metabolic syndrome. Mayo Clin Proc 2008; 83:932-943

19. Blair SN, Cheng Y, Holder JS: Is physical activity or physical fitness more important in defining health benefits? Med Sci Sports Exerc 2001, 33(6 Suppl):S379-99

20. Bouchard C, Shephard RJ. Physical activity, fitness and health the model and key concepts. In: Bouchard C, Stephard RJ, Stephens T. Physical activity, fitness and health. Champaign, IL: Human Kinetics 1994

21. Boudreau F, Godin G: Using the Theory of Planned Behaviour to predict exercise intention in obese adults. Can J Nurs Res 2007, 39:112-25

22. Brouwer W, Oenema A, Crutzen R, de Nooijer J, de Vries NK, Brug J. An exploration of factors related to dissemination of and exposure to webbased behavior change interventions aimed at adults: a Delphi study approach. J Med Internet Res. 2008 Apr 16;10(2):e10

23. Brug J, de Vet E, de Nooijer J, Verplanken B: Predicting fruit consumption: cognitions, intention, and habits. J Nutr Educ Behav 2006. 38:73-81

24. Bryan A, Schmiege SJ, Broaddus MR. Mediational analysis in HIV/AIDS research: estimating multivariate path analytic models in a structural equation modeling framework. AIDS Behav. 2007 May;11(3):365-83

25. Buckland GG, Salas-Salvado J, Serra-Majem L, Castell C, Cabré J, Salleras-Sanmarit L. Increase in metabolic syndrome as defined by ATPIII from 1992-1993 to 2002-2003 in a Mediterranean population. Nutrition Reviews 2009; 67: S117-S125

26. Carroll S, Cooke CB, Butterly RJ. Metabolic clustering, physical activity and fitness in nonsmoking middle-aged men. Med Sci Sports Exerc 2000; 32:2079-2086

27. Chobanian, AV, Bakris GL, Black HR, Crushman WC, Green LA, Izzo JL, Jonas DW, 
Materson BJ, Oparil S, Wright JT, Roccella EJ: the National High Blood Pressure Education Program Coordinating Committee: Seventh report of the joint national committee on prevention, detection, evaluation and treatment of high blood pressure. Hypertension 2003, 42:1206-52

28. Church TS, Earnest CP, Skinner JS, Blair SN: Effects of different doses of physical activity on cardiorespiratory fitness among sedentary, overweight or obese postmenopausal women with elevated blood pressure: a randomized controlled trial. JAMA 2007, 297(19):2081-91

29. Cole DA, Maxwell SE. Testing mediational models with longitudinal data: questions and tips in the use of structural equation modeling. J Abnorm Psychol. 2003, 112(4):558-77

30. Conner M, Armitage CJ: Extending the Theory of Planned Behavior: A review and avenues for further research. J Appl Soc Psychol 1998, 28:1429-1464

31. Cornelissen VA, Fagard RH. Effects of endurance training on blood pressure, blood pressure-regulating mechanisms, and cardiovascular RF. Hypertension 2005; 46:667675.

32. Crutzen R, de Nooijer J, Brouwer W, Oenema A, Brug J, de Vries NK. A conceptual framework for understanding and improving adolescents' exposure to Internetdelivered interventions. Health Promot Int. 2009 Sep;24(3):277-84

33. de Bruin M, Viechtbauer W, Schaalma HP, Kok G, Abraham C, Hospers HJ. Standard care impact on effects of highly active antiretroviral therapy adherence interventions: A meta-analysis of randomized controlled trials. Arch Intern Med. 2010 Feb 8;170(3):240-50

34. Durstine LJ, Grandjeann PW, Davis PG, Ferguson MA, Alderson NL, DuBose KD. Blood lipid and lipoprotein adaptations to exercise: a quantitative analysis. Sports Med 2001; 31:1033-1062

35. Dvorak RV, Tchernof A, Starling RD, Ades PA, DiPietro L, Poehlman ET. Respiratory fitness, freel living physical activity and cardiovascular disease risk in older individuals: a double labeled water study. J Clin Endocrinol Metab 2000; 85:957-963

36. Eccles MP, Hrisos S, Francis J, Kaner EF, Dickinson HO, Beyer F, Johnston M: Do selfreported intentions predict clinicians' behaviour: a systematic review. Implement Sci 2006, 21:1-28

37. Eckel RH, Grundy SM, Zimmet PZ: The metabolic syndrome. Lancet 2005, 365:141528

38. Ekelund U, Brage S, Franks PW, Hennings S, Emms S, Wareham NJ: Physical activity 
energy expenditure predicts changes in body composition in middle-aged healthy whites: effect modification by age. Am J Clin Nutr 2005, 81:964-9

39. Ekelund U, Brage S, Franks PW, Hennings S, Emms S, Wong MY, et al. Physical activity energy expenditure predicts changes in body composition in middle-aged healthy whites: effect modification by age. Am J Clin Nutr 2005;81:964-9

40. Fife-Schaw C, Sheeran P, Norman P. Simulating behaviour change interventions based on the theory of planned behaviour: Impacts on intention and action. Br J Soc Psychol. 2007 Mar;46(Pt 1):43-68

41. Fishbein M, Ajzen I. Predicting and changing behavior : the reasoned action approach. New York : Psychology Press 2010

42. Foley KA, Vasey J, Alexander CM, Markson LE: Development and validation of the hyperlipidemia: attitudes and beliefs in treatment (HABIT) survey for physicians. J Gen Intern Med 2003.18:984-90

43. Gami AS, Witt BJ, Howard DE, Erwin PJ, Gami LA, Somers VK, et al. Metabolic syndrome and risk of incident cardiovascular events and death: a systematic review and meta-analysis of longitudinal studies. J Am Coll Cardiol. 2007;49:403-14

44. Gill JM. Physical activity, cardiorespiratory fitness and insulin resistance: a short update. Curr Opin Lipidol 2007;18:47-52

45. Godin G, Bélanger-Gravel A, Amireault S, Gallani MC, Vohl MC, Pérusse L. Effect of implementation intentions to change behaviour: moderation by intention stability. Psychol Rep. 2010 Feb;106(1):147-59

46. Godin G, Conner M. Intention-behavior relationship based on epidemiologic indices: an application to physical activity. Am J Health Promot. 2008 Jan-Feb;22(3):180-2

47. Godin G, Kok G. The theory of planned behavior: a review of its applications to health-related behaviors. Am J Health Promot 1996, 11:87-98

48. Gollwitzer PM, Schaal B: Metacognition in action: the importance of implementation intentions. Pers Soc Psychol Rev. 1998;2(2):124-36

49. Graham I, Atar D, Borch-Johnsen K, Boysen G, Burell G, Cifkova R, Dallongeville J, De Backer G, Ebrahim S, Gjelsvik B, Herrmann-Lingen C, Hoes A, Humphries S, Knapton M, Perk J, Priori SG, Pyorala K, Reiner Z, Ruilope L, Sans-Menendez S, Scholte op Reimer W, Weissberg P, Wood D, Yarnell J, Zamorano JL, Walma E, Fitzgerald T, Cooney MT, Dudina A; European Society of Cardiology (ESC) Committee for Practice Guidelines (CPG). European guidelines on cardiovascular disease prevention in clinical practice. Fourth Joint Task Force of the European Society of Cardiology and other societies on cardiovascular disease prevention in clinical practice (constituted 
by representatives of nine societies and by invited experts). Eur J Cardiovasc Prev Rehabil. 2007: 2:S1-113

50. Griffiths F, Lindenmeyer A, Powell J, Lowe P, Thorogood M. Why are health care interventions delivered over the internet? A systematic review of the published literature. J Med Internet Res. 2006 Jun 23;8(2):e10

51. Grimshaw JM, Eccles MP, Walker AE, Thomas RE: Changing physicians' behavior: what works and thoughts on getting more things to work. J Contin Educ Health Prof 2002, 22:237-43

52. Grimshaw JM, Thomas RE, MacLennan G, Fraser C, Ramsay CR, Vale L, Whitty P, Eccles MP, Matowe L, Shirran L, Wensing M, Dijkstra R, Donaldson C. Effectiveness and efficiency of guideline dissemination and implementation strategies. Health Technol Assess. 2004, 8:1-72

53. Grundy SM, Cleeman JL, Daniels SR, Donato KA, Eckel RH, Franklin BA, Gordon DJ, Krauss RM, Savage PJ, Smith SC, Spertus JA, Costa F: Diagnosis and management of the metabolic syndrome: An American Heart Association/National Heart and Lung, and Blood Institute Scientific Statement. Circulation 2005, 112:2735-52

54. Hagger MS, Chatzisarantis N, Biddle SJH: The influence of self-efficacy and past behavior on the physical activity intentions of young people. J Sports Sci 2001, 19:711-23

55. Halbert JA, Silagny CA, Finucane P, Withers RT, Hamdorf PA. Exercise training and blood lipids in hyperlipidemic and normolipidemic adults: a meta-analysis of randomized, controlled trials. Eur J Clin Nut 1999;53:514-22

56. Haskell WL, Lee IM, Pate RR, Powell KE, Blair SN, Franklin BA, Macera CA, Heath GW, Thompson PD, Bauman A; American College of Sports Medicine; American Heart Association. Physical activity and public health: updated recommendation for adults from the American College of Sports Medicine and the American Heart Association. Circulation 2007 Aug 28;116(9):1081-93

57. Hawkins RP, Kreuter M, Resnicow K, Fishbein M, Dijkstra A. Understanding tailoring in communicating about health. Health Educ Res. 2008 Jun;23(3):454-66

58. Heinen MM, Bartholomew LK, Wensing $M$, van de Kerkhof $P$, van Achterberg $T$. Supporting adherence and healthy lifestyles in leg ulcer patients: systematic development of the Lively Legs program for dermatology outpatient clinics. Patient Educ Couns. 2006 May;61(2):279-91

59. Hrisos S, Eccles MP, Francis JJ, Bosch M, Dijkstra R, Johnston M, Grol R, Kaner EF, Steen IN: Using psychological theory to understand the clinical management of type 
2 diabetes in Primary Care: a comparison across two European countries. BMC Health Serv Res 2009. 9:140

60. Hu G, Lakka TA, Kipeläinen TO, Tuomilehto J. Epidemiological studies of exercise in diabetes prevention. Appl Physiol Nutr Metab 2007; 32:583-95

61. Kline RB. Principles and practice of structural equation modeling. New York/London: The Guilford press; 2011

62. Kok G, Schaalma H, Ruiter RA, van Empelen P, Brug J. Intervention mapping: protocol for applying health psychology theory to prevention programmes. J Health Psychol 2004, 9:85

63. Kroeze W, Werkman A, Brug J. A systematic review of randomized trials on the effectiveness of computer-tailored education on physical activity and dietary behaviors. Ann Behav Med. 2006 Jun;31(3):205-23

64. Kwaliteitsinstituut voor de Gezondheidszorg $\mathrm{CBO}$ en Nederlands Huisartsen Genootschap. Multidisciplinaire richtlijn Cardiovasculair risicomanagement. Utrecht: 2006

65. Lakka H, Laaksonen DE, Lakka TA, Niskanen LK, Kumpusalo E, Tuomilehto J, et al. The metabolic syndrome and total and cardiovascular disease mortality in middle-aged men. JAMA 2002;288:2709-2716

66. Lakka TA, Laaksonen DE, Lakka HM, Männikö N, Niskanen LK, Rauramaa R, et al. Sedentary lifestyle, poor cardiorespiratory fitness, and the metabolic syndrome. Med Sci Sports Exerc 2003; 35:1279-86

67. Lamonte MJ, Barlow CE, Jurca R, Kampert JB, Church TS, Blair SN. Cardiorespiratory fitness is inversely associated with the incidence of metabolic syndrome: a prospective study of men and women. Circulation 2005;112:505-12

68. Laukkanen JA, Kurl S, Salonen R, Rauramaa R, Salonen JT. The predictive value of cardiorespiratory fitness for cardiovascular events in men with various risk profiles: a prospective population-based cohort study. Eur Heart J 2004; 25:1428-1437

69. Löllgen H, Böckenhoff A, Knapp G: Physical activity and all-cause mortality: an updated meta-analysis with different intensity categories. Int J Sports Med 2009, 30:213-24

70. Manson JE, Frank B, Rich-Edwards JW, Colditz GA, Stampfer MJ, Willett WC, et al. A prospective study of walking as compared with vigorous exercise in the prevention of coronary heart disease in women. New Eng J Med 1999; 341:650-658

71. Manson JE, Greenland P, LaCroix AZ, Stefanick ML, Mouton CP, Oberman A, Perii 
MG, Sheps DS, Pettinger MB, Siscovick DS: Walking compared with vigorous exercise for the prevention of cardiovascular events in woman. NEJM 2002, 347:716-17

72. Marlat GA, Gordon JR. Relapse prevention: maintenance strategies in the treatment of addictive behaviors. New York: 1985

73. Moebus S, Hanish JY, Aidelsburger P, Bramlage P, Wasem J, Jöckel KH. Impact of 4 different definitions used for the assessment of the prevalence of the metabolic syndrome in primary healthcare: the german metabolic and cardiovascular risk projects (GEMCAS). Cardiovasc Diabetology 2007; 6: 22-32.

74. Myers J, Prakash M, Froelicher V, Do D, Partington S, Atwood JE. Exercise capacity and mortality among men referred for exercise testing. NEJM 2002; 14: 346: 793801.

75. Noar SM, Benac CN, Harris MS. Does tailoring matter? Meta-analytic review of tailored print health behavior change interventions. Psychol Bull. 2007 Jul;133(4):673-93

76. Nocon M, Hiemann T, Müller-Riemenschneider F, Thalau F, Roll S, Willich SN. Association of physical activity with all-cause and cardiovascular mortality: a systematic review and meta-analysis. Eur J Cardiovasc Prev Rehabil 2008;15:239-46

77. Orakzai RH, Orakzai SH, Nasir K, Roguin A, Pimentel I, Carvalho JAM, et al. Association of increased cardiorespiratory fitness with low risk for clustering of metabolic syndrome components in asymptomatic men. Archives of Medical Research 2006; 37:522-528

78. Ouelette JA, Wood W. Habit and intention in everyday life: the multiple processes by which past behavior predict future behavior. Psychological Bulletin 1998. 124:54-74

79. Perkins MB, Jensen PS, Jaccard J, Gollwitzer P, Oettingen G, Pappadopulos E, Hoagwood KE: Applying theory-driven approaches to understanding and modifying clinicians' behavior: what do we know? Psychiatr Serv 2007. 58:342-8

80. Perkins MB, Jensen PS, Jaccard J, Gollwitzer P, Oettingen G, Pappadopulos E, Hoagwood KE: Applying theory-driven approaches to understanding and modifying clinicians' behavior: what do we know? Psychiatr Serv 2007. 58:342-8

81. Petrella RJ, Lattanzio CN, Demeray A, Varello V, Blore R. Can adoption of regular exercise later in life prevent metabolic risk for cardiovascular disease? Diabetes Care 2005;28:694-701

82. Portnoy DB, Scott-Sheldon LA, Johnson BT, Carey MP. Computer-delivered interventions for health promotion and behavioral risk reduction: a meta-analysis of 
75 randomized controlled trials, 1988-2007. Prev Med. 2008 Jul;47(1):3-1

83. Rennie KL, McCarthy N, Yazdgerdi S, Marmot M, Brunner E. Association of the metabolic syndrome with both vigorous and moderate physical activity. Int J Epidemiol 2003;32:600-6

84. Rhodes RE, Courneya KS, Blanchard CM, Plotnikoff RC: Prediction of leisure-time walking: an integration of social cognitive, perceived environmental, and personality factors. Int J Behav Nutr Phys Act 2007, 31:4:51

85. Rhodes RE, Courneya KS. Investigating multiple components of attitude, subjective norm, and perceived control: an examination of the theory of planned behaviour in the exercise domain. Br J Soc Psychol 2003, 42:129-46

86. Rodgers WM, Conner M, Murray TC. Distinguishing among perceived control, perceived difficulty, and self-efficacy as determinants of intentions and behaviours. Br J Soc Psychol 2008, 47:607-30

87. Sassen B, Cornelissen V, Kiers H, Wittink H, Kok GJ, Vanhees L. Physial fitness matters more than physical activity in controlling cardiovascular disease risk factors. Eur J Cardiovasc Prev Rehabil 2009, 16:667-683

88. Sassen B, Kok G, Schaalma H, Kiers H, Vanhees L. Cardiovascular risk profile: crosssectional analysis of motivational determinants, physical fitness and physical activity. BMC Public Health 2010,10:592

89. Sassen B. Predictors of healthcare professionals' intention and behavior to encourage physical activity in patients with cardiovascular risk factors. BMC Public Health. 2011,19;246

90. Schaalma H, Kok G. Decoding health education interventions: the times are achangin'. Psychol Health 2009 Jan;24(1):5-9

91. Schulz KF, Altman DG, Moher D, for the CONSORT Group. CONSORT 2010 Statement: updated guidelines for reporting parallel group randomised trials. Ann Int Med $2010 ; 152$

92. Selvin S. Statistical Analysis for Epidemiologic Data. New York: Oxford University Press Inc; 1996

93. Shaw K, Gennat H, O'Rourke P, Del Mar C. Exercise for overweight or obesity. Cochrane Database Syst Rev 2006;4:CD003817

94. Sheeran P, Trafimow D, Armitage CJ. Predicting behaviour from perceived behavioural control: tests of the accuracy assumption of the theory of planned 
behaviour. Br J Soc Psychol 2003, 42:393-410

95. Sheeran P, Webb TL, Gollwitzer PM. The interplay between goal intentions and implementation intentions. Pers Soc Psychol Bull. 2005 Jan;31(1):87-98

96. Sniehotta FF, Scholz U, Schwarzer R. Action plans and coping plans for physical exercise: A longitudinal intervention study in cardiac rehabilitation. $\mathrm{Br} \mathrm{J}$ Health Psychol. 2006 Feb;11(Pt 1):23-37

97. Sofi F, Capalbo A, Cesari F, Abbate R, Gensini GF. Physical activity during leisure time and primary prevention of coronary heart disease: an updated meta-analysis of cohort studies. Eur J Cardiovasc Prev Rehabil 2008;15:247-57

98. SQUASH Wendel-Vos GCW, Schuit AJ, Saris WHM, Kromhout D: Reproducibility and relative validity of the Short Questionnaire to Assess Health enhancing physical activity. J Clin Epid 2003, 56:1163-69

99. Swain PD, Franklin BA. Comparison of cardioprotective benefits of vigorous versus moderate intensity aerobic exercise. Am J Cardiol 2006; 97:141-147

100. Talbot LA, Morrell CH, Metter EJ, Fleg JL. Comparison of cardiorespiratory fitness versus leisure time physical activity as predictors of coronary events in men aged $<$ or $=65$ years and $>65$ years. Am J Cardiol 2002; 89: 1187-1192

101. Tanasescu M, Leitzmann MF, Rimm EB, Willett WC, Stampfer MJ, Hu FB. Exercise type and intensity in relation to coronary heart disease in men. JAMA 2002; 288:1994-2000

102. Third Report of the National Cholesterol Education Program (NCEP): Expert Panel on Detection, evaluation and treatment of high blood cholesterol in adults (Adult Treatment Panel III). Final report. National Institutes of Health 2002

103. van Bokhoven MA, Kok G, van der Weijden T. Designing a quality improvement intervention: a systematic approach. Qual Saf Health Care 2003 Jun;12(3):215-20

104. Van den Berg MH, Schoones JW, Vliet Vlieland TP. Internet-based physical activity interventions: a systematic review of the literature. J Med Internet Res. 2007 Sep 30;9(3):e26

105. Van Kesteren NM, Kok G, Hospers HJ, Schippers J, De Wildt W. Systematic development of a self-help and motivational enhancement intervention to promote sexual health in HIV-positive men who have sex with men. AIDS Patient Care STDS. 2006 Dec;20(12):858-75

106. Van Stralen MM, Kok G, de Vries H, Mudde AN, Bolman C, Lechner L. The 
Active plus protocol: systematic development of two theory- and evidence-based tailored physical activity interventions for the over-fifties.BMC Public Health. 2008 Dec 4;8:399

107. Vanhees L, Lefevre J, Phillippaerts R, Martens M, Huygens W, Troosters T, et al. How to assess physical activity? How to assess physical fitness? Eur J Cardiovasc Prev Rehabil 2005;12:102-14

108. Verplanken B, Wood W: Interventions to break and create consumer habits. J Public Policy Mark 2006, 25:90-103

109. Wantland DJ, Portillo CJ, Holzemer WL, Slaughter R, McGhee EM. The effectiveness of Web-based vs. non-Web-based interventions: a meta-analysis of behavioral change outcomes. J Med Internet Res. 2004 Nov 10;6(4):e40

110. Webb TL, Joseph J, Yardley L, Michie S. Using the internet to promote health behavior change: a systematic review and meta-analysis of the impact of theoretical basis, use of behavior change techniques, and mode of delivery on efficacy. J Med Internet Res. 2010 Feb 17;12(1):e4

111. Webb TL, Sheeran P. Does changing behavioral intentions engender behavior change? A meta-analysis of the experimental evidence. Psychol Bull 2006, 132:24968

112. Weinstein ND. The precaution-adoption process. Health Psychology. 1988. 7:355-86

113. Wendel-Vos GCW, Schuit AJ, Saris WHM, Kromhout D. Reproducibility and relative validity of the Short Questionnaire to Assess Health enhancing physical activity. J Clin Epid 2003;56:1163-69

114. Williams PT. Physical fitness and activity as separate heart disease RF: a meta-analysis. Med Sci Sports Exerc 2001; 33: 754-761

115. Wolfers ME, van den Hoek C, Brug J, de Zwart O. Using Intervention Mapping to develop a programme to prevent sexually transmittable infections, including HIV, among heterosexual migrant men. BMC Public Health. 2007 Jul 5;7:141

116. Yeazel MW, Lindstrom Bremer KM, Center BA: A validated tool for gaining insight into clinicians' preventive medicine behaviors and beliefs: the preventive medicine attitudes and activities questionnaire (PMAAQ). Prev Med 2006.43:86-91

117. Yusuf S, Hawken S, Ounpuu S, Dans T, Avezum A, Lanas F, McQueen M, Budaj A, Pais P, Varigos J, Lisheng L; INTERHEART Study Investigators. Effect of potentially modifiable risk factors associated with myocardial infarction in 52 countries (the 
INTERHEART study): case-control study. Lancet. 2004:(9438):937-52 
II

Summery 


\section{SUMMARY}

The consequences of cardiovascular diseases are substantial and include increasing numbers of morbidity and mortality. With a population getting more and more inactive and having a sedentary lifestyle, the risk for cardiovascular disease and type 2 diabetes rises. This dissertation reports on people with one or more cardiovascular risk factor(s) and who are having an inactive lifestyle, and how healthcare professionals can encourage these people at risk to become and stay physically active in a way that cardiovascular fitness is improved. The assumption is that if an intervention can reduce the prevalence of risk factors, it can also reduce the prevalence of disease. When cardiovascular fitness improves and a person is capable of keeping a physically active lifestyle, levels and number of cardiovascular risk factors can decrease in a population.

The dissertation started in chapter 1 with a general introduction about the importance of cardiovascular risk factors, aims of the dissertation and the outline. The dissertation has three parts. In part one the association between cardiovascular risk factors, physical activity and physical fitness was described. In addition, the predictors of physical active lifestyle behavior of patients with one or more cardiovascular risk factors were described, meaning the intention to engage in physical activity and their actual physical active behavior. In part one also the predictors of encouraging professional behavior for healthcare professionals were described, meaning the intention to encourage patients with cardiovascular risk factors to become physically active and the corresponding behavior. The aim of part one was to study patients with cardiovascular risk factors and their expected lack of physical activity and physical fitness, causing high cardiovascular morbidity and diabetes type 2 rates. The aim was also to study the predicators of intention, behavior, physical activity and physical fitness for people with cardiovascular risk factors to stay physically active for one hour a day. The final aim of part one was to study the predictors of the intention to encourage patients with cardiovascular risk factors to become physical active and the subsequent behavior of healthcare professionals.

In part two of this dissertation we described the stability of social-cognitive determinants over time. We described if social-cognitive determinants are indeed, as predicted, stable over time. Next to testing the stability of social-cognitive determinants, we studied the interdependence of social-cognitive determinants. In part two we studied in a longitudinal design, the stability and the interdependence of the social-cognitive determinants over time.

On base of the results of part one of this dissertation, we developed the PIB2intervention, applying the protocol of Intervention Mapping. In part three of this dissertation it is shown that it takes an extensive Intervention Mapping process when the aim is to direct an intervention at patients with cardiovascular risk factors by reaching them via healthcare professionals working in a healthcare setting. We developed the PIB2- 
intervention, for patients with cardiovascular risk factors as well as for healthcare professionals. The PIB2-intervention aims at risk-reduction behavior for patients with cardiovascular risk factors and extending the encouraging behavior of healthcare professionals.

The first chapter of this dissertation described the background and the rationale for this dissertation. Part one, chapter 2 described the cross-sectional analysis of people having cardiovascular risk factors, and their physical activity levels and cardiovascular physical fitness. This study investigated the association between cardiovascular risk factors, physical activity and physical fitness. In the prevention of cardiovascular disease, the control of cardiovascular risk factors is important. Cardiovascular risk factors, that are abdominal obesity, high blood pressure, low HDL-C cholesterol, elevated triglycerides and elevated blood glucose, can be beneficially influenced by increasing levels of physical activity and physical fitness. The aim of this study was to explore the importance of duration, average intensity and volume of physical activity in controlling cardiovascular risk factors, to explore the importance of physical fitness in comparison with physical activity in controlling cardiovascular risk factors, and finally to elucidate the pathway between physical activity and cardiovascular risk score.

In this study, police employees participated in the Utrecht Police Lifestyle Intervention Fitness and Training (UP-LIFT) study. Results were that $18.6 \%$ (22.5\% in men, $10.6 \%$ in women) showed to have 3 or more cardiovascular risk factors. Physical activity and physical fitness are inversely associated with the clustering of cardiovascular risk factors. With regard to physical activity, it seems that intensity and more specifically higher intensity is the main characteristic determining its effect on cardiovascular risk factors. However, compared to physical activity, physical fitness exerts greater effects on each of the individual cardiovascular risk factors and also on the combination of cardiovascular risk factors.

When one aims at recommending and implementing a healthy lifestyle, the total time of physical activity, as well as the hours of physical activity performed at low and moderate intensity and the total volume of physical activity, appeared to be of no great importance in optimizing the cardiovascular risk profile. This suggests that intensity is the major characteristic of physical activity, determining its effect on overall cardiovascular risk. As a consequence increasing exercise intensity or increasing the time spent at vigorous intensity may result in greater risk reductions. Although physical activity and physical fitness both have a cardiovascular risk lowering effect, physical fitness seems more important in the relationship compared to physical activity. This may suggest that physical activity should preferably increase $\mathrm{VO}_{2}$ peak in order to maximally influence cardiovascular risk factors.

In chapter 3 of this dissertation the results of the investigation of social-cognitive determinants are described, studied in the UP-LIFT-study in a cross-sectional design. We described the self-reported behavior of people having one or more cardiovascular risk factors to become physically active, physical activity levels and cardiovascular physical 
fitness. Cardiovascular risk factors are associated with physical fitness and, to a lesser extent, with physical activity, as described in chapter 2. Lifestyle interventions directed at enhancing physical fitness in order to decrease the risk of cardiovascular diseases should be extended. In order to enable the development of effective lifestyle interventions that prevent cardiovascular morbidity related to an inactive lifestyle, the social-cognitive determinants of an active lifestyle should be identified. To enable the development of effective lifestyle interventions for people with cardiovascular risk factors, we investigated social-cognitive determinants, next to physical activity and physical fitness.

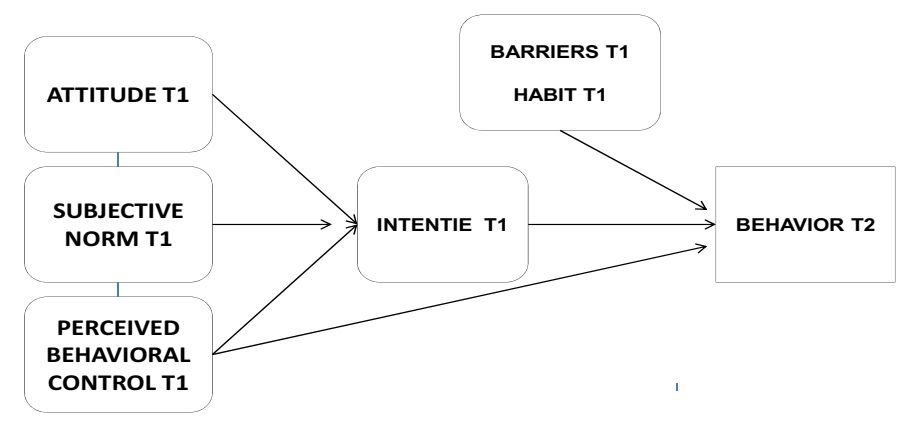

Figure 1 - Theory of Planned Behavior

In the prevention of cardiovascular risk factors, lifestyle interventions directed at increasing physical activity and hereby enhancing physical fitness may improve the cardiovascular risk profile. A better understanding of the social-cognitive correlates of intention to engage in physical activity on a daily basis and physical active behavior is imperative. Most studies refer to research on social-cognitive determinants without investigating physical activity and physical fitness in a broader scope. We studied socialcognitive determinants of the intention to engage in physical activity and physical active behavior, as well as extensive self-reported physical activity (in intensity and duration) and measured cardiovascular physical fitness (peak $\mathrm{VO}_{2}$ ).

According to the Theory of Planned Behavior, Social Cognitive Theory and other health behavior theories (Figure 1 Theory of Planned Behavior, Social Cognitive Theory and other health behavior theories), the intention to engage in physical activity predicts future physical active behavior. Intention is the key motivational determinant of behavior. Behavioral intentions, in turn, are determined by three social-cognitive factors, namely attitude, subjective norm and perceived behavioral control.

Attitude refers to the general evaluation of the behavior, and is determined by behavioral beliefs (perceptions regarding the advantages and disadvantages of the behavior), and perceptions regarding the consequences of the behavior. 
Subjective norm refers to perceived social approval for the behavior. The subjective norm is determined by normative beliefs and by expectations regarding whether important reference individuals or groups will approve of the behavior. In addition to the subjective norm, the descriptive norm, which can viewed as the behavior of others in the social environment, is important. The moral norm is essential as the individuals' responsibility and the individuals' moral obligation towards the behavior to act in a specific way.

Perceived behavioral control is one's confidence in one's ability to perform a specific behavior. Perceived behavioral control is determined by control beliefs that are based upon perceptions of opportunities, as well as perceived barriers and required resources. People intend to engage in behaviors when the evaluation of the behavior is positive, when social influence is perceived as influential and when the behavior is considered to be under personal control.

According to the Theory of Planned Behavior, Social Cognitive Theory and other health behavior theories, the influence of general dispositions and socio-demographic factors are mediated by attitude, subjective norms and perceived behavioral control. The intention-behavior relationship is influenced by barriers and these can obstruct the behavior, even though the intention to engage in the behavior is positive. Habit can also predict behavior, as it concerns the individuals' personal experience with a specific behavior in a stable context.

For people with one or more cardiovascular risk factor(s) $(78.7 \%$ of the total population), social-cognitive variables accounted for the variance in the intention to engage in physical activity for 60 minutes every day and in the corresponding behavior. Important correlates of intention to engage in physical activity were attitude, self-efficacy, descriptive norm and barriers. The intention to engage in physical activity and self-efficacy were, in turn, important correlates of physical active behavior. An important goal of our study was to investigate the association between physical fitness, the intensity of physical activity and social-cognitive variables. Physical fitness was positively associated with physical active behavior, self-efficacy and the intensity of physical activity. For people with 1 or more cardiovascular risk factors, $39.9 \%$ had positive intentions to engage in physical activity and were also physically active, and $10.5 \%$ had low intentions but were physically active. $37.7 \%$ had low intentions and were physically inactive, and about $11.9 \%$ had high intentions but were physically inactive.

This study contributed to our ability to optimize cardiovascular risk profiles by demonstrating an important association between physical fitness and social-cognitive variables. Physical fitness can be predicted by physical active behavior as well as by selfefficacy and the intensity of physical activity, and the latter by physical active behavior. Physical active behavior can be predicted by intention, self-efficacy, descriptive norms and barriers. Intention to engage in physical activity by attitude, self-efficacy, descriptive norms and barriers. An important input for lifestyle changes for people with one or more cardiovascular risk factors was that for ca. $40 \%$ of the population the intention to engage in 
physical activity was in line with their actual physical active behavior.

In chapter 4 of this dissertation the results of the investigation of social-cognitive determinants are described for healthcare professionals. Healthcare professionals, who encourage patients with cardiovascular risk factors to become and stay physically active, were studied in a longitudinal design. Healthcare professionals can play a crucial role in optimizing the health status of patients with cardiovascular risk factors. In order to do this, it is imperative that we understand the social-cognitive determinants that underlie healthcare professionals' intention and the corresponding behavior of actually encouraging patients with cardiovascular risk factors to engage in physical activity.

In this Professionals' Intention and Behavior (PIB) study, (types of healthcare professionals physiotherapy and nursing) we showed that social-cognitive determinants accounted for the variance in healthcare professionals' intention to encourage physical activity among cardiovascular patients. Important correlates of intention were attitude, subjective norms and perceived behavioral control. Habit and barriers were significant correlates of professionals' behavior of encouraging patients to engage in physical activity. For healthcare professionals we also explored the congruence between their intention to encourage patients and their self-reported behavior of encouraging patients. We found that intention and behavior was congruent in $39.7 \%$ of the healthcare professionals. Additionally, the intention to encourage and the corresponding behavior of encouraging was incongruent in $31.7 \%$ of the healthcare professionals.

In the prevention of cardiovascular disease, healthcare professionals' intention to encourage physical activity among patients and subsequent behavior of encouraging patients is important for the improvement of patients' cardiovascular risk profiles. We found that the intentions and self-reported behavior of healthcare professionals working with patients with cardiovascular risk factors can be predicted by social-cognitive determinants thus implying that efforts to change and strengthen the intention-behavior relationship of healthcare professionals may have beneficial effects for cardiovascular risk patients.

In the first part of this dissertation, the analyses are described that constitute the input to develop an intervention. In the development process of the intervention we focused on the risk-reduction behavior of people with cardiovascular risk factors and on extending the encouraging behavior of healthcare professionals, with the aim to reduce the prevalence of cardiovascular disease.

In part two of this dissertation, chapter 5 investigated in a longitudinal design the stability of social-cognitive determinants over time. The Theory of Planned Behavior, Social Cognitive Theory and other health behavior theories has extensively been studied to predict intention and behavior, for all kind of (health) problems and (healthcare) settings. The underlying assumption is that the intention is an important predictor of behavior and that intention and behavior can be changed in a positive direction by implementing carefully 
designed behavior change interventions. We hypothesized that, if no intervention is implemented, social-cognitive determinants are stable over time. The aim was to provide insight in the stability of social-cognitive determinants over time and the interdependence of social-cognitive determinants.

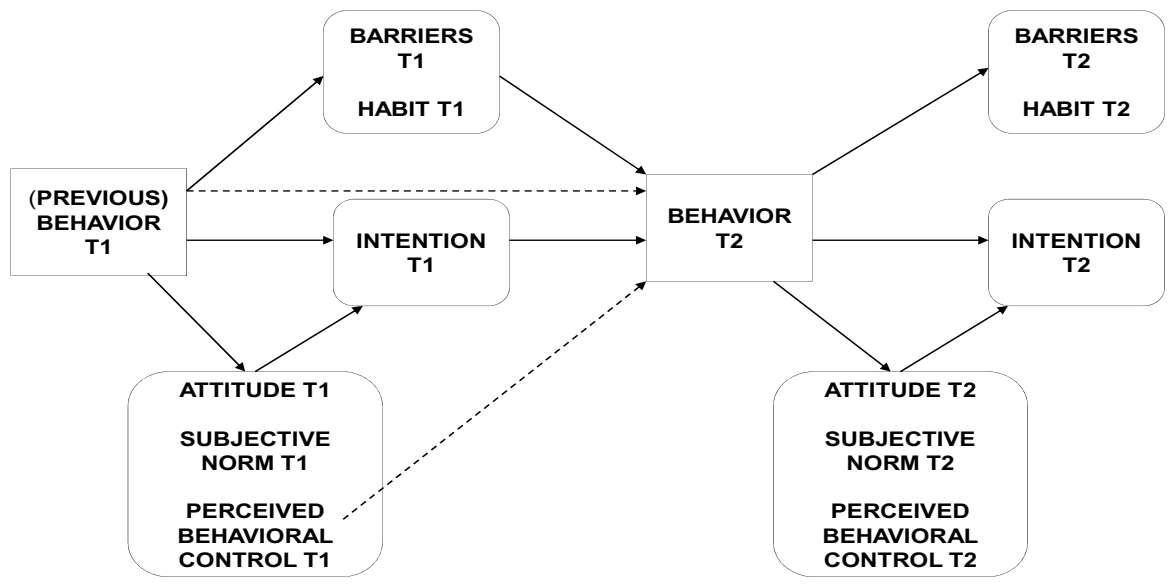

Figure 2 - Theoretical model of predictors of intention and behavior measured at T1 and T2

In this longitudinal study, part of the Professionals' and Patients' Intention and Behavior (PIB2) study, healthcare professionals completed online surveys. We measured all relevant social-cognitive determinants of healthcare professionals' intention and the subsequent behavior of encouraging patients with cardiovascular risk factors to engage in physical activity, at two moments in time (Figure 2 Theoretical model of predictors of intention and behavior measured at T1 and T2). No intervention took place. Analysis showed no differences on all social-cognitive determinants measured at time one (T1) compared to time 2 (T2), except for the intention to encourage patients with cardiovascular risk factors to become physically active. We conducted a path analysis, thereby constituting a test of the Theory of Planned Behavior, Social Cognitive Theory and other health behavior theories. The path model showed that (previous) behavior T1 and attitude T1 predicted intention T1; that (previous) behavior T1 and barriers T1 predicted behavior T2 (to encourage patients with cardiovascular risk factors to become physically active); and that behavior T2, intention T1 and attitudeT1 predicted intention T2.

In part two, our findings revealed that social-cognitive determinants are, overall, stable over time, when no intervention is implemented, with only intention being less stable over time. When no intervention is implemented and the focus is on the influence of time, behavior is stable. In exploring the interdependence of social-cognitive determinants by using structural equation modeling (Figure 3), first we showed that intention T1 can be 
predicted by (previous) behavior T1; and we showed that behavior T2 can be predicted by (previous) behavior T1. Healthcare professionals are experienced in encouraging patients with cardiovascular risk factors to become physically active to decrease cardiovascular risk, and professionals probably have learned during education and in practice how to encourage patients. Previous behavior (experience and education) influences the healthcare professionals' intention T1 and behavior T2. Secondly and different than expected, we showed that there is neither a direct nor an indirect path between the social-cognitive determinant intention T1 and behavior T2. Finally we showed in our path model, that intention $\mathrm{T} 2$ can be predicted by behavior $\mathrm{T} 2$.

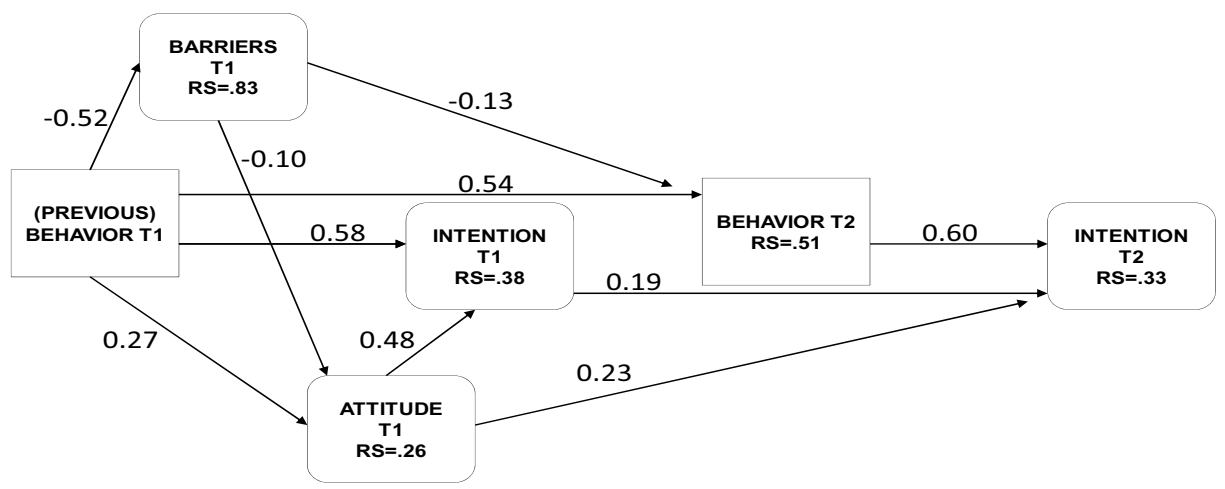

Figure 3 - Path model predicting intention and encouraging behavior of healthcare professionals

Chi-square, $\chi^{2}(5, N=278)=2.35, p=0.80$;

RMSEA=.000;

RS, residual variance;

Standardized path coefficients

In part three, chapter 6 of this dissertation described how the Intervention Mapping Protocol guided the development of the theory and evidence-based Internet-delivered Professional and Patient Intention and Behavior (PIB2) Intervention. According to the guidelines for cardiovascular risk management, healthcare professionals should encourage their patients to engage in physical activity. The aim was to provide insight regarding the systematic development of the web-based PIB2-intervention for both healthcare professionals and patients by making use of the development method Intervention Mapping. The different steps of this development process are described to open up the black box of web-based intervention development and providing support for future webbased intervention development. The development of the Professional and Patient Intention and Behavior Intervention (PIB2-intervention) was initiated with a needs assessment for both healthcare professionals and their patients with cardiovascular risk factors. We then formulated the performance and change objectives. Subsequently, theory and evidence-based intervention methods and strategies were selected that were thought to affect the determinants of intention and behavior of healthcare professionals and 
patients. The rationale of the intervention was based on different behavioral change methods that allowed us to describe the scope and sequence of the intervention and produced the web-based intervention components. The intervention consisted of five theory and evidence-based modules, comprised of individualized messages and selfcompletion forms, as well as charts and tables for healthcare professionals and patients.

The first step in the Intervention Mapping protocol is exploring the problem, the causes and the risk groups. In the second step of Intervention Mapping we defined the program objectives and specified the determinants that should be changed and why. The third phase was the selection of theory-based intervention methods to effect these changes. In the fourth step the intervention was developed based on the integration of these theory-based methods of behavior change and the intervention was tested. During the fifth step, an adoption and implementation plan for the intervention was created in order to facilitate sustained implementation.

The systematic and planned development of the PIB2-intervention resulted in an internet-delivered behavior change intervention. The intervention was not developed as a substitute for face-to-face contact between professionals and patients, but as an application to complement and optimize health services. The web-based intervention may improve social-cognitive determinants, intention, (health) behaviors and (health) maintenance for healthcare professionals as well as their patients, and long-term improvement in cardiovascular risk profiles.

The Intervention Mapping protocol provided a systematic method for developing the intervention and each intervention design choice was carefully thought-out and justified. Although it is neither a rapid nor an easy method for developing an intervention, the protocol guides and directs the development process to open up the black box of webbased intervention development. The application of evidence-based behavior change methods used in our intervention offers insight regarding how an intervention may change intention and (health) behavior. Further research should test the effectiveness of the PIB2intervention.

In part three the development process of the PIB2-intervention is described. The PIB2-intervention is implemented in a randomized control design. At this time, healthcare professionals and patients with cardiovascular risk factors are making use of the PIB2website. We are gathering the data to evaluate the PIB2-intervention. We undertook an extensive process evaluation and these findings are described in the general discussion. We will evaluate the PIB2-intervention to determine if the intervention achieved the desired results, according to the performance and change objectives stated in the Intervention Mapping protocol, at the end of 2011.

In chapter 7, the final chapter of this dissertation, the general discussion is generated on the research findings, both findings acquired through the research on physical fitness and physical activity, social-cognitive determinants to ground the intervention on one hand and development, implementation and evaluation on the other. This chapter also 
reflects on the methods used to conduct the research done reported in this dissertation. This chapter ends with the outline of implications of the research findings, and provided recommendations for future research. 
III

Samenvatting 


\section{SAMENVATTING}

De gevolgen van hart- en vaatziekten zijn aanzienlijk en omvatten een toename in morbiditeit en mortaliteit. In de algemene bevolking neemt de inactiviteit toe, gekoppeld aan een sedentaire levensstijl, waardoor het risico op hart- en vaatziekten en diabetes type 2 stijgt. Dit proefschrift rapporteert over mensen met een of meer cardiovasculaire risicofactoren en met een inactieve leefstijl, en hoe professionals werkzaam in de gezondheidszorg mensen die een gezondheidsrisico lopen aanmoedigen om te (blijven) bewegen op een manier die de cardiovasculaire conditie verbeterd. De veronderstelling hierbij is dat een interventie de prevalentie van risicofactoren positief kan beïnvloeden, evenals de prevalentie van hart- en vaatziekten en diabetes type 2. Als de cardiovasculaire fitheid verbetert en een persoon in staat is een fysiek actieve levensstijl te behouden, kan het niveau en het aantal cardiovasculaire risicofactoren afnemen in een populatie.

Het proefschrift begon in hoofdstuk 1 met een algemene introductie op cardiovasculaire risicofactoren, het doel en de opbouw van het proefschrift. Het proefschrift bestaat vervolgens uit drie delen. In deel een wordt de relatie tussen cardiovasculaire risicofactoren, fysieke activiteit en fysieke fitheid beschreven. Daarnaast zijn de voorspellers van een fysiek actief leefstijl van patiënten met een of meer cardiovasculaire risicofactoren beschreven, dit wil zeggen de intentie om fysiek actief te zijn en het werkelijke fysieke actieve gedrag. In het eerste deel worden ook de voorspellers van het stimuleren van fysiek actief gedrag door professionals in de gezondheidszorg beschreven, dit wil zeggen de intentie om patiënten met cardiovasculaire risicofactoren te motiveren tot een fysiek actieve leefstijl en het bijbehorende aanmoedigende gedrag. Het doel van deel een was patiënten met cardiovasculaire risicofactoren en hun verwachte gebrek aan fysieke activiteit en fysieke fitheid te bestuderen, hetgeen hoge cardiovasculaire morbiditeit en diabetes type 2 cijfers te zien geeft. Het doel was ook om de predictoren van intentie, gedrag, fysieke activiteit en fysieke fitheid van mensen met cardiovasculaire risicofactoren om fysiek actief te blijven voor een uur per dag, in kaart te brengen. Het laatste doel van deel een was om de predictoren van de intentie en het aanmoedigende gedrag van professionals werkzaam in de gezondheidszorg in kaart te brengen.

In deel twee van dit proefschrift beschrijven we de stabiliteit van de gedragsdeterminanten in de tijd. We beschreven of gedragsdeterminanten inderdaad, zoals voorspeld, stabiel zijn in de tijd. Naast het testen van de stabiliteit van de gedragsdeterminanten, bestudeerden we de onderlinge samenhang van de gedragsdeterminanten. In deel twee werd in een longitudinale studie, de stabiliteit en de onderlinge samenhang van gedragsdeterminanten bestudeerd.

Op basis van de resultaten van deel een van dit proefschrift, werd de Professionals' and Patients' Intention and Behavior (PIB2) interventie ontwikkeld, door het toepassen van het protocol van Intervention Mapping. In deel drie van dit proefschrift werd aangetoond 
dat er een uitgebreid Intervention Mapping proces voorafgaat aan de uiteindelijk te implementeren interventie, een interventie gericht op zowel patiënten met cardiovasculaire risicofactoren als professionals werkzaam in de gezondheidszorg. De PIB2-interventie is gericht op risico-reductiegedrag voor patiënten met cardiovasculaire risicofactoren en op de uitbreiding van professioneel gedrag van professionals werkzaam in de gezondheidszorg.

Het eerste hoofdstuk van dit proefschrift beschreef de achtergrond en de beweegredenen voor dit proefschrift. In deel een, hoofdstuk 2 werd de cross-sectionele analyse beschreven van mensen met cardiovasculaire risicofactoren, en hun fysieke activiteit en fysieke fitheid. Deze studie onderzocht het verband tussen cardiovasculaire risicofactoren, fysieke activiteit en fysieke fitheid. Bij de preventie van hart- en vaatziekten, is de controle van cardiovasculaire risicofactoren belangrijk. Cardiovasculaire risicofactoren, te weten abdominale obesitas, hoge bloeddruk, lage HDL-C cholesterol gehaltes in het bloed, verhoogde triglyceriden en verhoogde bloedglucose, kunnen gunstig worden beïnvloed door het verhogen van het niveau van fysieke activiteit en fysieke fitheid. Het doel van deze studie was het belang van de duur, de gemiddelde intensiteit en het volume van fysieke activiteit in het controleren van cardiovasculaire risicofactoren te onderzoeken, om het belang van de fysieke fitheid te onderzoeken in vergelijking met de fysieke activiteit in het begunstigen van cardiovasculaire risicofactoren, en uiteindelijk de relatie toe te lichten tussen fysieke activiteit en cardiovasculair risicoscore.

In deze studie, werden politiemedewerkers uitgenodigd om deel te nemen aan de Utrecht Police Lifestyle Intervention Fitness and Training (UP-LIFT) studie. De resultaten waren dat $18,6 \%$ (22,5\% bij mannen, $10,6 \%$ bij vrouwen) drie of meer cardiovasculaire risicofactoren hebben. Fysieke activiteit en fysieke fitheid zijn invers geassocieerd met de clustering van cardiovasculaire risicofactoren. Met betrekking tot de fysieke activiteit, lijkt het dat de intensiteit en meer specifiek hogere intensiteit het belangrijkste kenmerk is dat een effect heeft op cardiovasculaire risicofactoren. Echter, in vergelijking met fysieke activiteit, heeft fysieke fitheid een groter effect op elk van de individuele cardiovasculaire risicofactoren en ook op de combinatie van cardiovasculaire risicofactoren.

Wanneer de aandacht zich richt op een gezonde levensstijl, is de totale tijd van fysieke activiteit, evenals de uren besteedt aan fysieke activiteit op een lage en matige intensiteit en het totale volume van de fysieke activiteit, niet van groot belang voor het optimaliseren van het cardiovasculair profiel. Dit suggereert dat de intensiteit het belangrijkste kenmerk is van fysieke activiteit en het effect bepaalt in het cardiovasculaire risico. Als meer gebruik wordt gemaakt van intensiteit of het verhogen van de tijd doorgebracht op hoge intensiteit kan dit leiden tot een grotere reductie in het cardiovasculair risico. Hoewel fysieke activiteit en fysieke fitheid beiden een cardiovasculair risicoverlagend effect hebben, lijkt fysieke fitheid belangrijker in de relatie ten opzichte van fysieke activiteit. Dit kan erop wijzen dat fysieke activiteit bij voorkeur de VO2peak zou dienen te verbeteren om maximaal de cardiovasculaire risicofactoren te beïnvloeden. 


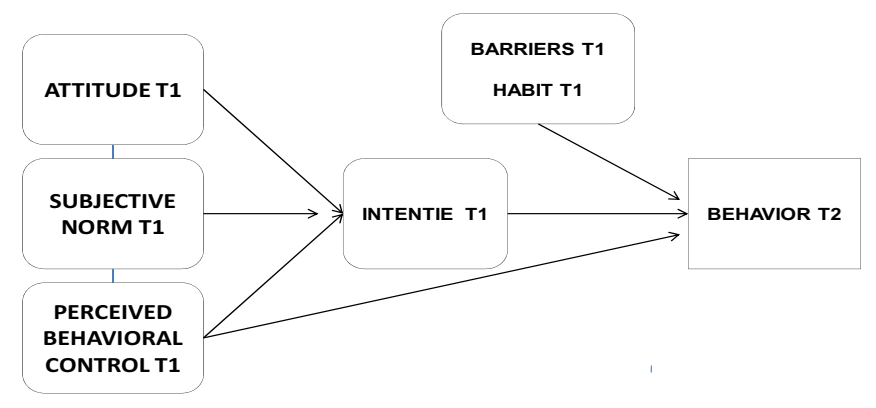

Figure 1 - Theory of Planned Behavior

In hoofdstuk 3 van dit proefschrift werden de resultaten van het onderzoek naar bepalende factoren van intentie en gedrag beschreven, onderzocht in de UP-LIFT-studie in een cross-sectionele onderzoeksopzet. We beschreven het zelfgerapporteerde gedrag van mensen met een of meer cardiovasculaire risicofactoren, fysieke activiteit en cardiovasculaire fitheid. Cardiovasculaire risicofactoren worden geassocieerd met fysieke fitheid en, in mindere mate, met fysieke activiteit, zoals beschreven in hoofdstuk 2. Lifestyle interventies gericht op het versterken van fysieke fitheid zouden moeten worden uitgebreid om zo het risico op hart- en vaatziekten te verminderen. Met het oog op de ontwikkeling van effectieve leefstijlinterventies gericht op het voorkomen van een inactieve leefstijl en het voorkomen van cardiovasculaire morbiditeit, dienen de determinanten van een actieve levensstijl te worden geïdentificeerd. Om de ontwikkeling van effectieve leefstijlinterventies voor mensen met cardiovasculaire risicofactoren te effectueren, onderzochten we gedragsdeterminanten, naast de fysieke activiteit en fysieke fitheid.

$\mathrm{Bij}$ de preventie van cardiovasculaire risicofactoren, kunnen lifestyle interventies gericht op het verbeteren van fysieke activiteit en de fysieke fitheid, het cardiovasculaire risicoprofiel optimaliseren. Een beter begrip van de bepalende factoren van zowel het voornemen deel te nemen aan fysieke activiteit op dagelijkse basis als van fysiek actief gedrag is noodzakelijk. De meeste studies hebben betrekking op determinantenonderzoek zonder fysieke activiteit en fysieke fitheid in de studie te betrekken. Wij onderzochten bepalende factoren van de intentie om deel te nemen aan fysieke activiteit en fysieke actief gedrag, evenals uitgebreide zelfgerapporteerde fysieke activiteit (in intensiteit en duur) en gemeten cardiovasculaire fitheid (piek VO2).

Volgens de Theory of Planned Behavior, Social Cognitive Theory en andere health behavior theories (Figuur 1 Theory of Planned Behavior), voorspelt de intentie om deel te nemen aan fysieke activiteit het toekomstige fysiek actieve gedrag. Intentie is de belangrijkste voorspellende determinant van gedrag. Gedragsintenties, worden op hun 
beurt bepaald door drie factoren, namelijk attitude, subjectieve norm en waargenomen gedragscontrole.

Attitude verwijst naar de algemene evaluatie van het gedrag, deze wordt bepaald door opvattingen (percepties ten aanzien van de voor- en nadelen van het gedrag) en percepties over de gevolgen van het gedrag.

Subjectieve normen verwijst naar de ervaren sociale goedkeuring voor het gedrag. De subjectieve norm wordt bepaald door de normatieve overtuigingen en verwachtingen ten aanzien van de vraag of belangrijke referentindividuen of -groepen het gedrag zullen goedkeuren. In aanvulling op de subjectieve norm, kan de descriptieve norm worden beschouwd als het gedrag van anderen in de sociale omgeving. De morele norm is van essentieel belang als de individuele verantwoordelijkheid en morele verplichting jegens het gedrag te handelen op een bepaalde manier.

De gepercipieerde gedragscontrole is het vertrouwen in de mogelijkheid om een bepaald gedrag uit te voeren. Gepercipieerde gedragscontrole wordt bepaald door controle overtuigingen die gebaseerd zijn op percepties van de mogelijkheden, evenals ervaren belemmeringen en de benodigde middelen. Mensen zijn van plan om gedrag uit te voeren, wanneer de evaluatie van het gedrag positief is, wanneer sociale invloed wordt gezien als invloedrijk en wanneer het gedrag wordt beschouwd als zijnde onder persoonlijke controle.

Volgens de Theory of Planned Behavior, Social Cognitive Theory en andere health behavior theories, worden de invloeden van de sociaaldemografische factoren gemedieerd door attitude, subjectieve normen en waargenomen gedragscontrole. De relatie tussen intentie en gedrag wordt beïnvloed door barrières en deze kunnen het gedrag belemmeren, ook al is de intentie om het gedrag uit te gaan voeren positief. Gewoonten kunnen ook het gedrag voorspellen, als het gaat om de individuele persoonlijke ervaring met een specifiek gedrag in een stabiele context.

Voor mensen met een of meer cardiovasculaire risicofactoren $(78,7 \%$ van de populatie), bleek de intentie om deel te nemen aan fysieke activiteit voor 60 minuten per dag en het overeenkomstige gedrag goed in kaart te brengen. Belangrijke bepalende factoren van het voornemen om deel te nemen aan fysieke activiteit zijn de attitude, de gepercipieerde gedragscontrole, de descriptieve norm en de barrières. De bedoeling deel te nemen aan fysieke activiteit en gepercipieerde gedragscontrole waren op hun beurt belangrijke bepalende factoren van fysiek actief gedrag. Een belangrijk doel van deze studie was om de associatie tussen fysieke fitheid, de intensiteit van de fysieke activiteit en sociaalcognitieve variabelen te onderzoeken. Fysieke fitheid was positief geassocieerd met fysieke actief gedrag, gepercipieerde gedragscontrole en de intensiteit van fysieke activiteit. Het bleek dat voor mensen met een of meer cardiovasculaire risicofactoren, 39,9\% een positieve intentie heeft om deel te nemen aan fysieke activiteit en ook fysiek actief gedrag hadden, $10,5 \%$ had een lage intentie, maar waren lichamelijk actief; $37,7 \%$ had een lage intentie en waren fysiek inactief, en tenslotte had $11,9 \%$ een hoge intentie maar waren fysiek inactief. 
Dit onderzoek heeft bijgedragen aan ons vermogen om het cardiovasculair risicoprofiel te optimaliseren door aan te tonen dat er een belangrijk verband bestaat tussen fysieke fitheid en sociaalcognitieve variabelen. Fysieke fitheid kan worden voorspeld door zowel fysiek actief gedrag als door gepercipieerde gedragscontrole en de intensiteit van fysieke activiteit, en de laatste door fysieke actief gedrag. Fysiek actief gedrag kan worden voorspeld door intentie, gepercipieerde gedragscontrole, descriptieve normen en barrières. De intentie kan worden voorspeld door de attitude, de gepercipieerde gedragscontrole, de descriptieve normen en de barrières. Een belangrijke input voor wijzigingen in de lifestyle van mensen met een of meer cardiovasculaire risicofactoren, was dat voor ca. $40 \%$ de intentie om deel te nemen aan fysieke activiteit in lijn is met hun werkelijke fysiek actieve gedrag.

In hoofdstuk 4 van dit proefschrift werden de resultaten van het onderzoek naar de sociaalcognitieve determinanten beschreven voor professionals werkzaam in de gezondheidszorg. Beroepsbeoefenaren in de gezondheidszorg die patiënten met cardiovasculaire risicofactoren aanmoedigen om fysiek actief te worden en te blijven, werden bestudeerd in een longitudinaal design. Professionals werkzaam in de gezondheidszorg kunnen een cruciale rol spelen bij het optimaliseren van de gezondheidstoestand van patiënten met cardiovasculaire risicofactoren. Om dit te bewerkstelligen, is het noodzakelijk dat we inzicht hebben in welke sociaalcognitieve determinanten ten grondslag liggen aan de intentie en het bijbehorende gedrag van het daadwerkelijk stimuleren van patiënten met cardiovasculaire risicofactoren om deel te nemen aan fysieke activiteit.

In deze Professionals' Intention and Behavior (PIB) studie, gericht op fysiotherapeuten en verpleegkundigen, tonen we aan dat de intentie om patiënten met cardiovasculaire risicofactoren aan te moedigen fysiek actief te zijn, wordt bepaald door de sociaalcognitieve determinanten attitude, subjectieve normen en waargenomen gedragscontrole. Het gedrag van professionals om patiënten aan te moedigen om deel te nemen aan fysieke activiteit, wordt bepaald door gewoonte en barrières. Voor professionals in de gezondheidszorg hebben we ook onderzocht of er sprake is van congruentie tussen hun voornemen om patiënten aan te moedigen fysiek actief te zijn en hun zelfgerapporteerde gedrag. We vonden dat de intentie en het gedrag congruent zijn voor $39,7 \%$ van de onderzochte professionals. Daarnaast is het van plan zijn patiënten met een of meer cardiovasculaire risicofactoren aan te moedigen fysiek actief te zijn en het bijbehorende gedrag incongruent voor $31,7 \%$ van de professionals.

Voor de preventie van hart- en vaatziekten en diabetes type 2 , is het belangrijk dat beroepsbeoefenaren in de gezondheidszorg patiënten stimuleren tot fysieke activiteit gericht op het optimaliseren van het cardiovasculaire risicoprofiel. We vonden dat de intentie en het zelfgerapporteerde gedrag van professionals die werkten met patiënten met cardiovasculaire risicofactoren kan worden voorspeld door sociaalcognitieve determinanten, hetgeen impliceert dat inspanningen om de intentie-gedragsrelatie te 
veranderen en te versterken van professionals in de gezondheidszorg positieve effecten kan hebben voor cardiovasculaire risicopatiënten.

In het eerste deel van dit proefschrift, zijn de analyses beschreven die de input vormen om een interventie te kunnen ontwikkelen. In het ontwikkelproces van de interventie hebben we ons gericht op het risico-reductiegedrag van mensen met een of meer cardiovasculaire risicofactoren en op de uitbreiding van het aanmoedigende gedrag van professionals werkzaam in de gezondheidszorg, met als doel om de prevalentie van hart- en vaatziekten en diabetes type 2 te verminderen.

In deel twee van dit proefschrift, hoofdstuk 5 hebben we in een longitudinale onderzoeksopzet de stabiliteit van de sociaalcognitieve determinanten in de tijd bestudeerd. De Theory of Planned Behavior, Social Cognitive Theory en andere health behavior theories is veelvuldig bestudeerd om intentie en gedrag te voorspellen, voor allerlei (gezondheids-)problemen en in allerlei (zorg-)settings. De onderliggende veronderstelling is dat de intentie een belangrijke voorspeller is van het gedrag en dat de intentie en het gedrag in een positieve richting kan worden gewijzigd door het implementeren van zorgvuldig ontworpen interventies uitgaande van gezondheidsbevordering. Onze hypothese was dat, als er geen interventie wordt geïmplementeerd, sociaalcognitieve determinanten stabiel zijn in de tijd. Het doel was om inzicht te geven in de stabiliteit van sociaalcognitieve determinanten in de tijd en in de onderlinge samenhang van de sociaalcognitieve determinanten.

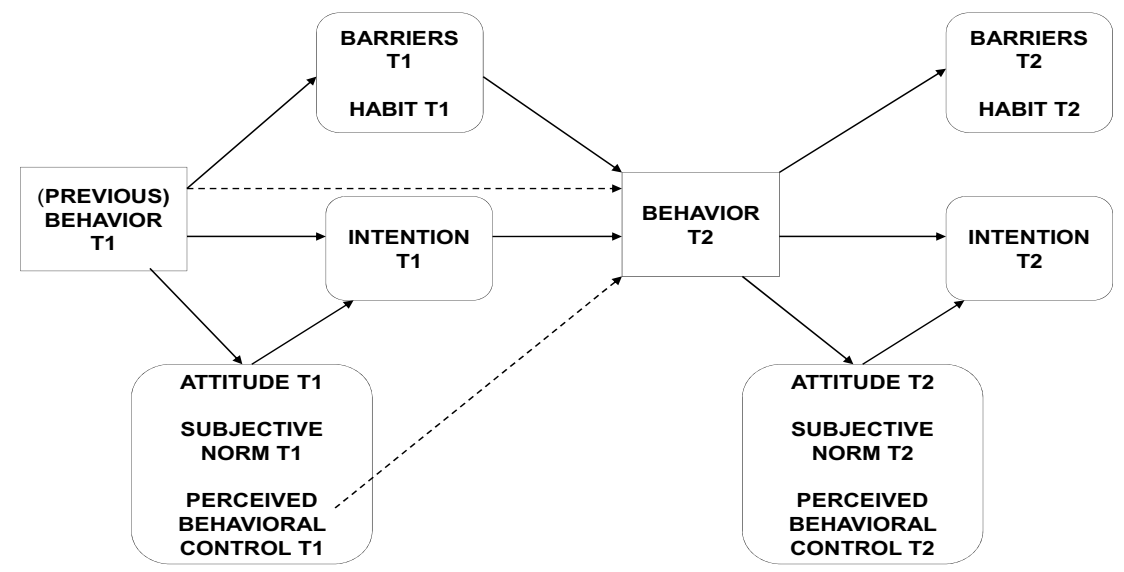

Figure 2 - Theoretical model of predictors of intention and behavior measured at T1 and T2

In deze longitudinale studie, een onderdeel van de Professionals' Intention and Behavior (PIB) studie, hebben beroepsbeoefenaren werkzaam in de gezondheidszorg online enquêtes ingevuld. Relevante sociaalcognitieve determinanten van de intentie en het latere 
gedrag van patiënten met cardiovasculaire risicofactoren om deel te nemen aan fysieke activiteit, zijn op twee momenten in de tijd gemeten (Figuur 2 Theoretisch model van de voorspellers van intentie en het gedrag gemeten op T1 en T2). Tussen meetmoment 1 en meetmoment 2 heeft geen interventie plaatsgevonden. Analyses van de data heeft aangetoond dat er geen verschillen zijn tussen de sociaalcognitieve determinanten, gemeten op het meetmoment 1 (T1) in vergelijking met meetmoment 2 (T2), behalve voor de intentie; het van plan zijn om patiënten met cardiovasculaire risicofactoren te motiveren om fysiek actiever te worden. Vervolgens werd een path-analyse uitgevoerd, met als onderliggend doel de Theory of Planned Behavior, Social Cognitive Theory en andere health behavior theories te testen. Het model toonde aan dat het (eerdere) gedrag en de attitude op meetmoment 1 , de intentie voorspeld; dat het (eerdere) gedrag en de barrières op meetmoment 1 , het gedrag op meetmoment 2 voorspeld (patiënten met cardiovasculaire risicofactoren aan te moedigen om fysiek actief te zijn), en dat het gedrag op meetmoment 2 , de intentie op meetmoment 1 en de attitude op meetmoment 1 , de intentie op meetmoment 2 voorspeld.

In deel twee, waren de bevindingen dat sociaalcognitieve determinanten over het algemeen, stabiel zijn in de tijd, wanneer er geen interventie wordt geïmplementeerd; hierbij is de intentie de minder stabiele gedragsdeterminant. Als er geen interventie wordt geïmplementeerd en de nadruk ligt op de invloed van de tijd, is het gedrag stabiel. Bij het verkennen van de onderlinge samenhang van sociaalcognitieve determinanten met behulp van structural equation modeling (Figuur 3), toonden we ten eerste aan dat de intentie T1 kan worden voorspeld door (vorige) gedrag T1, en hebben we aangetoond dat het gedrag op T2 kan worden voorspeld door (vorige) gedrag op T1. Beroepsbeoefenaren in de gezondheidszorg zijn ervaren in het motiveren van patiënten met cardiovasculaire risicofactoren om fysiek actief te worden en zo het cardiovasculaire risico te verminderen, ook professionals hebben waarschijnlijk geleerd tijdens opleiding en in de praktijk hoe patiënten te motiveren. Eerder gedrag (ervaring en opleiding) uitgevoerd door beroepsbeoefenaren werkzaam in de gezondheidszorg, beïnvloedt de intentie gemeten op T1 en gedrag op T2. Ten tweede, en anders dan verwacht, wordt weergegeven dat er noch een directe, noch een indirecte relatie kon worden aangetoond tussen de sociaalcognitieve determinant intentie T1 en gedrag T2. Tot slot werd in ons model aangetoond, dat de intentie op $\mathrm{T} 2$ kan worden voorspeld door het gedrag van $\mathrm{T} 2$.

In deel drie, hoofdstuk 6 van dit proefschrift wordt beschreven hoe het Intervention Mapping Protocol heeft geleid tot een internetgestuurde interventie, de Professionals' and Patients' Intention and Behavior (PIB2) interventie. Volgens de richtlijnen voor cardiovasculair risicomanagement, zouden beroepsbeoefenaren in de gezondheidszorg hun patiënten moeten aanmoedigen om deel te nemen aan fysieke activiteit. Het doel van deze studie was inzicht te bieden ten aanzien van de systematische ontwikkeling van de webbased PIB2-interventie, een interventie gericht op zowel beroepsbeoefenaren werkzaam in de gezondheidszorg als patiënten met een of meer cardiovasculaire risicofactoren door 
gebruik te maken van Intervention Mapping. De verschillende stappen van dit ontwikkelproces werden beschreven om zodoende de black box van web-based interventieontwikkeling te openen en als ondersteuning te dienen voor toekomstig interventieontwikkeling. De ontwikkeling van de PIB2-interventie was gestart met een studie naar de (voorlichtings-)behoeften voor zowel beroepsbeoefenaren in de gezondheidszorg als hun patiënten met cardiovasculaire risicofactoren. Vervolgens zijn doelstellingen geformuleerd en werden theorie- en evidence-based interventiemethoden en -strategieën geselecteerd waarmee werd beoogd de determinanten van intentie en het gedrag van beroepsbeoefenaren in de gezondheidszorg en patiënten te kunnen beïnvloeden. De interventie bestaat uit een website (www.gezondheidsbevordering.eu) die vijf theorie- en evidence-based modules omvat, bestaande uit individuele berichten en zelf in te vullen formulieren, evenals grafieken en tabellen voor professionals en patiënten.

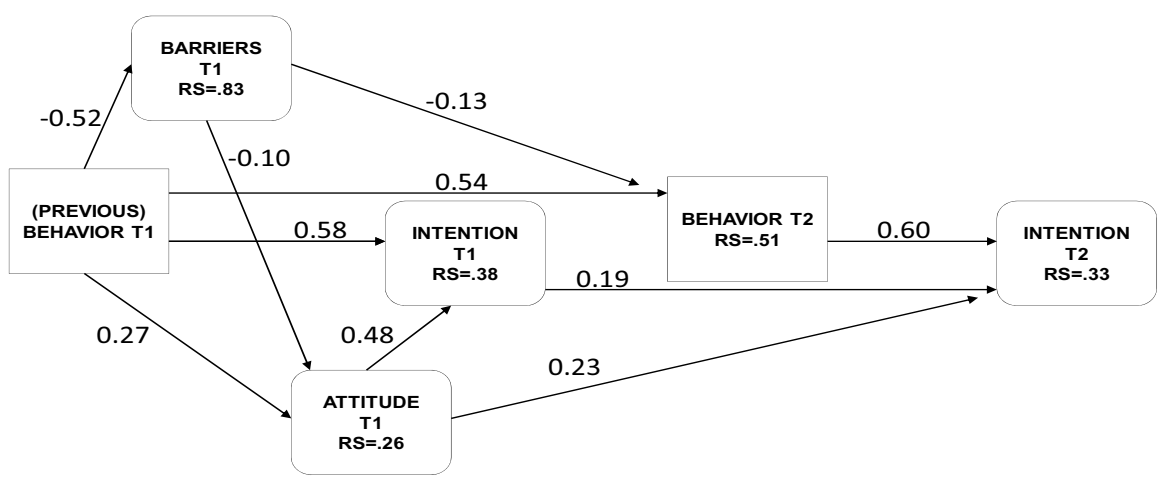

Figure 3 - Path model predicting intention and encouraging behavior of healthcare professionals Chi-square, $\chi^{2}(5, N=278)=2.35, p=0.80$; RMSEA=.000; RS, residual variance; Standardized path coefficients

De eerste stap in het Intervention Mapping protocol was het verkennen van het probleem, de oorzaken en de risicogroepen. In de tweede stap van Intervention Mapping definieerden we doelstellingen van de interventie en specificeerden we de determinanten die moeten worden veranderd en waarom. De derde fase was de selectie van de theorie-en evidene-based interventie methoden om deze veranderingen in te zetten. In de vierde stap was de interventie ontwikkeld op basis van de integratie van deze methoden van gedragsverandering en werd de interventie getest. Tijdens de vijfde stap, werd een adoptieen implementatieplan voor de interventie in het leven geroepen om duurzame implementatie te vergemakkelijken.

De systematische en geplande ontwikkeling van de PIB2-interventie resulteerde in een theorie- en evidence-based, internetgestuurde interventie. De interventie was niet ontwikkeld als een substituut voor face-to-face contact tussen professionals en patiënten, maar als een applicatie om de communicatie aan te vullen en te optimaliseren. De web- 
based interventie beoogt de sociaalcognitieve determinanten, de intentie, het (gezondheids)gedrag en het (gezondheids)gedragsbehoud voor beroepsbeoefenaren in de gezondheidszorg en hun patiënten te optimaliseren, en op langere termijn het cardiovasculaire risicoprofiel van patiënten te begunstigen.

De Intervention Mapping protocol voorziet in een systematische methode voor het ontwikkelen van de interventie en elke ontwerpkeuze werd doordacht en is verantwoord. Hoewel het geen snelle, noch een eenvoudige methode bleek voor het ontwikkelen van een interventie, stuurde het protocol gericht het ontwikkelproces en wordt de black box van web-based interventie ontwikkeling geopend. De toepassing van de theorie- en evidencebased methoden om intentie en gedrag te veranderen biedt zicht op de wijze waarop een interventie de intentie en het (gezondheids)gedrag kan veranderen. Verder onderzoek staat gepland om de effectiviteit van de PIB2-interventie te beoordelen.

In deel drie werd het ontwikkelproces van de PIB2-interventie beschreven. De PIB2interventie wordt thans uitgevoerd in een gerandomiseerd gecontroleerde studie. Op dit moment maken professionals werkzaam in de gezondheidszorg en patiënten met cardiovasculaire risicofactoren gebruik van de PIB2-website. We gaan bepalen of de PIB2interventie tot het gewenste resultaat leidt, aan het einde van 2011.

In hoofdstuk 7, het laatste hoofdstuk van dit proefschrift, wordt de algemene discussie gegenereerd op de onderzoeksresultaten, zowel de bevindingen verkregen via het onderzoek naar fysieke fitheid en fysieke activiteit, de sociaalcognitieve determinanten die aan de interventie ten grondslag liggen aan de ene kant en de ontwikkeling en implementatie van de evaluatie aan de andere kant. Dit hoofdstuk rapporteert ook over de methoden die worden gebruikt voor het doen van onderzoek zoals beschreven in dit proefschrift. Dit hoofdstuk eindigt met de beschrijvingen van implicaties van de onderzoeksresultaten, en geeft aanbevelingen voor toekomstig onderzoek. 
IV

Aknowledgements 


\section{AKNOWLEDGEMENTS}

Mijn dank gaat uit naar velen van jullie, zowel degenen die mij inhoudelijk dan wel persoonlijk hebben ondersteund en aangemoedigd bij het schrijven van mijn proefschrift. Het schrijven van een proefschrift is een langdurig en energievragend proces, ook voor de mensen direct om mij heen. Speciaal voor mijn kinderen, Beatrijs en Ewout. Zij hebben mij in het vroege voorjaar van 2011 aangespoord met de opmerkingen in de trant van "Mama, je zult wel weer uitstel krijgen voor het afronden van je proefschrift", dat ik een eindspurt inzette. En zie, kinderen, de klus is af. "Nu die Ipad 2 nog!", hoor ik jullie denken. Op naar, in andere opzichten, betere tijden, daar kijk ik naar uit.

Mijn dank gaat uit naar Gerjo. Ik heb het als een enorm voorrecht ervaren om met jouw begeleiding en ondersteuning tot een afronding van dit proefschrift te komen. Je bent rechtdoorzee, inspirerend, je hebt mij uitgedaagd en je hebt mij de ruimte gegeven. Je bent een kei in ons vakgebied, ik loop graag nog wat met je op.

Mijn dank gaat uit naar Luc. Het was in het begin van mijn promotietraject even zoeken, maar als 'vreemde eend in de bijt'-discipline binnen jouw kenniskring, heb ik jouw begeleiding als erg ondersteunend ervaren. Ik heb het erg gewaardeerd hoe je samen met mij bent blijven zoeken naar de overeenkomsten tussen onze vakgebieden en hierin de aanknopingspunten hebt gezocht. En dat ik steeds een beroep op je heb kunnen doen.

Mijn dank gaat uit naar alle co-auteurs die een inspirerende invloed hebben gehad bij het schrijven van onze artikelen. Jan, je persoonlijkheid was in vele opzichten zeer inspirerend. Rik, je had een enorme persoonlijke betrokkenheid en bereidheid, ook vaker 'tussendoor', om mee te denken en samen te werken. Ilse, altijd net een stapje verder, de goede aspecten benoemend, zeer onderhoudend. We gaan de effecten van de interventie nog samen beschrijven. Misschien nog een path-analyse? Ik kijk er naar uit! Anita, meedenkend hoe kan een website beter, betrokken, motiverend, bedankt.

Mijn dank gaat uit naar alle (oud-)leden van de kenniskring Leefstijl \& Gezondheid en mensen van de Hogeschool Utrecht die, op een inhoudelijke of persoonlijke manier betrokken zijn geweest bij dit promotietraject. Harm, André, Ingrid, Mieke, jullie speciaal bedankt.

Mijn dank gaat uit naar de mensen van de vakgroep Work \& Social Psychology, voor jullie betrokkenheid, interesse en collegialiteit. Het is en was prettig werken op de $3^{\mathrm{e}}$ etage!

Mijn dank gaat verder uit naar iedereen die op zijn/haar eigen wijze mij heeft bijgestaan, ook al word je naam hier niet genoemd, ik laat het je nog weten! Een drietal personen wil ik speciaal noemen. Wim en Carolien, paranimifen, (alvast) bedankt. Lex, bedankt tot nu toe, www.gezondheidsbevordering.eu is goed geworden, maak de klus graag met je af.

Mijn dank gaat tenslotte uit naar alle professionals en (oud-)studenten die hebben deelgenomen aan het vooronderzoek van de interventie, de interventie hebben getest en zij die nu (gaan) deelnemen aan de interventie; alsook alle deelnemers aan de UP-LIFT-studie. 
V

Curriculum vitae 


\section{CURRICULUM VITAE}

Barbara Sassen studeerde Gezondheidswetenschappen aan de Universiteit Maastricht met als afstudeerrichting Gezondheidsbevordering en gezondheidsvoorlichting. Voorafgaande aan deze opleiding deed zij een bachelor Verpleegkunde in Eindhoven. Aan de Universiteit Utrecht volgde zij Onderwijskunde en deed daar het afstudeertraject Bedrijfsopleidingen. Sinds 1990 werkt zij als docent aan de Hogeschool Utrecht, en later als docent/onderzoeker binnen het Lectoraat Leefstijl \& Gezondheid, onderdeel van het Kenniscentrum Innovatie van Zorgverlening, Faculteit Gezondheidszorg, Hogeschool Utrecht. Barbara Sassen is auteur van 'Gezondheidsbevordering en preventie door verpleegkundigen en verpleegkundig specialisten ( $4^{\mathrm{e}}$ druk 2010) en 'Gezondheidsbevordering en preventie door paramedici' (3 ${ }^{\mathrm{e}}$ druk 2011). 